RENATO CANDIDO

A QUESTÃO DA EQUALIZAÇÃO EM SISTEMAS DE
COMUNICAÇÃO QUE UTILIZAM SINAIS CAÓTICOS

Tese apresentada à Escola Politécnica da Universidade de São Paulo para obtenção do Título de Doutor em Ciências. 

RENATO CANDIDO

\section{A QUESTÃO DA EQUALIZAÇÃO EM SISTEMAS DE COMUNICAÇÃO QUE UTILIZAM SINAIS CAÓTICOS}

Tese apresentada à Escola Politécnica da Universidade de São Paulo para obtenção do Título de Doutor em Ciências.

Área de Concentração:

Sistemas Eletrônicos

Orientador:

Prof. Dr. Magno T. M. Silva

Coorientador:

Prof. Dr. Marcio Eisencraft 
Este exemplar foi revisado e corrigido em relação à versão original, sob responsabilidade única do autor e com a anuência de seu orientador.

São Paulo, 07 de janeiro de 2015.

Renato Candido

Prof. Dr. Magno T. M. Silva

Prof. Dr. Marcio Eisencraft

Catalogação-na-publicação

Candido, Renato

A questão da equalização em sistemas de comunicação que utilizam sinais caóticos / R. Candido. - versão corr. - São Paulo, 2015.

$97 \mathrm{p}$.

Tese (Doutorado) - Escola Politécnica da Universidade de São Paulo. Departamento de Engenharia de Sistemas Eletrônicos.

1. Filtros elétricos adaptativos 2. Algoritmos 3. Caos (Sistemas Dinâmicos) I. Universidade de São Paulo. Escola Politécnica. Departamento de Engenharia de Sistemas Eletrônicos II. t. 


\section{Agradecimentos}

Ao meu orientador, Prof. Magno T. M. Silva, pela amizade e por toda a atenção dedicada durante o mestrado e o doutorado. Este trabalho só foi possível graças às inúmeras conversas que tivemos e às suas várias ideias e sugestões.

Ao meu coorientador, Prof. Marcio Eisencraft, pelos esclarecimentos sobre sistemas dinâmicos e por todas as conversas e discussões técnicas, fundamentais para o desenvolvimento deste trabalho.

Ao Prof. Phillip M. S. Burt e ao Prof. Luiz H. A. Monteiro pelas sugestões dadas no exame de qualificação.

Aos demais professores que contribuíram na realização deste trabalho, em especial à Profa. Maria D. S. Miranda, ao Prof. Vitor H. Nascimento e ao Prof. Miguel A. Ramírez.

À minha namorada Lúcia e a toda a minha família, em especial aos meus pais Maria e Luiz e à minha irmã Fabiana pelo apoio, motivação e dedicação.

Ao amigo Ricardo Martins pelo companheirismo, motivação e pelos momentos de descontração.

Aos colegas do Laboratório de Processamento de Sinais, em especial ao amigo João Mendes pelas conversas e ótima convivência. 


\section{Resumo}

Nas últimas décadas, vários sistemas de comunicação baseados em sincronismo caótico têm sido propostos na literatura como alternativa a sistemas de espalhamento espectral que melhoram o nível de privacidade na transmissão da mensagem. No entanto, devido à falta de robustez do sincronismo caótico, um pequeno nível de ruído ou uma simples imperfeição no canal é suficiente para impedir a comunicação. Neste trabalho, equalizadores adaptativos são utilizados para permitir a comunicação em um sistema de comunicação baseado em caos quando a resposta em frequência do canal não é ideal. São propostos algoritmos de equalização baseados em versões modificadas do algoritmo normalized least-mean-squares para a versão de tempo discreto do sistema de comunicação baseado no modelo de sincronismo de Wu e Chua. Para esses algoritmos, é calculado o intervalo para a escolha do passo de adaptação para evitar a divergência. Como geradores de sinais caóticos (GSC), são utilizados os mapas de Hénon e de Ikeda e, para a codificação da mensagem, são consideradas duas funções, sendo uma baseada na multiplicação da mensagem por um dos estados do GSC e a outra baseada na soma da mensagem com um dos estados do GSC. Os resultados de simulação indicam que os algoritmos propostos são capazes de equalizar o canal de comunicação e permitir o sincronismo caótico em diferente cenários. 


\section{Abstract}

In the last decades, many communication systems applying synchronism of chaotic systems have been proposed as an alternative spread spectrum modulation that improves the level of privacy in data transmission. However, due to the lack of robustness of chaos synchronization, even a low level of noise or minor channel imperfections are enough to hinder communication. In this work, adaptive equalizers are used to enable chaotic synchronization when the communication channel is not ideal. Adaptive equalization algorithms are proposed based on a modified version of the normalized least-mean-squares algorithm, considering the discrete-time version of the communication system based on $\mathrm{Wu}$ and Chua's synchronization model. For these algorithms, the interval for the choice of the step-size is computed, in order to avoid divergence. The Hénon and the Ikeda maps are used as chaotic signal generators (CSG) and two functions are considered to encode the message, one based on the multiplication of the message by one of the states of the CSG and the other based on the addition of the message to one of the states of the CSG. Simulation results show that the proposed algorithms can successfully equalize the channel in different scenarios. 


\section{Sumário}

1 Introducão e formulacão do problema $\quad 1$

1.1 Sistemas de comunicacão baseados em caos . . . . . . . . . . . . . . . . . 1

1.2 Formulacão do problema . . . . . . . . . . . . . . . . . . . 3

1.3 Objetivos . . . . . . . . . . . . . . . . . . . 6

1.4 Justificativa . . . . . . . . . . . . . . . . . . . . . . . . . . . . . 8

1.5 Contribuicões da tese $\ldots \ldots \ldots$. . . . . . . . . . . . . . . . . . 9

1.6 Organização da tese . . . . . . . . . . . . . . . . . . . . . . . . 11

2 Conceitos de sinais caóticos de tempo discreto 12

2.1 Definicões básicas . . . . . . . . . . . . . . . . . . . . . . . . . . . . . . 12

2.2 Expoentes de Lvapunov . . . . . . . . . . . . . . . . . . . . . . 13

2.3 Sinais caóticos: definicão e mapas utilizados . . . . . . . . . . . . . . . . 17

2.3.1 Mapa de Hénon . . . . . . . . . . . . . . . . . . . . . . . . . . . . . . . 18

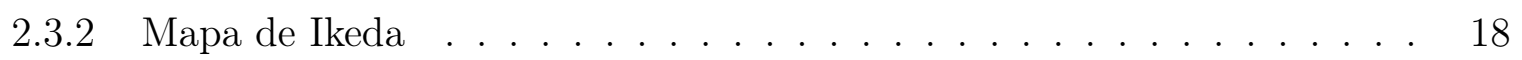

2.4 Conclusões . . . . . . . . . . . . . . . . . . . . . . . . . . . 20

3 Fundamentos de equalizacão adaptativa $\quad 22$

3.1 Uma breve introducão à equalizacão adaptativa $\ldots . . . . . . .22$

3.2 Equalizacão linear com o algoritmo NLMS . . . . . . . . . . . . . . . 25

3.3 Estabilidade do NLMS . . . . . . . . . . . . . . . . . . . . . . . . . . . . . . . . . . . . 29

3.4 Resultados de simulação . . . . . . . . . . . . . . . . . . . . . . . 29

3.5 Conclusões . . . . . . . . . . . . . . . . . . . . . . . . . 35

4 Equalizacão aplicada a sincronismo caótico - codificacão com multiplicação 36

4.1 Sistema de comunicacão baseado em caos com equalizador . . . . . . . . . . . 36

$4.2 \quad \mathrm{O}$ algoritmo NLMS caótico . . . . . . . . . . . . . . . . . . . . . . . . 39

4.2 .1 Condicões de estabilidade . . . . . . . . . . . . . . . . . . . . 41

4.3 Sistema com o mapa de Hénon . . . . . . . . . . . . . . . . . . . . . . 42 
4.3 .1 Resultados de simulacão . . . . . . . . . . . . . . . . . . . . 43

4.4 Sistema com o mapa de Ikeda . . . . . . . . . . . . . . . . . . . . . . 53

4.4 Resultados de simulacão . . . . . . . . . . . . . . 56

4.4.2 Sobre a geração de sinais com DSCI no sistema com o mapa de Ikedal . 59

4.5 Conclusões . . . . . . . . . . . . . . . . . . . . . . . . . . . 61

5 Equalizacão aplicada a sincronismo caótico - codificação com soma $\quad 63$

5.1 A codificacão com soma . . . . . . . . . . . . . . . . . . . . 63

5.2 O algoritmo cNLMS c $_{+} \ldots \ldots \ldots \ldots \ldots \ldots \ldots$

5.2 .1 Condicões de estabilidade . . . . . . . . . . . . . . . . 70

5.3 A escolha dos parâmetros da codificação com soma . . . . . . . . . . . . . . 71

5.4 Resultados de simulacão . . . . . . . . . . . . . . . . . . . . . . . 76

5.5 Conclusões . . . . . . . . . . . . . . . . . . . . . . . . . . 83

6 Conclusões e trabalhos futuros $\quad 84$

$\begin{array}{ll}\text { Referências Bibliográficas } & 94\end{array}$

$\begin{array}{ll}\text { Apêndice } & 95\end{array}$

A Transmissor com mapa de Ikeda e DSCI 


\section{Lista de Figuras}

1.1 Sistema de comunicação baseado em caos. . . . . . . . . . . . . . . . . 5

1.2 Simulação do sistema de comunicação mostrado na Fig. 1.1 utilizando o mapa de Hénon e canal ideal: (a) mensagem $m(n)$; (b) inal transmitido $s(n)$; (c) sinal recebido $r(n) ;(\mathrm{d})$ mensagem recuperada $\widehat{m}(n) \ldots \ldots \ldots$. . . . . . 7

1.3 Simulação do sistema de comunicação mostrado na Fig. 1.1 utilizando o mapa de Hénon e $H(z)=0,9$ na ausência de ruído: (a) menłagem $m(n)$; (b) sinal transmitido $s(n)$; (c) sinal recebido $r(n)$; (d) mensagem recuperada $\widehat{m}(n) \ldots . \quad 8$

2.1 Evolução de uma disco de raio unitário após $n$ iterações do mapa f(·) . . . . . . . . 14

2.2 Atrator do mapa de Hénon com $\alpha=1.4$ e $\beta=0.3$. A área amarela indica a bacia de atração para o atrator caótico mostrado em preto. . . . . . . . . . . . 18

$\underline{\underline{2.3} \text { Trechos de } x_{1}}(n)$ e $x_{2}(n)$ do mapa de Hénon com $\alpha=1,4$ e $\beta=0,3$ inicializado $\operatorname{com} \mathbf{x}(0)=0 \ldots \ldots \ldots \ldots \ldots$

2.4 Atratores do mapa de Ikeda. A área amarela indica a bacia de atração para o atrator caótico mostrado em preto. Órbitas iniciadas fora da área amarela são levadas para o ponto fixo indicado pela cruz. . . . . . . . . . . . 20

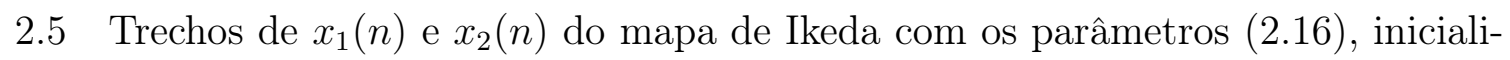

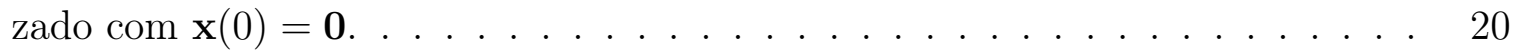

3.1 Sistema de comunicação simplificado com um equalizador adaptativo no modo de treinamento. . . . . . . . . . . . . . . . . . . . . . 23

3.2 Equalizador adaptativo no modo de decisão direta. . . . . . . . . . . . . . . . 24

3.3 Função custo do erro quadrático médio, considerando a transmissão de uma sequência binária $s(n) \in\{-1,+1\}$ através do Canal 1 com função de transferência dado pela Eq. (3.10). . . . . . . . . . . . . . . . . . 
3.4 Sequência recuperada (a) sem equalizador e (b) com uma realização do NLMS $(\widetilde{\mu}=0,1 ; \delta=0,5 ; M=2 ; \Delta=0)$; (c) Erro após decisão; (d) Média dos coeficientes do NLMS e solução de Wiener (linhas tracejadas); (e) EMSE estimado; média de 1000 realizações; Canal 1.

3.5 Sequência recuperada (a) sem equalizador e (b) com uma realização do NLMS $\left(\widetilde{\mu}=0,1 ; \delta=10^{-5} ; M=12 ; \Delta=7\right) ;$ (c) Erro após decisão; (d) Média dos coeficientes do NLMS e solução de Wiener (linhas tracejadas); (e) EMSE estimado; média de 1000 realizações; variação abrupta do Canal 2 para o Canal 3 em $n=5 \times 10^{3}$.

3.6 Sequência recuperada (a) sem equalizador e (b) com uma realização do NLMS $\left(\widetilde{\mu}=0,1 ; \delta=10^{-5} ; M=5 ; \Delta=3\right.$ ); (c) Erro após decisãp; (d) Média dos coeficientes do NLMS e solução de Wiener (linhas tracejadas); (e) EMSE estimado; média de 1000 realizações; Canal 4, variante no tempo. . . . . . . . . . . . . .

3.7 Taxa de erro de bit para o canal AWGN não dispersivo e para o Canal 5 com $h_{0}=0,25$, em função da relação sinal-ruído (SNR); Equalização com NLMS com $\widetilde{\mu}=0,01 ; \delta=10^{-5} ; M=21 ; \Delta=11 \ldots \ldots \ldots \ldots$

4.1 Sistema de comunicação baseado em caos com um equalizador no caso supervisionado.

4.2 Receptor do sistema de comunicacão baseado em caos com um equalizador adaptativo no modo de decisão direta.

4.3 Atrator reconstruído usando: (a) sinal transmitido. (b) sinal recebido e (c) sinal recuperado com o cNLMS $\times$ para $m(n) \equiv 1 ; M=2 ; \Delta=0$; Canal $1 . \quad$. . . .

4.4 Sequência recuperada com o sistema utilizando o mapa de Hénon e codificação com multiplicação (a) sem equalizador e (b) com uma realização do $\mathrm{NLMS}_{\times}$ $\left(\widetilde{\mu}=0,01 ; \delta=10^{-5} ; \varepsilon=0,1 ; M=2 ; \Delta=0\right)$; (c) Média dos coeficientes do $\mathrm{cNLMS}_{\times}$e solução de Wiener (linhas tracejadas); (d) $x_{1}(n)$ vs. $\widehat{x}_{1}(n)$ : pontos vermelhos para $0<n<2000$ e pontos azuis para $n>2000$ (e) EMSE estimado; média de 1000 realizações; Canal 1.

4.5 Sequência recuperada com o sistema utilizando o mapa de Hénon e codificação com multiplicação (a) sem equalizador e (b) com uma realização do cNLMS $\times$ $\left(\widetilde{\mu}=0,01 ; \delta=10^{-5} ; \varepsilon=0,1 ; M=2 ; \Delta=0\right)$ ( ) Erro após decisão; (d) Média dos coeficientes do cNLMS $\times$ e solução de Wienłr (linhas tracejadas); (e) EMSE estimado; média de 1000 realizações; Canal 1. 
4.6 Atrator reconstruído usando: (a) sinal transmitido, (b) sinal recebido e (c) sinal recuperado com o $\mathrm{cNLMS}_{\times}$para a sequência $m(n)$ binária, aleatória equiprovável (parâmetros iguais aos da Figura 4.5). . . . . . . . . . . . . . . . .

4.7 Sequência recuperada com o sistema utilizando o mapa de Hénon e codificação com multiplicação (a) sem equalizador e (b) com o $\mathrm{cNLMS}_{\times}\left(\widetilde{\mu}=0,1 ; \delta=10^{-5}\right.$; $\varepsilon=0,1 ; M=12 ; \Delta=7$ ); (c) Erro após decisão; (d) Média dos coeficientes do cNLMS $_{x}$ e solução de Wiener (linhas tracejadas); (e) EMSE estimado; média de 1000 realizações; variação abrupta do Canal 2 para o Canal 3 em $n=30 \times 10^{3}$. 49

4.8 Sequência recuperada com o sistema utilizando o mapa de Hénon e codificação com multiplicação (a) sem equalizador e (b) com o cNLMS $\times\left(\widetilde{\mu}=0,25 ; \delta=10^{-5}\right.$; $\varepsilon=0,1 ; M=25 ; \Delta=12$ ); (c) Erro após decisão; (d) Média dos coeficientes do cNLMS $_{\times}$e solução de Wiener (linhas tracejadas); (e) EMSE estimado; média de 1000 realizações; variação abrupta do Canal 2 para o Canal $3 \mathrm{em} n=30 \times 10^{3}$. 50

4.9 Sequência recuperada com o sistema utilizando o mapa de Hénon e codificação com multiplicação (a) sem equalizador e (b) com o cNLMS $\times\left(\widetilde{\mu}=0,1, \delta=10^{-5}\right.$, $\varepsilon=0,1 ; M=5 ; \Delta=3$ ); (c) Erro após decisão; d) Média dos coeficientes do cNLMS $\times$ e solução de Wiener (linhas tracejadas); (e) EMSE estimado; média de 1000 realizações; Canal 4, variante no tempo. . . . . . . . . . . . . . .

4.10 Taxa de erro de bit para o Canal 5 em função de $h_{0}$ na ausência de ruído; Sistema utilizando o mapa de Hénon e codificação com multiplicação; cNLMS $\times$ $\operatorname{com} \widetilde{\mu}=0,05 ; \delta=10^{-5} ; \varepsilon=0,1 ; M=21 ; \Delta=11$. . . . . . . . . . . . . .

4.11 Taxa de erro de bit para o Canal 5 em função de $h_{0}$ com SNR $=60$ dB; Sistema utilizando o mapa de Hénon e codificação com multiplicação; cNLMS $\times$ com $\widetilde{\mu}=0,05 ; \delta=10^{-5} ; \varepsilon=0,1 ; M=21 ; \Delta=11 \ldots \ldots \ldots \ldots$

4.12 Taxa de erro de bit para o canal AWGN não dispersivo e para o Canal 5 com $h_{0}=0,25$, em função da relação sinal-ruído (SNR); Sistema utilizando o mapa de Hénon e codificação com multiplicação; $\operatorname{cNLMS}_{\times} \operatorname{com} \widetilde{\mu}=0,05 ; \delta=10^{-5}$; $\varepsilon=0,1 ; M=21 ; \Delta=11 \ldots \ldots \ldots \ldots$

4.13 (a) Logaritmo do máximo valor de $\left|\lambda_{\max }(n)\right|$ entre $L=10^{4}$ realizações independentes e (b) histograma do máximo valor absoluto dos autovalores de $\mathbf{A}_{r}(n)-\mathbf{A}_{t}(n)$ em $n=30$, considerando uma mensalgem binária equiprovável. Inicialização com $\mathbf{x}(0)=\left[\begin{array}{ll}0 & 0\end{array}\right]^{\mathrm{T}}$ e $\widehat{\mathbf{x}}(0)=[0,1-0,1]^{\mathrm{T}} \ldots \ldots \ldots$. . . . . . . . 
4.14 Sequência recuperada com o sistema utilizando o mapa de Ikeda com a codificação da mensagem com nultiplicação usando o estado $x_{2}(n)$ (a) sem equalizador e (b) com uma realizaçăo do $\operatorname{cNLMS}_{\times}\left(\widetilde{\mu}=0,1 ; \delta=10^{-2} ; \varepsilon=0,1 ; M=2\right.$; $\Delta=0$ ); (c) Erro após decisão; (d) Média dos coeficientes do cNLMS $\times$ e solução de Wiener (linhas tracejadas); (e) EMSE estimado; média de 1000 realizações; Canal 1; SNR $=30 \mathrm{~dB}$.

4.15 Sequência recuperada com o sistema utilizando o mapa de Ikeda com a codificação da mensagem com multiplicação usando o estado $x_{1}(n)$ (a) sem equalizador e (b) com uma realizaçăo do $\mathrm{cNLMS}_{\times}\left(\widetilde{\mu}=0,1 ; \delta=10^{-2} ; \varepsilon=0,1 ; M=2\right.$; $\Delta=0$ ); (c) Erro após decisão; (d) Média dos coeficientes do cNLMS $\times$ e solução de Wiener (linhas tracejadas); (e) EMSE estimado; média de 1000 realizações; Canal 1; SNR $=30 \mathrm{~dB}$.

4.16 Exemplo onde a codificação da mensagem leva a um comportamento não caótico: (a) Trecho da mensagem a ser codificada; (b) Trecho do sinal obtido após a codificação da mensagem; (c) Espaço de fases $\left(x_{1}\left(h^{\prime}\right)\right.$ por $\left.x_{2}(n)\right)$ convergindo para o ponto fixo indicado pela cruz; Mapa de Ikeda.

4.17 Logaritmo do valor de $\left|\lambda_{\max }(n)\right|$ em uma realizacão do sistema. Mensagem $m(n)=1$ e inicialização com $\mathbf{x}(0)=\left[\begin{array}{ll}0 & 0\end{array}\right]^{\mathrm{T}} ; \widehat{\mathbf{x}}(0)=\left[\begin{array}{ll}2 & 2\end{array}\right]^{\mathrm{T}} \ldots \ldots \ldots \ldots$

5.1 Máximo expoente de Lyapunov obtido no transmissor utilizando a função de codificação (5.3). em função dos parâmetros $\gamma_{1}$ e $\gamma_{2}$. A área cinza indica que o máximo expoente de Lyapunov é negativo. A área branca indica que houve divergência do transmissor. . . . . . . . . . . . . . . . . .

5.2 Máximo expoente de Lyapunov obtido no transmissor utilizando a função de codificação (5.6). em função dos parâmetros $\gamma_{1}$ e $\gamma_{2}$. A área cinza indica que o máximo expoente de Lyapunov é negativo. A área branca indica que houve divergência no transmissor.

5.3 Indicação da área onde é possível equalizar o Canal 3 com a função de codificação (5.9) e obter EMSE $<-20 \mathrm{~dB}$ escolhendo $\gamma_{1}$ e $\gamma_{2}$ de forma a obter sinais com DSCI $\left(\widetilde{\mu}=0,02 ; \delta=10^{-2} ; M=12 ; \Delta=7\right)$. . . . . . . . . . .

5.4 Transmissor com o mapa de Hénon e a codificação (5.6) com $\gamma_{2}=0,3$ : (a) Máximo expoente de Lyapunpv $\kappa_{1}$ em função de $\gamma_{1}$, (b) diagrama de bifurcação considerando os últimos 100 valores de $x_{1}(n)$ para $0 \varangle \gamma_{1}<0,93$ e (c) detalhe

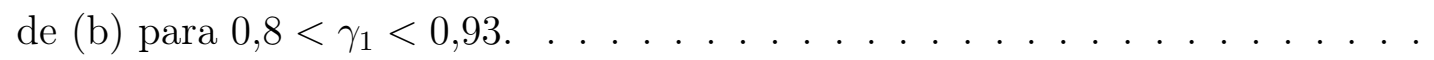

5.5 Sinal $x_{1}(n)$ considerando o mapa de Hénon e a codificacão (5.6) com $\gamma_{2}=0,3$ e (a) $\gamma_{1}=0,05$, (b) $\gamma_{1}=0,6$ e (b) $\gamma_{1}=0,92$. 
5.6 Sequência recuperada com o sistema utilizando o mapa de Hénon e codificação com soma $\left(\gamma_{1}(n)=0,9\right.$ e $\left.\gamma_{2}(n)=0,3\right)$ (a) sem equalizador e (b) com uma realização do $\mathrm{cNLMS}_{+}\left(\widetilde{\mu}=0,01 ; \delta=10^{-5} ; M=2 ; \Delta=0\right)$; (c) Erro após decisão; (d) Média dos coeficientes do cNLMS + e solucão de Wiener (linhas tracejadas); (e) EMSE estimado; média de 1000 realizações; Canal 1. . . . . . .

5.7 Sequência recuperada com o sistema utilizando o mapa de Hénon e codificação com soma $\left(\gamma_{1}(n)=0,9\right.$ e $\left.\gamma_{2}(n)=0,3\right)$ (a) sem equalizador e (b) com o cNLMS $\left(\widetilde{\mu}=0,02 ; \delta=1 \phi^{-2} ; M=12 ; \Delta=7\right) ;$ (c) Erro após decisão; (d) Média dos coeficientes do cNLMS $_{+}$e solução de Wiener (linhas tracejadas); (e) EMSE estimado; média de 1000 realizações; variação abrupta do Canal 2 para o Canal 3 em $n=30 \times 10^{3}$.

5.8 Sequência recuperada com o sistema utilizando o mapa de Hénon e codificação com soma considerando o chaveamento entre a transnhissão da mensagem sem codificação e a transmissão da mensagem codificada $\left(\gamma_{1}(n)=0\right.$ e $\gamma_{2}(n)=0,46$ para $0<n \leq 15 \times 10^{3}$ e para $30 \times 10^{3}<n \leq 45 \times 10^{3}$ e $\gamma_{1}(n)=0,9$ e $\gamma_{2}(n)=0,3$ para $15 \times 10^{3}<n \leq 30 \times 10^{3}$ e para $\left.45 \times 10^{3}<n \unlhd 60 \times 10^{3}\right)$. Perturbação no vetor de estados do transmissor quando o valor de $\gamma_{1}$ ou $\gamma_{2}$ é alterado. (a) sem equalizador e (b) com o $\mathrm{cNLMS}_{+}\left(\widetilde{\mu}=0,02 ; \delta=10^{-2} ; M=12 ; \Delta=7\right)$; (c) Erro após decisão; (d) Média dos coeficientes do cNLMS + e solução de Wiener (linhas tracejadas); (e) EMSE estimado; média de 1000 realizações; variação abrupta do Canal 2 para o Canal 3 em $n=30 \times 10^{3}$. . . . . . . . . . . . . .

5.9 Sequência recuperada com o sistema utilizando o mapa de Hénon e codificação com soma $\left(\gamma_{1}(n)=0,9\right.$ e $\left.\gamma_{2}(n)=0,3\right)$ (a) sem equalizador e (b) con o cNLMS $\left(\widetilde{\mu}=0,1, \delta=10^{-5}, M=5 ; \Delta=3\right.$ ); (c) Erro após decisão; (d) Média dos coeficientes do cNLMS + e solucão de Wiener (linhas tracejadas); (e) EMSE estimado; média de 1000 realizações; Canal 4, variante no tempo. . . . . . . . .

5.10 Taxa de erro de bit para o Canal 5 em função de $h_{0}$ com $\mathrm{SNR}=60 \mathrm{~dB}$; Sistema utilizando o mapa de Hénon e codificação com soma $\left(\gamma_{1}(n)=0,9\right.$ e $\left.\gamma_{2}(n)=0,3\right) ; \mathrm{cNLMS}_{+} \operatorname{com} \widetilde{\mu}=0,005$ para $h_{0}=0$ e $h_{0}=0,05$ e $\widetilde{\mu}=0,01$ para $h_{0} \geq 0,1 ; \delta=10^{-5} ; M=21 ; \Delta=11$.

5.11 Taxa de erro de bit para o canal AWGN não dispersivo e para o Canal 5 com $h_{0}=0,25$, em função da relação sinal-ruído (SNR); Sistema utilizando o mapa de Hénon e codificação com soma $\left(\gamma_{1}(n)=0,9\right.$ e $\left.\gamma_{2}(n)=0,3\right)$; cNLMS $_{+}$com $\widetilde{\mu}=0,02 ; \delta=10^{-5} ; M=21 ; \Delta=11 \ldots \ldots \ldots \ldots$ 
A.1 Espaço de fases $\left(x_{1}(n)\right.$ por $\left.x_{2}(n)\right)$, indicando os pontos que levariam a órbita a convergir para o ponto fixo se um bit "1" fosse codificado usando (A.1) com (a) $\gamma=1$, (b) $\gamma=10^{-2}$ e (c) $\gamma=10^{-3}$; Mapa de Ikeda com os parâmetros dados por $(2.16) . \ldots \ldots$. . . . . . . . . . . . . . . . . . . . . . . . . . . . 96

A.2 Máximo expoente de Lyapunov $\kappa_{1}$ em funcão de $\gamma$ da Eq. (A.1), considerando uma mensagem binária e equiprovável. . . . . . . . . . . . . . . . . . . . . 97 


\section{Lista de Tabelas}

3.1 Canais de comunicação utilizados nas simulações . . . . . . . . . . . . . . . 30

4.1 Algoritmo cNLMS $x_{x}$ considerando o mapa de Hénon . . . . . . . . . . . . . . . 43

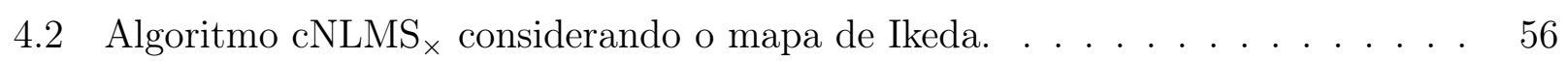

$5.1 \quad$ Algoritmo cNLMS ${ }_{+}$considerando o mapa de Hénon. . . . . . . . . . . . . . . 71

6.1 Tópicos abordados na tese $\ldots \ldots \ldots \ldots$. . . . . . . . . . . . 85 


\section{Lista de Abreviaturas}

AWGN Additive White Gaussian Noise.

BER Bit Error Rate.

cLMS chaotic LMS.

CMA Consant Modulus Algorithm.

cNLMS chaotic NLMS.

DFE Decision Feedback Equalizer.

DSCI Dependência Sensível às Condições Iniciais.

EMSE Excess Mean-Square Error.

FIR Finite Impulse Response.

GSC Gerador de Sinais Caóticos.

HOS High Order Statistics.

IIR Infinite Impulse Response.

ISI Intersymbol Interference.

LMS Least Mean Squares.

MSE Mean Square Error.

NLMS Normalized Least Mean Squares. 
PAM Pulse Amplitude Modulation.

PLL Phase Locked Loop.

QAM Quadrature Amplitude Modulation.

SNR Signal to Noise Ratio. 


\section{Lista de Símbolos}

Nesta tese, matrizes são indicadas por letras maiúsculas em negrito, por exemplo R. Vetores coluna são indicados usando-se letras minúsculas em negrito, por exemplo $\mathbf{r}(n)$ e $\mathbf{w}(n)$. Escalares são representados por letras maiúsculas ou minúsculas em itálico, por exemplo $M$, $\mu$ e $s(n)$. A seguir são listados os principais símbolos utilizados.

\section{Símbolos gerais}

$\begin{array}{ll}\mathbb{R} & \text { conjunto dos números reais } \\ \mathbb{N} & \text { conjunto dos números naturais } \\ (\cdot)^{\mathrm{T}} & \text { transposição de vetores ou matrizes } \\ \mathbf{E}\{\cdot\} & \text { valor estimado } \\ z^{-1} & \text { operador esperança matemática } \\ |x| & \text { operador de atraso, } z^{-1} y(n)=y(n-1) \\ \|\mathbf{x}\| & \text { módulo do escalar } x \\ \sigma_{x}^{2} & \text { norma euclideana ou } l_{2} \text { do vetor } \mathbf{x} \\ \operatorname{sign}(\cdot) & \text { variância do sinal } x \\ \mathbf{I} & \text { função sinal } \\ n & \text { matriz identidade } \\ M & \text { instante de tempo } \\ L_{h} & \text { número de coeficientes do filtro } \\ \Delta & \text { número de coeficientes do canal } \\ X(z) & \text { atraso imposto pelo sistema composto pelo canal e equalizador } \\ \lambda_{i} & \text { transformada Z da sequência } x(n) \\ & i \text {-ésimo autovalor de uma matriz }\end{array}$


$S$

$\widehat{s}$

$r$

$\mathbf{r}$

$\mathbf{R}$

$\mathrm{p}_{\Delta}$

$e$

W

$\mathbf{w}_{\mathrm{O}}$

h

C

$\widehat{C}$

$\nabla_{\mathrm{w}} \widehat{C}$

$e_{a}$

$e_{p}$

$\mu$

$\widetilde{\mu}$

$\delta$

sinal transmitido

sinal recuperado na saída do equalizador

sinal de entrada do equalizador

vetor regressor de entrada do equalizador

matriz de autocorrelação do sinal de entrada do equalizador

vetor de correlação cruzada entre o vetor regressor de entrada e o sinal transmitido

sinal de erro entre o sinal desejado e a mensagem recuperada

vetor de coeficientes do equalizador

vetor de coeficientes ótimos

vetor de coeficientes do canal

função custo exata

aproximação da função custo

vetor gradiente instantâneo da função custo

sinal de erro a priori do equalizador

sinal de erro a posteriori do equalizador

passo de adaptação para o algoritmo LMS

passo de adaptação para o algoritmo NLMS

constante positiva pequena para evitar divisão por zero

\section{Sistema de comunicação baseado em caos}

X

$\widehat{\mathbf{x}}$

$x_{i}$

$\widehat{x}_{i}$

$X$

e

$m$

$\widehat{m}$

$c(\cdot, \cdot)$ vetor de estados do gerador de sinais caóticos no transmissor

vetor de estados do gerador de sinais caóticos no receptor

$i$-ésimo componente de $\mathbf{x}$

$i$-ésimo componente de $\widehat{\mathbf{x}}$

limite superior imposto para $\widehat{x}_{i}$

erro entre os vetores de estados no transmissor e no receptor

mensagem a ser codificada

mensagem recuperada

função de codificação 
$c^{-1}(\cdot, \cdot) \quad$ função de decodificação

$K$

número de dimensões do sistema dinâmico gerador de sinais caóticos

$\mathbf{f}(\cdot)$

função $\mathbb{R} \rightarrow \mathbb{R}^{K}$

$\mathbf{f}^{n}(\cdot)$

função equivalente à aplicação de $\mathbf{f}$ por $n$ iterações consecutivas

$\operatorname{Df}(x)$

matriz Jacobiana do mapa $\mathbf{x}(n+1)=\mathbf{f}(\mathbf{x}(n))$

$L_{k}$

$k$-ésimo número de Lyapunov

$\kappa_{k}$

$k$-ésimo expoente de Lyapunov

$\alpha$ e $\beta$

parâmetros do mapa de Hénon

$C_{1}, C_{2}, C_{3}$ e $R$

parâmetros do mapa de Ikeda

$\theta$

variável auxiliar utilizada no mapa de Ikeda, função dos estados $x_{1}$ e $x_{2}$

$\gamma, \gamma_{1}$ e $\gamma_{2}$

parâmetros utilizados na função de codificação que utiliza a soma 


\section{Capítulo 1}

\section{Introdução e formulação do problema}

Neste capítulo são apresentados o contexto, as contribuições e a organização do trabalho. Inicialmente é feita uma breve introdução a sistemas de comunicação baseados em caos. Por fim, são apresentados os objetivos, a justificativa, as contribuições e a organização da tese.

\subsection{Sistemas de comunicação baseados em caos}

O objetivo principal de um sistema de comunicação é transmitir informação de forma confiável entre dois pontos, emissor e receptor [Lathi e Ding, 2009]. Ao longo da história, sistemas de comunicação se mostraram essenciais para promover o desenvolvimento e integração de pessoas e, por isso, sempre houve esforços para torná-los mais eficientes, seguros e confiáveis [Maral e Bousquet, 1998]. Nesse contexto, os sistemas caóticos têm se mostrado uma solução a ser considerada.

Um sinal caótico é um sinal limitado em amplitude, determinista, aperiódico e que apresenta Dependência Sensível às Condições Iniciais (DSCI). Esta última propriedade significa que, se o sistema que o gerou for iniciado com uma condição ligeiramente diferente, o sinal obtido pode apresentar valores completamente distintos daqueles do sinal anterior em um curto espaço de tempo [Alligood et al., 1997].

Costuma-se considerar que o primeiro pesquisador a analisar o comportamento caótico foi o matemático francês Henri Poincaré. ao estudar o clássico problema dos três corpos [Alligood et al., 1997]. Em seu trabalho, utilizando o conceito de variedade e análises qualitativas, Poincaré mostrou que as soluções assintóticas desse problema podem ser muito mais complicadas do que as três possibilidades conhecidas até então: a convergência para um ponto fixo, para uma órbita periódica ou para uma órbita quasi-periódica. Estava descoberto o que hoje denomina-se caos. 
Baseado no trabalho de Poincaré, principalmente no seu enfoque qualitativo e geométrico, algumas áreas da matemática nasceram e floresceram ao longo do século XX, como a topologia algébrica e geométrica. Porém, uma compreensão mais profunda da natureza das órbitas complicadas observadas por Poincaré só foi obtida na década de 1960, com o aparecimento dos computadores digitais. A pesquisa na área passou a ter um "componente experimental" e a possibilidade de "visualizar" resultados matemáticos abstratos tornou o assunto mais atraente e acessível, chamando a atenção de pesquisadores de inúmeras áreas. Desde então, o número de aplicações de sistemas não lineares e caos cresceu muito. Em [Strogatz, 2001], citam-se dezenas de exemplos dessas aplicações.

Em telecomunicações e processamento de sinais, essas pesquisas se intensificaram no começo da década de 1990 após os trabalhos de Pecora e Carroll [1990] e Haves et al. [1993]. Desde então as possibilidades de aplicação da teoria do caos nessas áreas vêm aumentando, indo desde modulações analógicas e digitais até criptografia, geração de sequências pseudoaleatórias. marcas d'água. compressão de dados, entre outras (veia. por exemplo. [Grzybowski et al. 2011: Kaddoum et al.| 2012. 2013:|Kennedv e Kolumbán. 2000:|Kennedv et al., 2000: Lau e Tse, 2003; Stavroulakis, 2005; Tsekeridou et al., 2001]). Além disso, mostrou-se que modelos de muitos dispositivos usados em processamento de sinais como equalizadores autodidatas e redes de Phase Locked Loops (PLLs)] podem apresentar comportamento caótico [Attux e Romano, 2003; Endo e Chua, 1988; Harb e Harb, 2004; Monteiro et al., 2009; Tavazoei e Haeri, 2009].

Especificamente, em se tratando de modulação em banda base de dados digitais, várias ideias foram propostas Grzvbowski et al., 2011: Kennedv et al., 2000: Lau e Tse. 2003: Williams, 2001]. Nas últimas duas décadas, a viabilidade de sistemas de comunicação baseados em sincronismo caótico tem sido investigada teorica e experimentalmente Argvris et al., 2005; Cuomo e Oppenheim, 1993; Eisencraft et al., 2013; Pecora e Carroll, 1990; Wu e Chua, 1993].

Recentemente, alguns trabalhos com uma abordagem mais prática usando o sincronismo caótico têm surgido, principalmente na área de comunicações ópticas (por exemplo [Argyris et al., 2005; Uchida, 2012]). De certa forma, isso é natural, já que geradores de sinais caóticos podem ser facilmente criados usando propriedades intrínsecas dos lasers [Uchida, 2012]. Por exemplo, em [Argyris et al., 2005], foi proposto um sistema de comunicação baseado em sincronismo caótico, funcionando em um canal comercial de fibra óptica. Nesse sistema, foi possível obter taxas de erro de bit próximas das taxas obtidas em sistemas de comunicação convencionais. Entretanto, é importante notar que os efeitos de dispersão foram compensados de forma não adaptativa. O sistema proposto em [Argyris et al., 2005] apresentaria um desempenho ruim em um canal sem fio, onde as distorções variam constantemente com o tempo devido ao multipercurso, devido à presença de várias fontes de ruído, etc. 
De fato, um dos maiores problemas em sistemas de comunicação baseados em caos é a falta de robustez do sincronismo caótico devido à presença de ruído e interferência intersimbólica Intersymbol Interference- ISI) introduzidos pelo canal. Mesmo um pequeno nível de ruído ou uma simples distorção linear é suficiente para impedir a comunicação [Eisencraft et al., 2012; Williams, 2001]. Muitos sistemas de comunicação baseados em caos, se implementados como propostos na literatura, apresentam taxas de erro de bit proibitivas na presença de canais não ideais quando comparados com sistemas convencionais [Eisencraft et al., 2012]. Apesar da obtenção de alguns resultados preliminares para canais mais realistas [Eisencraft et al., 2013; Ren et al., 2013; Souza et al., 2012], é importante propor esquemas que possam se adaptar à dificuldades impostas por canais de comunicação reais para que os sistemas de comunicação baseados em caos tenham interesse comercial. Além disso, a modulação da mensagem a ser transmitida pode influenciar na dinâmica do sistema, fazendo com que os sinais gerados deixem de apresentar características dos sinais caóticos, como a DSCI. No entanto, na maioria dos sistemas propostos, não há a preocupação em verificar se os sinais gerados são de fato caóticos.

Em sistemas de comunicação convencionais, é usual considerar um equalizador no receptor para mitigar a ISI introduzida pelo canal [Haykin, 2000, 2002; Sayed, 2008]. Neste trabalho, equalizadores adaptativos são utilizados para permitir a comunicação em um sistema de comunicação baseado em caos quando a resposta em frequência do canal não é ideal. Nos sistemas de comunicação considerados, é verificado se os sinais gerados apresentam DSCI. O esquema de modulação caótica utilizado foi proposto por Wu e Chua [1993] e é descrito a seguir.

\subsection{Formulação do problema}

O esquema de sincronismo de Wu e Chua [1993], é uma maneira simples de utilizar sinais caóticos para comunicações. Eles abordaram o sincronismo de sistemas caóticos de forma diferente do trabalho de Pecora e Carroll [1990]. Em vez de utilizar expoentes de Lyapunov condicionados para verificar a estabilidade assintótica do receptor e, consequentemente, a possibilidade de sincronismo, Wu e Chua propuseram que as equações do transmissor e receptor fossem reescritas de forma que a dinâmica do erro de sincronismo fosse simples o suficiente para permitir a verificação direta de sua convergência para zero. Com base nesse esquema de sincronismo, um sistema de comunicação foi proposto em [Wu e Chua, 1993] e uma versão discreta desse sistema foi proposta posteriormente [Eisencraft et al., 2009]. Nesta seção, é feita uma breve introdução a essas ideias. 
Sejam dois sistemas de tempo discreto que possam ser escritos na forma

$$
\begin{aligned}
& \mathbf{x}(n+1)=\mathbf{A} \mathbf{x}(n)+\mathbf{b}+\mathbf{f}\left(x_{i}(n)\right) \\
& \widehat{\mathbf{x}}(n+1)=\mathbf{A} \widehat{\mathbf{x}}(n)+\mathbf{b}+\mathbf{f}\left(x_{i}(n)\right),
\end{aligned}
$$

com $n \in \mathbb{N}$ a variável que representa os instantes de tempo, $\mathbf{x}(n)$ e $\widehat{\mathbf{x}}(n)$ vetores coluna, reais, de tamanho $K$, ou seja, $\mathbf{x}(n)=\left[x_{1}(n) x_{2}(n) \cdots x_{K}(n)\right]^{\mathrm{T}}$ e $\widehat{\mathbf{x}}(n)=\left[\widehat{x}_{1}(n) \widehat{x}_{2}(n) \cdots \widehat{x}_{K}(n)\right]^{\mathrm{T}}$, $x_{i}$ e $\widehat{x}_{i}$ os estados do sistema, com $i=1, \cdots, K$ e $(\cdot)^{\mathrm{T}}$ a notação para transposição. A é uma matriz quadrada e b é um vetor coluna, ambos constantes, reais e de dimensão $K$. A função vetorial $\mathbf{f}(\cdot): \mathbb{R} \rightarrow \mathbb{R}^{K}$ é geralmente não linear e assume-se a hipótese de que ela dependa apenas de um componente de $\mathbf{x}(n)$, tendo a forma

$$
\mathbf{f}\left(x_{i}(n)\right)=[\underbrace{00 \cdots 0}_{i-1 \text { zeros }} f\left(x_{i}(n)\right) \underbrace{00 \cdots 0}_{K-i \text { zeros }}]^{\mathrm{T}}
$$

sendo $f(\cdot)$ uma função escalar. O sistema descrito por (1.1) é autônomo e é chamado de mestre, enquanto o sistema descrito por (1.2) depende de $x_{i}(n)$ e é chamado de escravo.

O erro de sincronismo entre os dois sistemas $\mathbf{e}(n) \triangleq \widehat{\mathbf{x}}(n)-\mathbf{x}(n)$, pode ser escrito como

$$
\mathbf{e}(n+1)=\mathbf{A e}(n)
$$

Os sistemas são considerados completamente sincronizados [Boccaletti et al., 2002], se $\mathbf{e}(n) \rightarrow \mathbf{0}$ conforme $n$ aumenta. Consequentemente, uma condição suficiente para a sincronismo completo é dada por

$$
\left|\lambda_{i}\right|<1, \quad 1 \leq i \leq K
$$

sendo $\lambda_{i}$ os autovalores de A [Agarwal, 1992]. Portanto, se um sistema puder ser escrito conforme (1.1) com os autovalores de A satisfazendo (1.5), implementar um sistema escravo que sincronize com ele torna-se uma tarefa simples.

Usando esse método de sincronismo, Wu e Chua [1993] propuseram um sistema de transmissão de informações usando sinais caóticos que não apresenta erros sob condições ideais de canal. Um diagrama de blocos da versão de tempo discreto desse sistema é mostrado na Figura 1.1 Eisencraft et al., 2009]. Nesse esquema, o sinal de informação $m(n)$ é codificado usando o $i$-ésimo componente do vetor de estados $\mathbf{x}(n)$ por meio da função de codificação

$$
s(n)=c\left(x_{i}(n), m(n)\right),
$$

de forma que o sinal de informação possa ser decodificado usando a função inversa em relação 


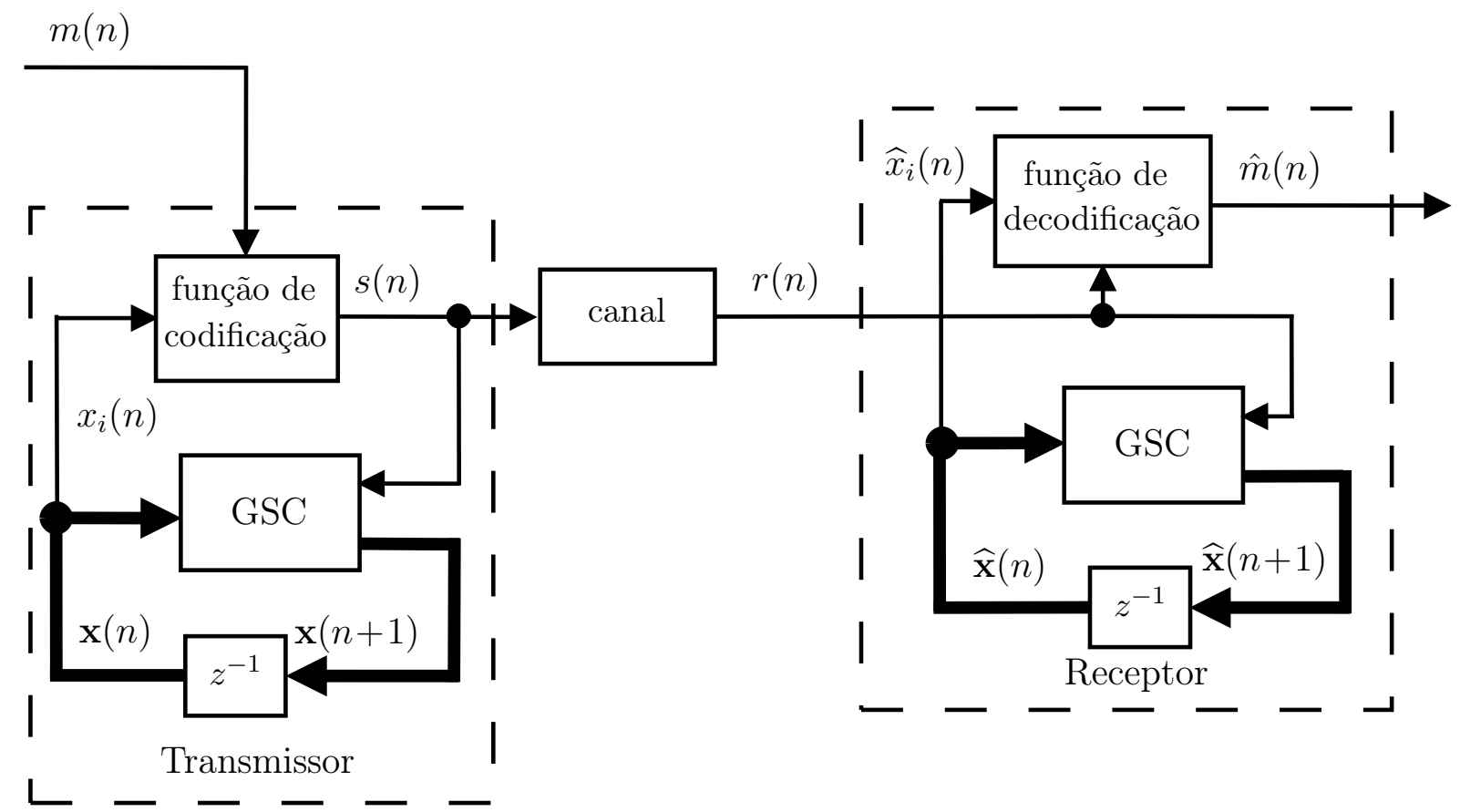

Figura 1.1: Sistema de comunicação baseado em caos.

a $m(n)$, ou seja,

$$
m(n)=c^{-1}\left(x_{i}(n), s(n)\right) .
$$

As equações que governam o sistema global tem a mesma forma que (1.1) e (1.2). As únicas diferenças são os argumentos de $\mathbf{f}(\cdot)$, ou seja,

$$
\begin{aligned}
& \mathbf{x}(n+1)=\mathbf{A x}(n)+\mathbf{b}+\mathbf{f}(s(n)) \\
& \widehat{\mathbf{x}}(n+1)=\mathbf{A} \widehat{\mathbf{x}}(n)+\mathbf{b}+\mathbf{f}(r(n)),
\end{aligned}
$$

sendo $r(n)$ o sinal que chega ao receptor. A dinâmica das equações (1.8) e (1.9) é representada na Figura 1.1 pelo bloco Gerador de Sinais Caóticos (GSC), O bloco "canal" da Figura 1.1 representa não só o canal físico de transmissão, mas também os sistemas de transmissão e modulação e os sistemas de recepção e demodulação efetivamente presentes em qualquer sistema de comunicação prático. Assim, denomina-se aqui como canal um modelo de tempo discreto para o sistema de transmissão, o canal físico e o sistema de recepção. Para um canal ideal e na ausência de ruído, $r(n)=s(n)$ e as Equações (1.8) e (1.9) podem ser reescritas como

$$
\begin{aligned}
& \mathbf{x}(n+1)=\mathbf{A x}(n)+\mathbf{b}+\mathbf{f}(s(n)) \\
& \widehat{\mathbf{x}}(n+1)=\mathbf{A} \widehat{\mathbf{x}}(n)+\mathbf{b}+\mathbf{f}(s(n)) .
\end{aligned}
$$


Considerando que a dinâmica do erro de sincronismo é dada novamente por (1.4) e, se (1.5) valer, $\widehat{\mathbf{x}}(n) \rightarrow \mathbf{x}(n)$ e, em particular, $\widehat{x}_{i}(n) \rightarrow x_{i}(n)$. Portanto, usando (1.7), obtém-se

$$
\widehat{m}(n)=c^{-1}\left(\widehat{x}_{i}(n), s(n)\right) \rightarrow c^{-1}\left(x_{i}(n), s(n)\right)=m(n) .
$$

Assim, quando os parâmetros do transmissor e do receptor estiverem ajustados adequadamente e o canal for ideal, a mensagem é recuperada sem degradação no receptor, exceto por um transitório de sincronismo do sistema caótico.

Nesse contexto, diferentes mapas caóticos podem ser escritos em uma forma similar à mostrada em (1.8) e (1.9), podendo ser usados em um sistema de comunicação baseado em caos. Por exemplo, pode ser citado o mapa de Hénon [1976], utilizado neste trabalho e descrito no Capítulo 2 ,

Na Figura 1.2, é mostrado um exemplo de uma mensagem $m(n)$, o sinal transmitido $s(n)$ com a mensagem codificada utilizando o mapa de Hénon, o sinal recebido $r(n)=s(n)$ e a mensagem recuperada $\widehat{m}(n)$ considerando um canal ideal. É possível observar que, nesse caso, a mensagem é recuperada sem erros, após um pequeno transitório, como esperado.

Entretanto, como indicado em [Rulkov e Tsimring, 1999] e em [Eisencraft et al., 2009], o sincronismo caótico é muito sensível a ruído aditivo ou a uma resposta em frequência não ideal do canal e, consequentemente, $\widehat{m}(n) \nrightarrow m(n)$, quando esses estão presentes. Devido à natureza não linear dos sistemas envolvidos, se uma componente espectral for modificada na transmissão do sinal pelo canal, várias componentes espectrais são afetadas no receptor. Na Figura 1.3, é mostrado um exemplo dos sinais envolvidos considerando o canal $H(z)=0,9$ e ausência de ruído. Como pode ser observado, mesmo quando o canal consiste de uma simples atenuação, a comunicação entre o transmissor e receptor é perdida.

Uma maneira de contornar esses problemas para canais ideais mas limitados em banda é ajustar o espectro do sinal caótico transmitido pelo canal usando filtros lineares na malha de realimentação do transmissor e do receptor. Essa ideia foi apresentada em Eisencraft et al., 2009, 2011]. Entretanto, essa solução é conveniente apenas para um canal com banda limitada, aproximadamente ideal. Quando a resposta em frequência do canal não é conhecida, não é possível utilizar essa solução. Diante disso, é interessante estudar soluções que possibilitem a utilização desses sistemas de comunicação em situações onde o canal não é ideal.

\subsection{Objetivos}

Nesta tese de doutorado, pretende-se estudar o desempenho do sistema de comunicação baseado em caos que utiliza a versão de tempo discreto da modulação caótica de Wu e Chua 

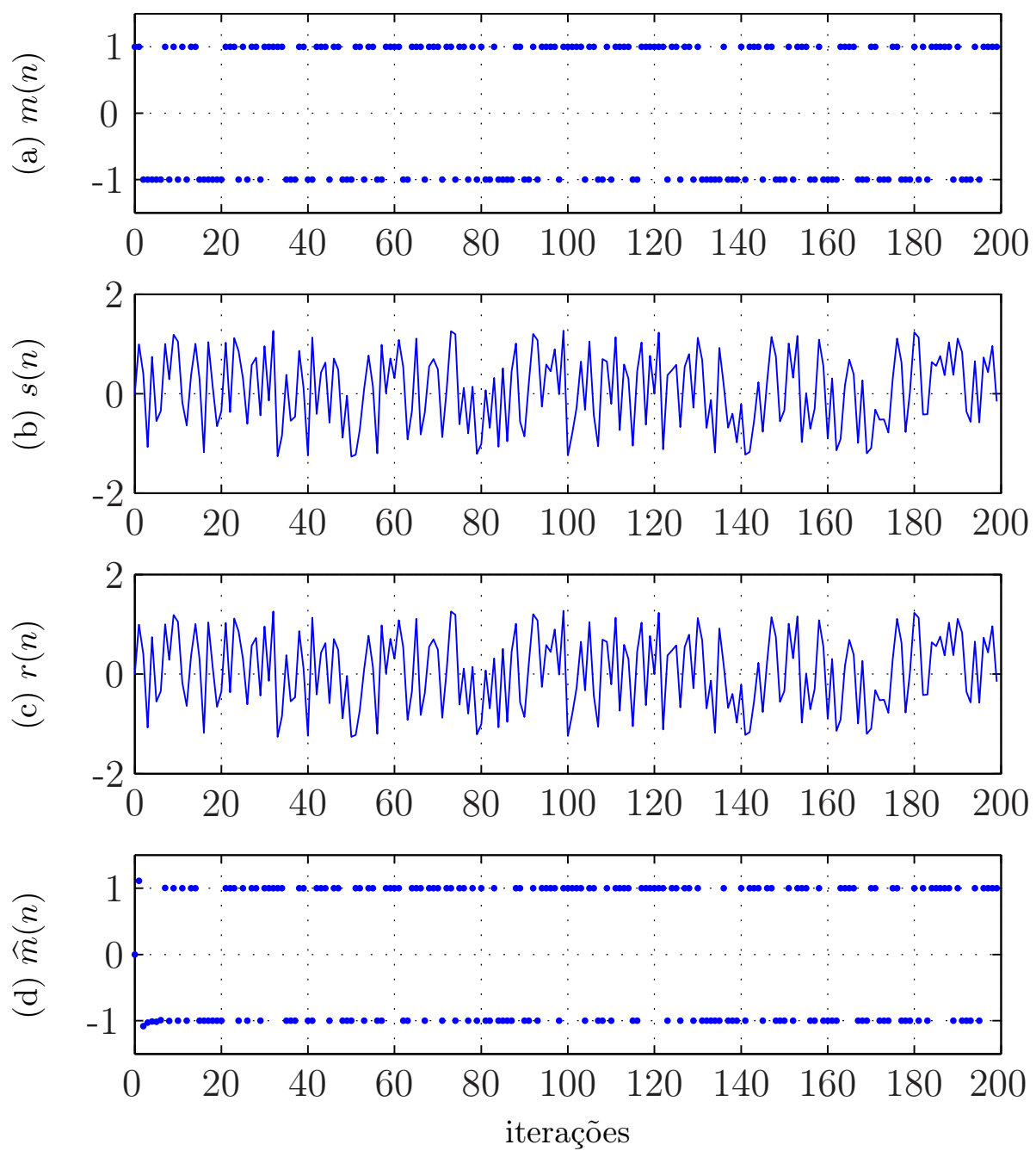

Figura 1.2: Simulação do sistema de comunicação mostrado na Fig. 1.1 utilizando o mapa de Hénon e canal ideal: (a) mensagem $m(n)$; (b) sinal transmitido $s(n)$; (c) sinal recebido $r(n)$; (d) mensagem recuperada $\widehat{m}(n)$.

[Eisencraft et al., 2009] quando ruído branco gaussiano aditivo e canais não ideais estão presentes. Dado que canais dispersivos introduzem interferência intersimbólica que varia com o tempo, um equalizador adaptativo deve ser incluído no sistema para recuperar adequadamente a mensagem transmitida. No sistema de comunicação, são considerados os mapas de Hénon [1976] e Ikeda [1979] como GSC e são utilizadas duas funções de codificação. Para esses casos, são propostos esquemas de equalização baseados no algoritmo NLMS (Normalized Least Mean

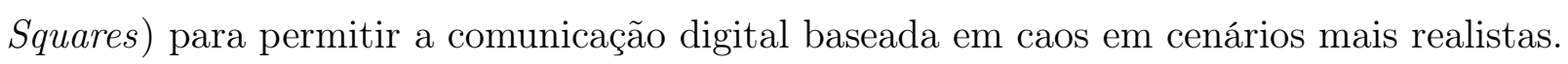



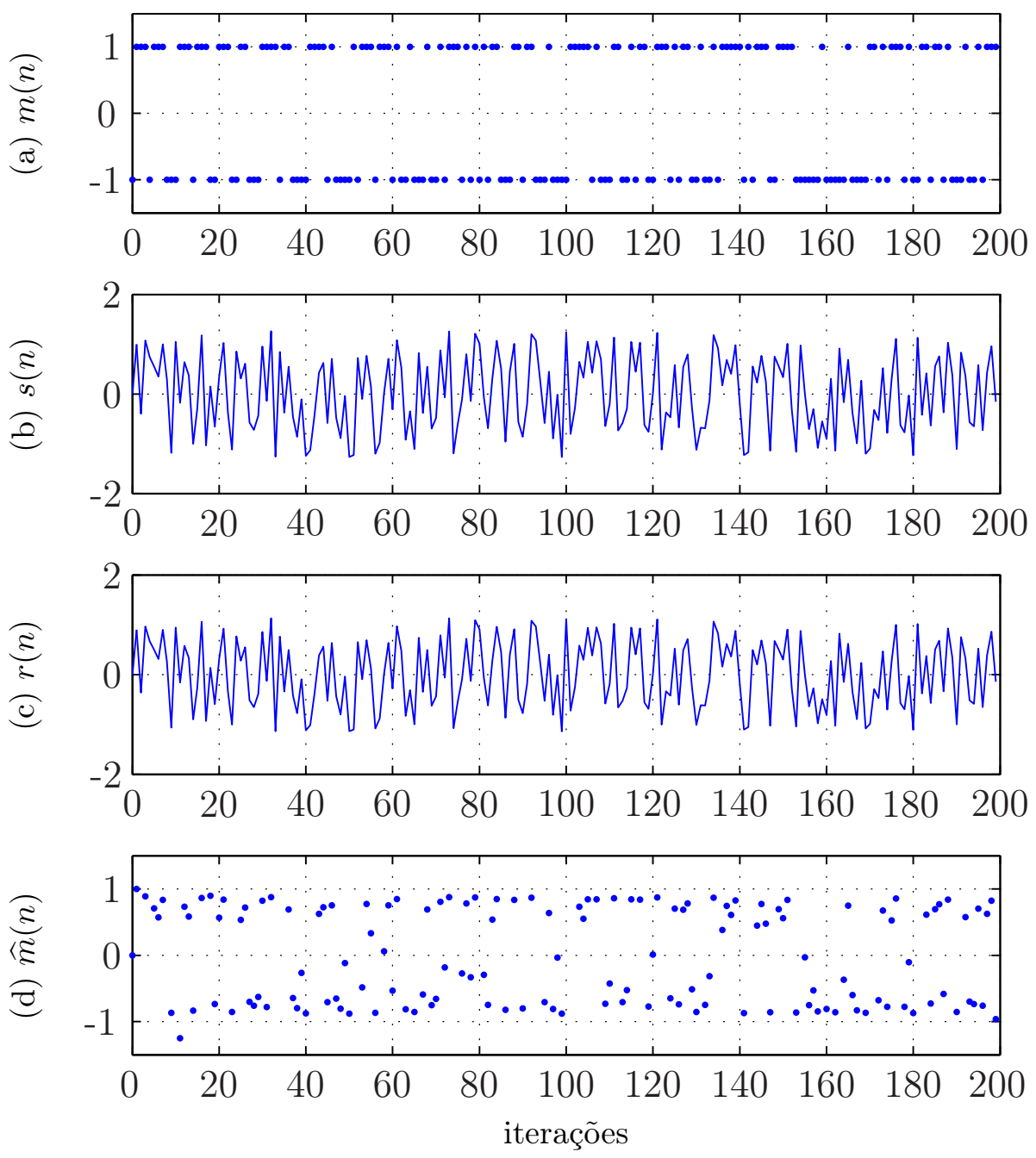

Figura 1.3: Simulação do sistema de comunicação mostrado na Fig. 1.1 utilizando o mapa de Hénon e $H(z)=0,9$ na ausência de ruído: (a) mensagem $m(n)$; (b) sinal transmitido $s(n)$; (c) sinal recebido $r(n)$; (d) mensagem recuperada $\widehat{m}(n)$.

\subsection{Justificativa}

Sinais caóticos apresentam uma série de características interessantes do ponto de vista de comunicações: são aperiódicos, possuindo espectro de Fourier contínuo; podem apresentar autocovariância aproximadamente impulsiva e baixa correlação cruzada entre sinais gerados por um mesmo sistema com condições iniciais diferentes, sendo candidatos naturais para sistemas de espalhamento espectral [Lau e Tse, 2003]. Assim, os sistemas que utilizam modulação caótica tendem a compartilhar as mesmas propriedades dos sistemas de espalhamento espectral convencionais, ou seja, dificuldade de detecção não autorizada, mitigação do desvanecimento devido ao multipercurso e robustez às interferências de banda estreita Haykin, 2000; Lau e 
Tse, 2003]. Além disso, têm o potencial de contribuir na questão da privacidade na transmissão dos dados e podem ser gerados usando circuitos muito simples, sendo uma potencial solução de custo efetivo para comunicações de banda larga [Argyris et al., 2005; Feki et al., 2003; Kolumbán et al., 1997; Ren et al., 2013.

Apesar de ser necessária muita pesquisa para tornar essas aplicações efetivamente competitivas, as primeiras implementações práticas vêm surgindo nos últimos anos. Por exemplo, como já mencionado, um grupo de pesquisadores do Optical Communications Laboratory da Athens University na Grécia, implementou um enlace de $120 \mathrm{~km}$ de fibras ópticas na região metropolitana de Atenas transmitindo na taxa de gigabits e usando portadoras caóticas. O trabalho foi publicado no prestigiado periódico Nature [Argvris et al., 2005; Syvridis, 2009].

Contudo, a grande maioria dos trabalhos na área descrevem o desempenho dos sistemas de comunicação baseados em caos em condições ideais de canal. Raramente confrontam-se esses sistemas com situações usualmente encontradas na prática, como distorção, limitação em banda, ruído aditivo e atrasos inerentes a canais, especialmente os sem fio.

Dessa forma, o estudo de soluções para possibilitar o funcionamento de sistemas de comunicação que utilizam sinais caóticos em condições não ideais, dentre elas a equalização, é fundamental para o desenvolvimento de aplicações práticas.

\subsection{Contribuições da tese}

A partir dos resultados deste trabalho, foram publicados dois artigos em periódicos internacionais [PI-1, PI-2], um artigo em um congresso internacional [CI], um artigo em um congresso nacional [CN] e um capítulo de livro [CL], listados a seguir:

[PI-1] R. Candido, M. Eisencraft e M. T. M. Silva. Channel equalization for synchronization of chaotic maps. Digital Signal Processing, Out. 2014.

[PI-2] R. Candido, D. C. Soriano, M. T. M. Silva, M. Eisencraft. Do chaos-based communication systems really transmit chaotic signals. Signal Processing, Mar. 2015.

[CI] R. Candido, M. Eisencraft e M. T. M. Silva. Channel equalization for Synchronization of Ikeda maps. In Proc. of $21^{\text {st }}$ European Signal Processing Conference (EUSIPCO'2013), Marrakech Marrocos, 2013.

[CN] R. Candido, M. Eisencraft e M. T. M. Silva. Equalização de canais de comunicação para a sincronização de mapas. In Conferência Brasileira de Dinâmica, Controle e Aplicações (DINCON'2013), Fortaleza, 2013. 
[CL] R. Candido, M. T. M. Silva e M. Eisencraft. Channel equalization for chaotic communications systems In M. Eisencraft, R. Attux e R. Suyama (eds.), Chaotic Signals in Digital Communications, CRC Press, 2013.

As principais contribuições da tese foram:

\section{Algoritmo de equalização considerando o mapa de Hénon e codificação com multiplicação.}

Foi proposto um algoritmo para equalização de canais para o sistema de comunicação baseado em caos, utilizando o sincronismo de Wu e Chua [1993] e a codificação do sinal transmitido feita por meio da multiplicação da mensagem por um estado do GSC. O algoritmo foi proposto com base no NLMS e foram mostradas as condições para a estabilidade e a escolha do passo de adaptação. Esses resultados são detalhados na Seção 4.3 e foram publicados em [PI-1], [CN] e [CL].

2. Sistema de comunicação baseado em caos e algoritmo de equalização considerando o mapa de Ikeda.

Considerando o mapa de Ikeda [1979], foi proposto um sistema de comunicação utilizando o sincronismo de $\mathrm{Wu}$ e Chua [1993]. Foi mostrado que, em condições ideais de canal, é possível obter sincronismo entre o transmissor e o receptor e recuperar a mensagem transmitida sem erros. Para esse sistema, e utilizando a codificação com a multiplicação, foi proposto um algoritmo de equalização baseado no NLMS e foram mostradas as condições para a estabilidade. Esses resultados são detalhados na Seção 4.4 e foram publicados em [CI].

3. Estudo quanto à geração de sinais caóticos no sistema com mapa de Ikeda. Foi mostrado que, devido às características do mapa de Ikeda, os sinais gerados pelo transmissor deixam de ser caóticos quando se utiliza a função de codificação com a multiplicação. Apesar de ser possível contornar o problema considerando uma função de codificação diferente, foi mostrado que o sistema utilizando o mapa de Ikeda pode apresentar problema de sincronismo quando o transmissor gera sinais caóticos e o canal de comunicação não é ideal. Esses resultados são detalhados na Seção 4.4 .2 e foram publicados em [PI-2].

\section{Função de codificação da mensagem com a soma.}

Tendo em vista que o desempenho do sistema baseado em caos obtido com a codificação utilizando a multiplicação é muito inferior ao desempenho de sistemas convencionais, foi proposta uma outra função de codificação, baseada na soma ponderada da mensagem 
com um estado do GSC. Nesse caso, foi considerado apenas o mapa de Hénon e foram mostradas as condições para a escolha dos parâmetros da função de codificação para que os sinais gerados pelo transmissor fossem caóticos. Esses resultados são detalhados na Seção 5.1 .

\section{Algoritmo de equalização considerando o mapa de Hénon e codificação com} soma.

Com base na função de codificação utilizando a soma, foi proposto um algoritmo de equalização para o sistema baseado em caos. Por meio de simulações, foi mostrado que o sistema com essa codificação apresenta um desempenho melhor do que o obtido com a codificação utilizando a multiplicação. Esses resultados são detalhados na Seção 5.2 ,

\subsection{Organização da tese}

A tese está estruturada em 6 capítulos e 1 apêndice. No Capítulo 2, são apresentados os fundamentos de sinais caóticos de tempo discreto, as definições utilizadas no trabalho e os detalhes referentes ao cálculo dos exponentes de Lyapunov.

No Capítulo 3, são apresentados fundamentos de equalização adaptativa, os algoritmos utilizados e alguns exemplos de aplicação.

Nos Capítulos 4 e 5, a partir do algoritmo apresentado no Capítulo 3, são derivadas as versões para sistemas baseados em caos utilizando duas funções de codificação distintas. Primeiramente, no Capítulo 4, é considerada uma função que utiliza a multiplicação para a codificação da mensagem no sinal caótico. Com base nessa codificação, é apresentado um algoritmo de equalização para o sistema de comunicação baseado em caos e são mostrados resultados de simulação utilizando o mapa de Hénon e o mapa de Ikeda. Sobre os mapas, são apresentados detalhes relacionados ao sincronismo caótico e à questão dos sinais transmitidos serem caóticos ou não. Por fim, é mostrado que o sinal gerado com o sistema de Ikeda não é caótico e que o sistema apresenta problemas quanto ao sincronismo em algumas situações. Em seguida, no Capítulo 5, a fim de obter um desempenho melhor do sistema, é considerada uma outra função que utiliza a soma para a codificação da mensagem no sinal caótico. Um algoritmo de equalização é apresentado para esse caso e são mostrados resultados de simulação utilizando o mapa de Hénon.

No Capítulo [6] são apresentadas as conclusões e propostas de trabalhos futuros.

No Apêndice A, é apresentada uma função de codificação para o sistema com o mapa de Ikeda, que possibilita a geração de sinais que apresentam DSCI. 


\section{Capítulo 2}

\section{Conceitos de sinais caóticos de tempo discreto}

Neste capítulo, são introduzidos alguns conceitos de sistemas dinâmicos e sinais caóticos de tempo discreto que serão utilizados nos capítulos seguintes. Inicialmente, estabelece-se a notação básica empregada. Em seguida, é apresentada a definição de expoentes de Lyapunov e é mostrada uma forma de calculá-los numericamente. Por fim, são apresentados os mapas utilizados nos sistemas de comunicação estudados nos próximos capítulos. A principal referência usada neste capítulo é [Alligood et al., 1997].

\subsection{Definições básicas}

Um sistema dinâmico consiste em um conjunto de possíveis estados com uma regra que determina o estado em um determinado instante em função dos estados nos instantes passados [Alligood et al., 1997]. Essa regra, para sistemas de tempo discreto, é chamada de mapa.

Um mapa $\mathbf{f}(\cdot)$ é uma funçãd 11 com domínio e contradomínio $U \subset \mathbb{R}^{K}$ que define um sistema dinâmico representado por

$$
\mathbf{x}(n+1)=\mathbf{f}(\mathbf{x}(n))
$$

$\operatorname{com} n \in \mathbb{N}$.

Dada uma condição inicial $\mathbf{x}(0) \subset U$ e um mapa $\mathbf{f}(\cdot)$, iterando-se o mapa, obtém-se uma órbita, definida pelo sinal formado pelo conjunto de estados $\mathrm{x}$ ao longo dos instantes de tempo, ou seja,

$$
\left\{\mathbf{x}(0), \mathbf{f}(\mathbf{x}(0)), \ldots, \mathbf{f}^{n}(\mathbf{x}(0))\right\}
$$

\footnotetext{
${ }^{1}$ Apesar de ser utilizada a mesma notação da função do Capítulo 1, neste capítulo, f(·) se refere a uma função $\mathbb{R}^{K} \rightarrow \mathbb{R}^{K}$.
} 
sendo $\mathbf{f}^{n}(\cdot)$ a $n$-ésima iteração do mapa e $\mathbf{f}^{0}(\mathbf{x})=\mathbf{x}$.

Quando a iteração da função a partir de um ponto $\mathbf{p}$ resulta no mesmo valor, ou seja,

$$
\mathbf{f}(\mathbf{p})=\mathbf{p}
$$

$\mathbf{p}$ é chamado de ponto fixo.

\subsection{Expoentes de Lyapunov}

Um conceito fundamental na caracterização de sinais caóticos é a dependência sensível às condições iniciais (DSCI $)$. A DSCI significa que, para duas condições iniciais muito próximas, os sinais resultantes vão se distanciando exponencialmente, em média, tornando-se totalmente distintos após algumas iterações.

Uma forma prática e operacional de verificar a DSCI das órbitas é por meio dos números de Lyapunov. Para um mapa em $\mathbb{R}^{K}$, cada órbita tem $K$ números de Lyapunov, que medem a taxa de divergência exponencial média entre duas órbitas próximas ao longo de $K$ direções ortogonais. Essas direções são dadas pela dinâmica do mapa. A primeira será a direção ao longo da qual a divergência entre as órbitas é a maior. A segunda será a direção de maior divergência dentre as direções perpendiculares à primeira. A terceira direção será a de maior divergência dentre as direções perpendiculares à primeira e à segunda e assim por diante. Os fatores de separação em cada uma dessas direções são os números de Lyapunov da órbita, associados a uma condição inicial.

Considerando-se uma esfera $S$ de raio pequeno com centro no ponto associado à condição inicial da órbita $\mathbf{x}(0)$ e examinando o resultado de uma iteração do mapa $\mathbf{f}(\cdot)$ sobre os pontos dessa esfera, o resultado é uma forma elipsoidal com eixos mais longos nas direções em que $\mathbf{f}(\cdot)$ proporciona uma maior separação entre duas condições iniciais próximas e eixos mais curtos nas direções em que $\mathbf{f}(\cdot)$ proporciona uma menor separação entre duas condições iniciais próximas. As mudanças nos eixos desse "elipsóide" imagem, ao longo das iterações, são dadas pelos números de Lyapunov. Eles medem a quantia de alongamento ou encurtamento dos eixos. Essa ideia é ilustrada na Figura 2.1 para o caso bidimensional.

Mais formalmente, basta substituir a esfera em torno de $\mathbf{x}(0)$ e o mapa $\mathbf{f}(\cdot)$ pela esfera de raio unitário $S_{1}$ e a matriz jacobiana $\mathbf{D f}(\mathbf{x}(0))$, já que o interesse está no comportamento infinitesimal em torno de $\mathbf{x}(0)$. Sendo

$$
\mathbf{J}_{n}=\mathbf{D f}^{n}(\mathbf{x}(0))
$$




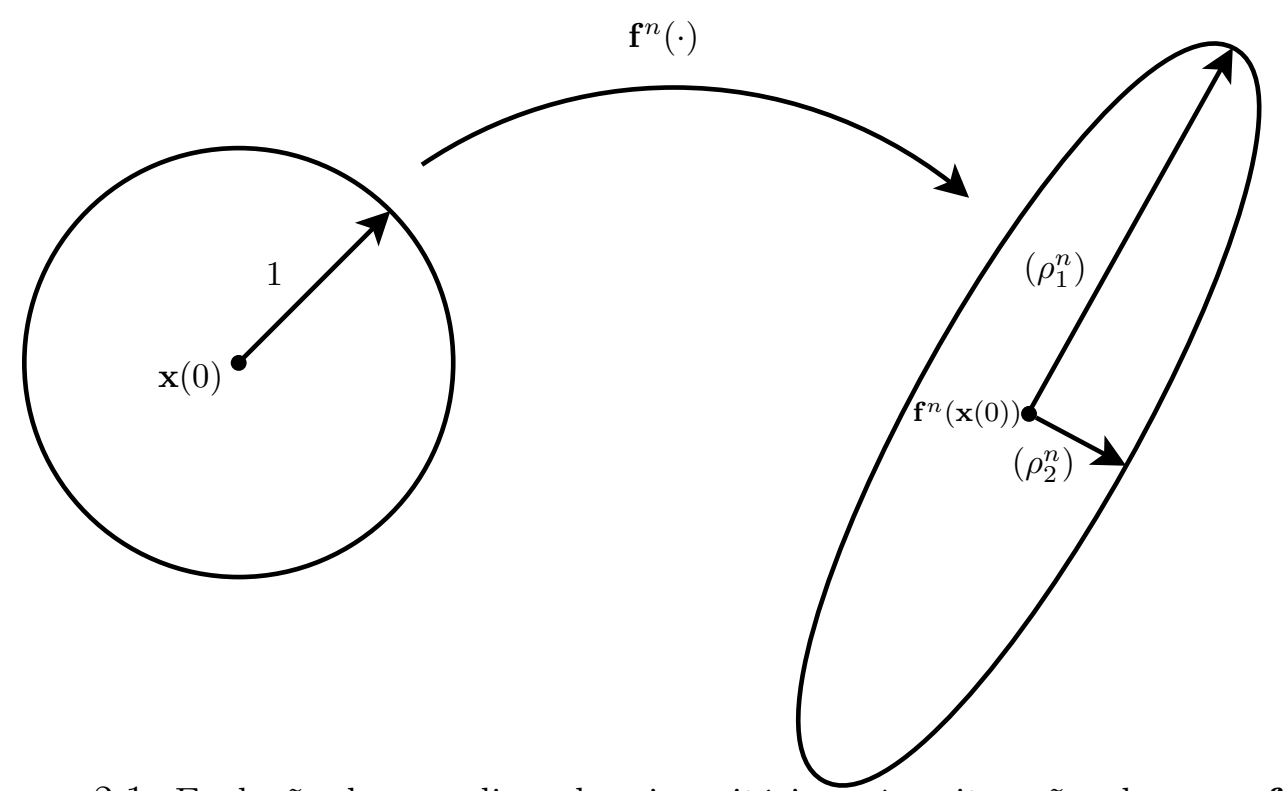

Figura 2.1: Evolução de uma disco de raio unitário após $n$ iterações do mapa $\mathbf{f}(\cdot)$.

a matriz jacobiana da função resultante da $n$-ésima iteração do mapa $\mathbf{f}(\cdot), \mathbf{J}_{n} S_{1}$ será um elipsóide com $K$ eixos ortogonais. Os eixos serão maiores que 1 nas direções de expansão e menores do que 1 nas direções de contração. As $K$ médias geométricas das taxas de expansão dos $K$ eixos ortogonais são os números de Lyapunov. Ou seja, para $k=1, \cdots, K$, sendo $\left(\rho_{k}^{n}\right)$ o comprimento do $k$-ésimo maior eixo ortogonal do elipsóide $\mathbf{J}_{n} S_{1}$, para uma órbita com ponto inicial $\mathbf{x}(0)$, o $k$-ésimo número de Lyapunov $L_{k}$ associado à condição inicial $\mathbf{x}(0)$ é dado por

$$
L_{k}=\lim _{n \rightarrow \infty}\left(\rho_{k}^{n}\right)^{1 / n}
$$

se o limite existir. A partir de $L_{k}$, pode-se obter o $k$-ésimo expoente de Lyapunov associado à condição inicial $\mathbf{x}(0)$, dado por

$$
\kappa_{k}=\ln L_{k}
$$

Sendo $S_{1}$ a esfera de raio unitário em $\mathbb{R}^{K}$ e $\mathbf{B}$ uma matriz $K \times K$, os tamanhos dos eixos ortogonais do elipsóide $\mathbf{B} S_{1}$ podem ser calculados diretamente como sendo as raízes quadradas dos $K$ autovalores da matriz $\mathbf{B B}^{\mathrm{T}}$ e as direções dos eixos serão dadas pelos $K$ autovetores correspondentes. Usando esse resultado, é possível calcular analiticamente os números de Lyapunov em alguns casos, dados o mapa, a matriz jacobiana $\mathbf{J}_{n}$ e a condição inicial.

Por exemplo, considere-se o mapa conhecido como cat map, dado por

$$
\mathbf{x}(n+1)=\mathbf{f}(\mathbf{x}(n))=\left[\begin{array}{ll}
2 & 1 \\
1 & 1
\end{array}\right]\left[\begin{array}{l}
x_{1}(n) \\
x_{2}(n)
\end{array}\right] \bmod 1=\mathbf{A x}(n) \bmod 1
$$

no qual a notação $x \bmod 1$ se refere ao número $x+k$, com $k$ sendo o único inteiro que faz 
com que $0 \leq x+k<1$. Assim, $14,92 \bmod 1=0,92$ e $-14,92 \bmod 1=0,08$. Nesse caso, a matriz jacobiana $\mathbf{D f}(\mathbf{x})$ é constante e igual à matriz $\mathbf{A}$ para qualquer $\mathbf{x}$. Usando o resultado citado anteriormente, os tamanhos dos eixos da elipse formada após a aplicação de $\mathbf{f}^{n}$ serão as raízes quadradas dos autovalores de $\mathbf{A}^{n}\left(\mathbf{A}^{n}\right)^{\mathrm{T}}$. Como $\mathbf{A}$ é uma matriz simétrica, ou seja $\mathbf{A}=\mathbf{A}^{\mathrm{T}}$, esses serão os mesmos autovalores de $\mathbf{A}^{n}$, que podem ser calculados como $\lambda_{i}^{n}$, sendo $\lambda_{i}, i=1,2$, os autovalores de $\mathbf{A}$, dados por $\lambda_{1}=2,618$ e $\lambda_{2}=0,382$. Assim, um disco de raio $r$ será transformado em uma elipse com raios $r \lambda_{1}$ e $r \lambda_{2}$ após uma iteração do mapa e em uma elipse com raios $r \lambda_{1}^{n}$ e $r \lambda_{2}^{n}$ após $n$ iterações do mapa. Usando (2.5), os números de Lyapunov para esse mapa serão dados por $L_{1}=\lambda_{1}=2,618$ e $L_{2}=\lambda_{2}=0,382$ e os expoentes de Lyapunov serão $\kappa_{1}=\ln L_{1} \approx 0,962$ e $\kappa_{2}=\ln L_{2} \approx-0,962$.

Entretanto, para quase todos os mapas não existe forma analítica de determinar os expoentes de Lyapunov a partir do mapa e da matriz jacobiana. Geralmente, a matriz $\mathbf{J}_{n}=\mathbf{D f}^{n}(\mathbf{x}(0))$ é difícil de ser calculada com precisão para valores grandes de $n$, sendo necessário fazer uma aproximação do elipsóide imagem $\mathbf{J}_{n} S_{1}$ por meio de algoritmos computacionais.

Dado que o elipsóide $\mathbf{J}_{n} S_{1}$ tem eixos de tamanho $p_{k}$ nas direções $\mathbf{u}_{k}$, a abordagem direta para obter os expoentes de Lyapunov seria o cálculo da matriz $\mathbf{J}_{n} \mathbf{J}_{n}^{\mathrm{T}}$ e a obtenção de seus autovalores $p_{k}^{2}$. No caso de o elipsóide possuir direções em que ele é alongado e comprimido, ele será muito longo e muito fino para um valor de $n$ grande. A matriz $\mathbf{J}_{n}$ será mal condicionada e os autovalores de $\mathbf{J}_{n} \mathbf{J}_{n}^{\mathrm{T}}$ vão conter números muito grandes ou muito pequenos, o que causa erros de precisão numérica nos algoritmos computacionais. Por essa razão, o cálculo do elipsóide $\mathbf{J}_{n} S_{1}$ na forma direta deve ser evitado.

Uma forma indireta que funciona melhor consiste em acompanhar o elipsóide conforme ele evolui. Sendo $\{\mathbf{x}(0), \mathbf{x}(1), \cdots, \mathbf{x}(n-1)\}$ os pontos de uma órbita do mapa $\mathbf{f}(\cdot)$ com condição inicial $\mathbf{x}(0)$ e usando a regra da cadeia, é possível escrever $\mathbf{J}_{n}$ na forma

$$
\mathbf{J}_{n}=\mathbf{D f}^{n}(\mathbf{x}(0))=\mathbf{D f}(\mathbf{x}(n-1)) \cdots \mathbf{D f}(\mathbf{x}(0)) \text {. }
$$

Assim, é possível calcular $\mathbf{J}_{n} S_{1}$ uma iteração por vez. Iniciando com uma base ortonormal $\left\{\left(\mathbf{u}_{1}^{0}\right), \cdots,\left(\mathbf{u}_{K}^{0}\right)\right\}$ para $\mathbb{R}^{K}$, calcula-se os vetores $\left(\mathbf{z}_{1}^{1}\right), \cdots,\left(\mathbf{z}_{m}^{1}\right)$ como

$$
\left(\mathbf{z}_{1}^{1}\right)=\operatorname{Df}(\mathbf{x}(0))\left(\mathbf{u}_{1}^{0}\right), \cdots,\left(\mathbf{z}_{K}^{1}\right)=\operatorname{Df}(\mathbf{x}(0))\left(\mathbf{u}_{K}^{0}\right) .
$$

Esses vetores estão sobre o elipsóide $\mathbf{D f}(\mathbf{x}(0)) S_{1}$, mas não serão necessariamente ortogonais. Para contornar essa situação, é necessário obter um novo conjunto de vetores ortogonais $\left\{\left(\mathbf{u}_{1}^{1}\right), \cdots,\left(\mathbf{u}_{K}^{1}\right)\right\}$ que geram um elipsóide com o mesmo volume de $\mathbf{D f}(\mathbf{x}(0)) S_{1}$. Para tanto, 
utilizando o processo de ortogonalização de Gram-Schmidt, obtém-se

$$
\begin{aligned}
\left(\mathbf{y}_{1}^{1}\right) & =\left(\mathbf{z}_{1}^{1}\right) \\
\left(\mathbf{y}_{2}^{1}\right) & =\left(\mathbf{z}_{2}^{1}\right)-\frac{\left(\mathbf{z}_{2}^{1}\right) \cdot\left(\mathbf{y}_{1}^{1}\right)}{\left\|\left(\mathbf{y}_{1}^{1}\right)\right\|^{2}}\left(\mathbf{y}_{1}^{1}\right) \\
\left(\mathbf{y}_{3}^{1}\right) & =\left(\mathbf{z}_{3}^{1}\right)-\frac{\left(\mathbf{z}_{3}^{1}\right) \cdot\left(\mathbf{y}_{1}^{1}\right)}{\left\|\left(\mathbf{y}_{1}^{1}\right)\right\|^{2}}\left(\mathbf{y}_{1}^{1}\right)-\frac{\left(\mathbf{z}_{3}^{1}\right) \cdot\left(\mathbf{y}_{2}^{1}\right)}{\left\|\left(\mathbf{y}_{2}^{1}\right)\right\|^{2}}\left(\mathbf{y}_{2}^{1}\right) \\
& \vdots \\
\left(\mathbf{y}_{K}^{1}\right) & =\left(\mathbf{z}_{K}^{1}\right)-\frac{\left(\mathbf{z}_{K}^{1}\right) \cdot\left(\mathbf{y}_{1}^{1}\right)}{\left\|\left(\mathbf{y}_{1}^{1}\right)\right\|^{2}}\left(\mathbf{y}_{1}^{1}\right)-\cdots-\frac{\left(\mathbf{z}_{K}^{1}\right) \cdot\left(\mathbf{y}_{K-1}^{1}\right)}{\left\|\left(\mathbf{y}_{K-1}^{1}\right)\right\|^{2}}\left(\mathbf{y}_{K-1}^{1}\right)
\end{aligned}
$$

Fazendo $\left(\mathbf{u}_{k}^{1}\right)=\left(\mathbf{y}_{k}^{1}\right)$, para $k=1, \cdots, K$, obtém-se um conjunto de vetores ortogonais que geram um elipsóide com o mesmo volume de $\mathbf{D f}(\mathbf{x}(0)) S_{1}$. A partir daí, bastaria continuar o procedimento, calculando o valor do jacobiano $\mathbf{D f}(\cdot)$ no segundo ponto da órbita, obtendose o conjunto de vetores $\left\{\left(\mathbf{z}_{1}^{2}\right), \cdots\left(\mathbf{z}_{K}^{2}\right)\right\}$ e, após a ortogonalização, o conjunto de vetores $\left\{\left(\mathbf{u}_{1}^{2}\right), \cdots\left(\mathbf{u}_{K}^{2}\right)\right\}$. Entretanto, para eliminar o problema dos números muito grandes ou muito pequenos, é necessário normalizar a base ortogonal a cada passo. Para tanto, obtém-se a nova base ortonormal fazendo $\left(\mathbf{u}_{k}^{1}\right)=\left(\mathbf{y}_{k}^{1}\right) /\left\|\left(\mathbf{y}_{k}^{1}\right)\right\|$ para $k=1, \cdots, K$.

Em seguida, calcula-se a matriz jacobiana no próximo ponto da órbita e obtém-se uma nova base ortonormal $\left\{\left(\mathbf{y}_{1}^{2}\right), \cdots\left(\mathbf{y}_{K}^{2}\right)\right\}$, a partir do conjunto de vetores

$$
\operatorname{Df}(\mathbf{x}(1))\left(\mathbf{u}_{1}^{1}\right), \cdots, \operatorname{Df}(\mathbf{x}(1))\left(\mathbf{u}_{K}^{1}\right)
$$

Fazendo isso, a cada passo $j,\left\|\left(\mathbf{y}_{k}^{j}\right)\right\|$ mede a taxa de crescimento na direção $k$ devido a ação de uma iteração do mapa. Dado que, usando um valor de $n$ suficientemente grande,

$$
\rho_{k} \approx\left\|\left(\mathbf{y}_{k}^{1}\right)\right\| \cdot\left\|\left(\mathbf{y}_{k}^{2}\right)\right\| \cdot \ldots \cdot\left\|\left(\mathbf{y}_{k}^{n}\right)\right\|
$$

é possível estimar o valor do $k$-ésimo expoente de Lyapunov pela da expressão

$$
\kappa_{k} \approx \frac{\ln \left\|\left(\mathbf{y}_{k}^{1}\right)\right\|+\cdots+\ln \left\|\left(\mathbf{y}_{k}^{n}\right)\right\|}{n}
$$

Pode-se mostrar que uma órbita com o maior expoente de Lyapunov positivo apresenta DSCI [Abraham et al., 2004]. Assim, calculando os expoentes de Lyapunov para uma um mapa $\mathbf{x}(n+1)=\mathbf{f}(\mathbf{x}(n))$, é possível determinar se o sistema apresenta DSCI, Se o maior expoente de Lyapunov $\kappa_{1}$ for positivo, o que equivale ao maior número de Lyapunov $L_{1}$ ser maior que um, existirá uma direção para a qual duas órbitas inicialmente próximas irão divergir após 
algumas iterações do mapa.

\subsection{Sinais caóticos: definição e mapas utilizados}

Não existe uma única definição geral para caracterizar sinais caóticos, como pode ser visto, por exemplo, em |Alligood et al., 1997; Devaney, 2003]. Neste trabalho, é utilizada a definição encontrada em [Li e Yorke, 1975], também expressa em [Alligood et al., 1997]. Por essa definição, um sinal limitado $\mathbf{x}(n)$ é caótico se

1. for aperiódico;

2. seu maior expoente de Lyapunov $\kappa_{1}$ for positivo.

Pelo fato de os sinais caóticos serem aperiódicos, os mesmos não convergem para pontos fixos ou para órbitas periódicas. Além disso, possuindo DSCI, representada pela presença do maior expoente de Lyapunov $\kappa_{1}>0$, órbitas com condições iniciais próximas divergem após poucas iterações do mapa. Sendo assim é sempre possível encontrar um ponto suficientemente próximo da condição inicial, cuja órbita relacionada estará relativamente distante após algumas iterações.

Ainda pela característica da DSCI, pode-se dizer que os sinais caóticos são de difícil previsão. Em um sistema prático, não se conhecendo exatamente a condição inicial com toda a precisão, não é possível prever o comportamento do sistema após um curto período de tempo [Strogatz, 2001].

Nos mapas geradores de sinais caóticos utilizados neste trabalho, apenas um conjunto de medida nula de condições iniciais gera órbitas periódicas com o maior expoente de Lyapunov positivo. Nesse caso, a probabilidade de se escolher ao acaso uma condição inicial no domínio $U$ que gere órbitas periódicas com o maior expoente de Lyapunov positivo ou que convirja para uma é zero. Por esse motivo, numericamente, considera-se aqui que o fato de o maior expoente de Lvapunov ser positivo é suficiente para afirmar que o sinal é caótico [Alligood et al., 1997].

Uma outra definição usual na literatura é a de atrator caótico. De forma simples, pode-se dizer que um atrator é um ponto, ou conjunto de pontos no espaço de fases para o qual toda órbita que passar suficientemente próxima converge [Alligood et al., 1997]. Os atratores de órbitas caóticas são chamados de atratores caóticos. Outro conceito utilizado é o de bacia de atração, representada pelo conjunto de pontos do espaço de fases que levam a órbita para o atrator caótico.

A seguir, são apresentados os mapas geradores de sinais caóticos de tempo discreto que são utilizados no trabalho. 


\subsubsection{Mapa de Hénon}

O mapa de Hénon [1976] é um mapa bidimensional de tempo discreto proposto como um modelo simples de um sistema que apresenta propriedades semelhantes às do sistema de Lorenz [Lorenz, 1963], em particular a presença de um atrator estranho [Hénon, 1976]. Ele é dado por

$$
\mathbf{x}(n+1)=\left[\begin{array}{c}
x_{1}(n+1) \\
x_{2}(n+1)
\end{array}\right]=\left[\begin{array}{c}
1-\alpha x_{1}^{2}(n)+x_{2}(n) \\
\beta x_{1}(n)
\end{array}\right],
$$

sendo $\alpha$ e $\beta$ parâmetros do mapa.

Para $\alpha=1,4$ e $\beta=0,3$ [Hénon, 1976], o mapa apresenta um atrator caótico com expoentes de Lyapunov $\kappa_{1}=0,42$ e $\kappa_{2}=-1,62$. Na Figura 2.2, é mostrado o atrator no espaço de fases assim como um trecho de sua bacia de atração, indicada em amarelo. Para condições iniciais fora dessa área, o mapa diverge, fazendo $x_{1}(n)$ e $x_{2}(n)$ tenderem a infinito. Na Figura 2.3, são mostrados trechos de $x_{1}(n)$ e $x_{2}(n)$ ao longo das iterações para $\mathbf{x}(0)=\mathbf{0}$.

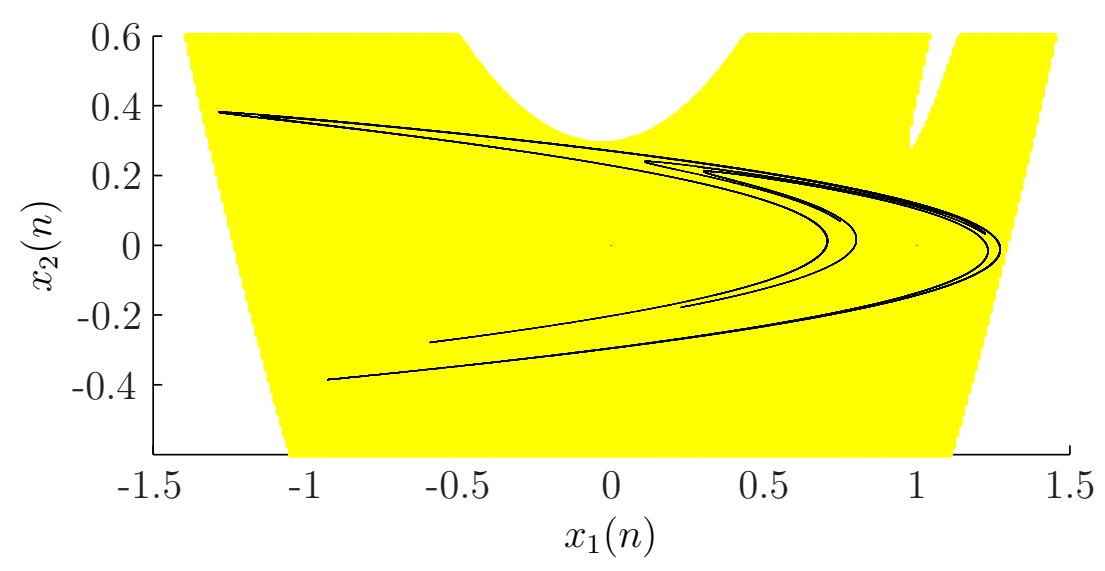

Figura 2.2: Atrator do mapa de Hénon $\operatorname{com} \alpha=1,4$ e $\beta=0,3$. A área amarela indica a bacia de atração para o atrator caótico mostrado em preto.

\subsubsection{Mapa de Ikeda}

Usando algumas hipóteses simplificadoras, o mapa de Ikeda é um modelo para um tipo de célula que pode ser utilizado em um computador óptico [Alligood et al., 1997; Ikeda, 1979]. É um mapa bidimensional dado por

$$
\mathbf{x}(n+1)=\left[\begin{array}{l}
x_{1}(n+1) \\
x_{2}(n+1)
\end{array}\right]=\left[\begin{array}{l}
C_{2} x_{1}(n) \cos \theta(n)-C_{2} x_{2}(n) \sin \theta(n)+R \\
C_{2} x_{1}(n) \sin \theta(n)+C_{2} x_{2}(n) \cos \theta(n)
\end{array}\right],
$$



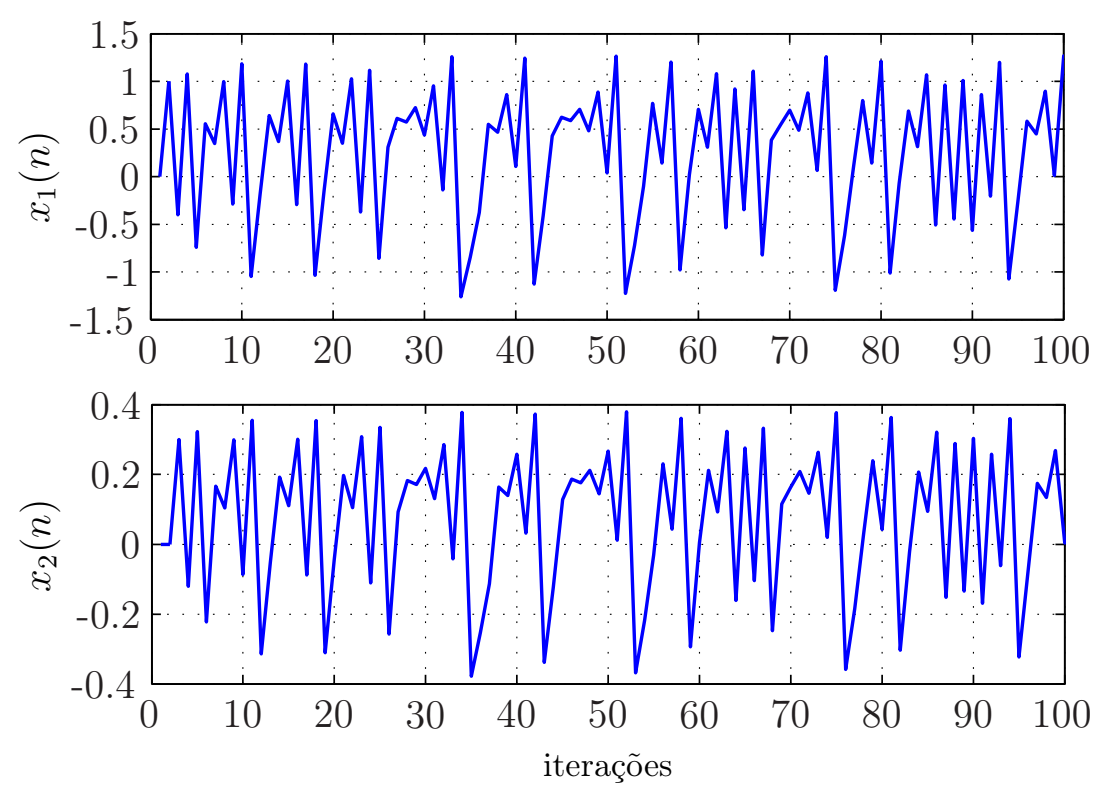

Figura 2.3: Trechos de $x_{1}(n)$ e $x_{2}(n)$ do mapa de Hénon com $\alpha=1,4$ e $\beta=0,3$ inicializado $\operatorname{com} \mathbf{x}(0)=\mathbf{0}$.

em que

$$
\theta(n)=C_{1}-\frac{C_{3}}{1+x_{1}^{2}(n)+x_{2}^{2}(n)}
$$

e $C_{1}, C_{2}, C_{3}$ e $R$ são constantes reais.

Considerando os parâmetros usuais [Alligood et al., 1997]

$$
C_{1}=0,4, \quad C_{2}=0,9, \quad C_{3}=6 \quad \text { e } \quad R=1,
$$

o mapa de Ikeda apresenta um atrator caótico com expoentes de Lyapunov $\kappa_{1} \approx 0,51$ e $\kappa_{2} \approx-0,72$ e um ponto fixo localizado em $\mathbf{x}^{*} \approx\left[\begin{array}{ll}2,97 & 4,15\end{array}\right]^{\mathrm{T}}$ com expoentes de Lyapunov $\kappa_{1} \approx-0,11$ e $\kappa_{2} \approx-0,10$. Para esse conjunto de parâmetros, as órbitas de (2.14) podem apresentar dois comportamentos distintos: (i) convergência para o ponto fixo $\mathbf{x}^{*}$ ou (ii) convergência para o atrator caótico. Na Figura 2.4 são mostrados ambos os atratores no espaço de fases assim como trechos de suas bacias de atração. O atrator caótico é mostrado em preto e o ponto fixo atrator é indicado pela cruz. A área em amarelo indica a bacia de atração para o atrator caótico, ou seja, os pontos do espaço de fases que levam a órbita para o atrator caótico. Os pontos fora dessa área levam a órbita para o ponto fixo. Na Figura 2.5, são mostrados trechos de $x_{1}(n)$ e $x_{2}(n)$ ao longo das iterações para $\mathbf{x}(0)=\mathbf{0}$. 


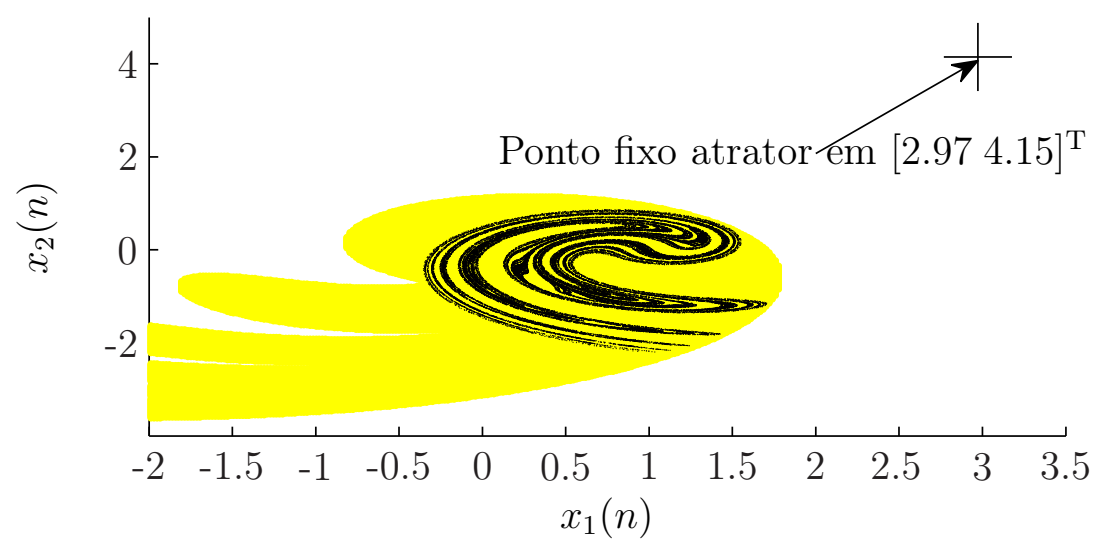

Figura 2.4: Atratores do mapa de Ikeda. A área amarela indica a bacia de atração para o atrator caótico mostrado em preto. Órbitas iniciadas fora da área amarela são levadas para o ponto fixo indicado pela cruz.
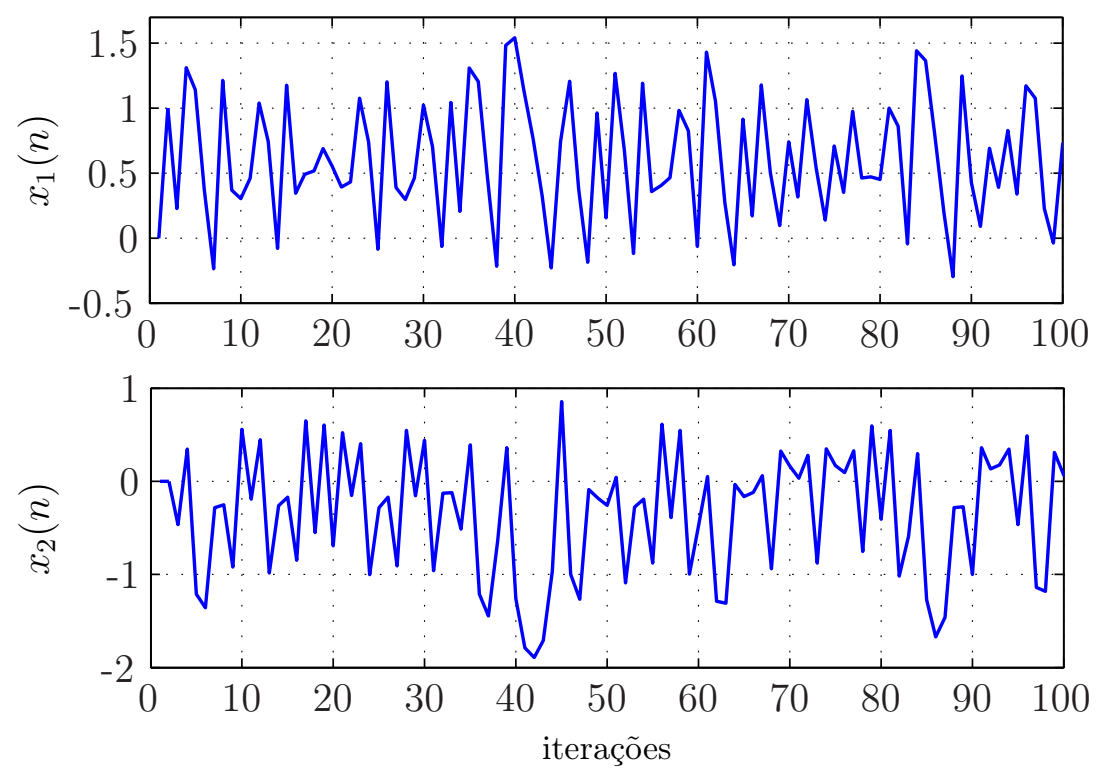

Figura 2.5: Trechos de $x_{1}(n)$ e $x_{2}(n)$ do mapa de Ikeda com os parâmetros (2.16), inicializado $\operatorname{com} \mathbf{x}(0)=\mathbf{0}$.

\subsection{Conclusões}

Neste capítulo, foram apresentados alguns conceitos básicos de sistemas dinâmicos como a definição de sinais caóticos, os mapas utilizados e uma forma de se verificar a DSCI, Claramente, a exposição limitou-se aos aspectos que serão utilizados nos capítulos restantes deste trabalho. No capítulo seguinte, serão introduzidos conceitos de equalização adaptativa e o 
algoritmo NLMS, Com base nos conceitos apresentados aqui e nesse algoritmo, são propostos nos Capítulos 4 e 5, algoritmos de equalização para o caso dos sistemas de comunicação baseados em caos utilizando os mapas de Hénon e Ikeda considerando duas funções de codificação. 


\section{Capítulo 3}

\section{Fundamentos de equalização adaptativa}

Neste capítulo, são introduzidos conceitos básicos de equalização adaptativa. Em seguida, é feita uma descrição do algoritmo NLMS e são apresentados resultados da aplicação desse algoritmo para equalização em alguns cenários.

\subsection{Uma breve introdução à equalização adaptativa}

Em sistemas de comunicação digital, sinais transmitidos entre dois pontos podem ser afetados por interferência intersimbólica (ISI) e ruído introduzidos por canais dispersivos. Alguns exemplos desses canais são os cabos coaxiais, as fibras ópticas ou cabos de pares trançados em sistemas de comunicação com fio e a atmosfera e o oceano em sistemas de comunicação sem fio [Johnson Jr. et al., 1998]. Para compensar os efeitos de distorção introduzidos pelo canal, é comum utilizar equalizadores adaptativos, na tentativa de recuperar a sequência de símbolos transmitida por meio da mitigacão dos efeitos de ISI] |Ding e Li. 2001: Havkin. 2002: Johnson Jr. et al., 1998; Qureshi, 1985; Treichler et al., 1996].

Um sistema de comunicação simplificado com um equalizador adaptativo é mostrado na Figura 3.1. Assume-se que todos os valores são reais e, nessa figura, é pressuposto que o sistema opere em banda base e portanto, a mensagem binária transmitida $m(n)$ e a sequência modulada $s(n)$ são sinais iguais. Desse modo, a sequência $m(n) \equiv s(n)$ é transmitida através de um canal desconhecido, modelado em geral como sendo um filtro de resposta ao impulso finita Finite Impulse Response- FIR com função de transferência

$$
H(z)=h_{0}+h_{1} z^{-1}+\cdots+h_{L_{h}-1} z^{-L_{h}+1},
$$

e ruído aditivo branco gaussiano (Additive White Gaussian Noise - AWGN $\eta(n)$, de média 


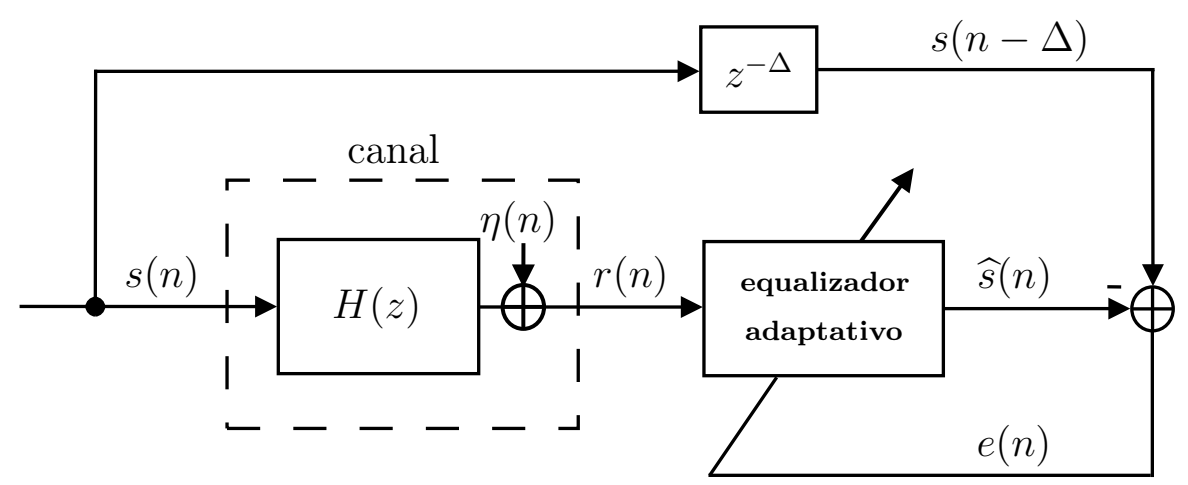

Figura 3.1: Sistema de comunicação simplificado com um equalizador adaptativo no modo de treinamento.

zero e variância $\sigma_{\eta}^{2}$. Usando esse modelo, $r(n)$ pode ser reescrito como

$$
r(n)=\sum_{k=0}^{L_{h}-1} h_{k} s(n-k)+\eta(n) .
$$

Devido à memória do canal, o sinal que chega ao receptor contém contribuições não apenas de $s(n)$ mas também dos símbolos anteriores $s(n-1), s(n-2), \ldots, s\left(n-L_{h}+1\right)$. Isto pode ser notado mais facilmente reescrevendo (3.2) como

$$
r(n)=\underbrace{\sum_{k=0}^{\Delta-1} h_{k} s(n-k)}_{\text {pré-ISI }}+h_{\Delta} s(n-\Delta)+\underbrace{\sum_{k=\Delta+1}^{L_{h}-1} h_{k} s(n-k)}_{\text {pós-ISI }}+\eta(n),
$$

sendo $\Delta$ um inteiro fixo que representa o atraso imposto pelo sistema composto pelo canal e equalizador. O equalizador adaptativo deve mitigar os dois somatórios mostrados em (3.3), eliminando dessa forma a ISI e encontrando uma aproximação $\widehat{s}(n)$ para $s(n-\Delta)$. O equalizador esquematizado na Figura 3.1 funciona no modo de treinamento, já que uma versão atrasada da sequência transmitida $s(n-\Delta$ ) (sequência de treinamento) é conhecida de antemão no receptor. Durante o modo de treinamento, o equalizador atualiza os seus coeficientes usando o sinal de erro $e(n)=s(n-\Delta)-\widehat{s}(n)$ juntamente com um algoritmo adaptativo. Quando a informação é efetivamente transmitida, o receptor não conhece de antemão o sinal $s(n-\Delta)$. Nesse caso, o sinal de treinamento $s(n-\Delta)$ é substituído por uma estimativa obtida na saída do decisor, como mostrado na Figura 3.2. Nessa configuração, diz-se que o equalizador trabalha no modo de decisão direta [Nascimento e Silva, 2014].

Devido à sua simplicidade, o equalizador linear transversal adaptado com o algoritmo do 


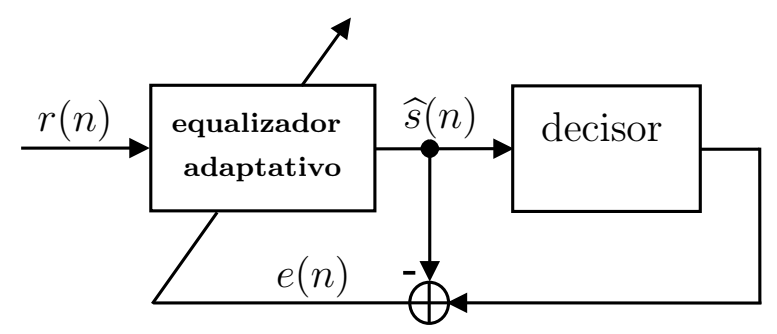

Figura 3.2: Equalizador adaptativo no modo de decisão direta.

gradiente estocástico é o esquema mais utilizado em sistemas de comunicação digital. Entretanto, um equalizador linear pode ter um desempenho ruim em muitas situações práticas, como canais com respostas ao impulso longas e esparsas, canais de fase não mínima, canais com nulos espectrais ou não linearidades |Bouchired et al.., 1998/1999: Gutierrez e Rvan, 2000; Park e Jeong, 2002; Rontogiannis e Berberidis, 2003]. Nesses casos, Forney Jr. [1972] mostrou que o equalizador ótimo é não linear e pode ser implementado com um filtro casado branqueador e o algoritmo de Viterbi. A necessidade da estimativa do canal e o custo computacional elevado do algoritmo de Viterbi tornam essa solução impraticável para canais longos. O mesmo ocorre com métodos bayesianos para equalização de canais, que, apesar de ótimos, são geralmente desenvolvidos pressupondo que as características do canal sejam previamente conhecidas e além disso, também apresentam alto custo computacional [Chen et al., 1993; Mulgrew, 1996]. Assim, soluções não lineares subótimas que apresentam um melhor compromisso entre custo computacional e desempenho, independentemente do canal, têm sido propostas na literatura. Alguns exemplos de equalizadores não lineares são: equalizadores de realimentação de decisões Decision Feedback Equalizer - DFE) QQureshi. 1985: Rontogiannis e Berberidis, 2003: Tsimbinos e White, 2001], redes neurais |Gibson et al., 1991; Mulgrew, 1996; Park e Jeong, 2002; Sweatman et al., 1998; Theodoridis et al., 1995], máquinas de vetores de suporte (support vector machines) [Santamaria et al., 2004], séries de Volterra [Gutierrez e Ryan, 2000] e filtros adaptativos baseados em núcleo (kernel adaptive filters) [Liu et al., 2010].

Uma outra abordagem não linear importante para equalização de canais é conhecida como equalização autodidata (ou não supervisionada). Nesse caso, a não linearidade está na estimativa do sinal transmitido com base em estatísticas de ordem superior High Order StatisticsHOS). Uma vez que a transmissão da sequência de treinamento não é feita, a banda disponível é usada de forma mais eficiente [Johnson Jr. et al., 1998]. Existem diversos algoritmos de equalização autodidata baseados em HOS na literatura, mas o mais popular é o algoritmo do módulo constante (Consant Modulus Alqorithm-CMA), proposto independentemente por Godard [Godard, 1980] e Treichler e Agee [Treichler e Agee, 1983]. Uma visão geral dos resultados relacionados ao CMA pode ser encontrada em [Ding e Li, 2001; Johnson Jr. et al., 1998]. 
Uma vez que os algoritmos de equalização autodidata são derivados a partir da minimização de funções não convexas, sua utilização em conjunto com esquemas não lineares (por exemplo, redes neurais) levam a soluções contendo diversos mínimos locais, para os quais os algoritmos podem convergir. Assim, algoritmos de equalização autodidata são comumente usados para adaptar filtros lineares transversais ou, no caso não linear, uma das estruturas que também é utilizada é o DFE

Neste trabalho, a fim de obter soluções relativamente simples para equalização de sequências caóticas, foi considerado um algoritmo de equalizacão baseado no algoritmo NLMS|[Haykin, 2002; Saved, 2008]. Esse algoritmo foi implementado em um filtro transversal, cuja entrada e vetor de coeficientes são dados por

$$
\mathbf{r}(n)=[r(n) r(n-1) \cdots r(n-M+1)]^{\mathrm{T}}
$$

e

$$
\mathbf{w}(n-1)=\left[\begin{array}{llll}
w_{0}(n-1) & w_{1}(n-1) & \cdots & w_{M-1}(n-1)
\end{array}\right]^{\mathrm{T}}
$$

e cuja saída é calculada como

$$
\widehat{s}(n)=\mathbf{r}^{\mathrm{T}}(n) \mathbf{w}(n-1) .
$$

A seguir, é feita uma descrição em detalhes do algoritmo NLMS.

\subsection{Equalização linear com o algoritmo NLMS}

Algoritmos do gradiente estocástico buscam minimizar o erro quadrático médio (Mean Square Error - MSE), definido como $C(n) \triangleq \mathrm{E}\left\{e^{2}(n)\right\}$, em que E $\{\cdot\}$ representa o operador de esperança matemática e

$$
e(n)=s(n-\Delta)-\widehat{s}(n)
$$

O MSE é uma função convexa, cujo mínimo é dado pela solução de Wiener

$$
\mathbf{w}_{\mathrm{o}}=\mathbf{R}^{-1} \mathbf{p}_{\Delta}
$$

na qual $\mathbf{R}=\mathrm{E}\left\{\mathbf{r}(n) \mathbf{r}^{\mathrm{T}}(n)\right\}$ é a matriz de autocorrelação do sinal de entrada e $\mathbf{p}_{\Delta}$ é o vetor de correlação cruzada entre o vetor regressor de entrada e o sinal transmitido, ou seja, $\mathbf{p}_{\Delta}=$ $\mathrm{E}\{s(n-\Delta) \mathbf{r}(n)\}$. A solução de Wiener é conhecida como solução linear ótima no sentido da minimização do erro quadrático médio e depende do atraso $\Delta$ do sinal transmitido [Farhang- 
Boroujeny, 1998; Havkin, 2002; Saved, 2008]. Na Figura 3.3 é mostrada a função custo MSE pressupondo a transmissão de uma sequência binária $s(n) \in\{-1,+1\}$ através do Canal 1 , com resposta ao impulso infinita (Infinite Impulse Response- IIR cuja saída está relacionada com a entrada de acordo com a equação de diferenças

$$
r(n)=s(n)-0,6 r(n-1)
$$

que corresponde à função de transferência

$$
H_{1}(z)=\frac{1}{1+0,6 z^{-1}}
$$

Como o Canal 1 é IIR o equalizador é um filtro FIR, é possível obter equalização perfeita na ausência de ruído, com apenas $M=2$ coeficientes e atraso nulo. Nesse caso, o mínimo MSE ocorre para

$$
\mathbf{w}_{\mathrm{O}}=\left[\begin{array}{ll}
1 & 0,6
\end{array}\right]^{\mathrm{T}} .
$$

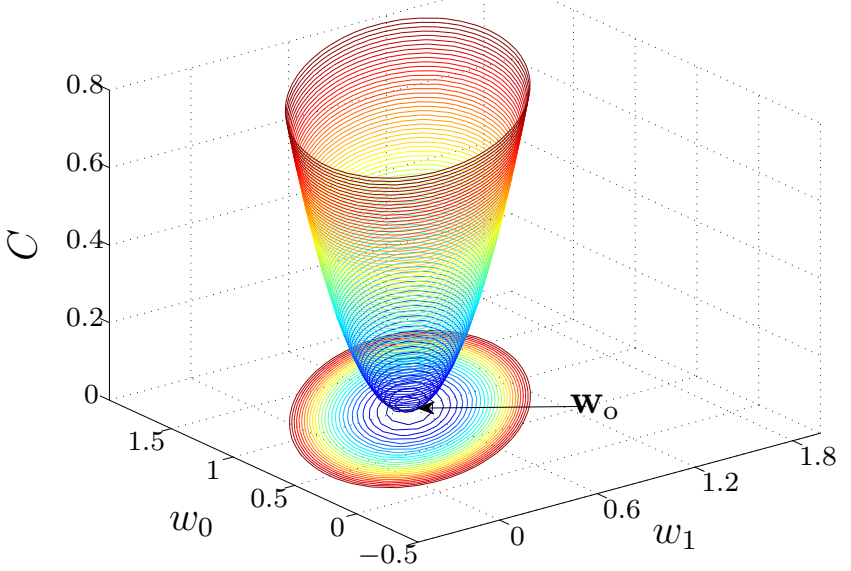

Figura 3.3: Função custo do erro quadrático médio, considerando a transmissão de uma sequência binária $s(n) \in\{-1,+1\}$ através do Canal 1 com função de transferência dado pela Eq. (3.10).

A solução de Wiener pode ser atingida pelo algoritmo do gradiente determinista (steepest descent), que evita o cálculo da inversa da matriz $\mathbf{R}$ atualizando-se $\mathbf{w}(n-1)$ na direção oposta à do gradiente de $C(n)$, isto é,

$$
\mathbf{w}(n)=\mathbf{w}(n-1)+\mu\left[\mathbf{p}_{\Delta}-\mathbf{R} \mathbf{w}(n-1)\right],
$$

sendo $\mu$ um passo de adaptação e $\mathbf{w}(-1)$ uma estimativa inicial para o ponto de mínimo 
de $C(n)$, usualmente assumido como sendo o vetor nulo $(\mathbf{w}(-1)=\mathbf{0})$. Por meio da escolha adequada de $\mu$, (veja [Farhang-Boroujeny, 1998; Havkin, 2002] para os detalhes sobre a estabilidade), esse algoritmo atinge exatamente a solução de Wiener. Entretanto, o gradiente exato requer o conhecimento prévio de $\mathbf{R}$ e $\mathbf{p}_{\Delta}$, o que geralmente não é praticável para aplicações de equalização. É importante notar que, em situações práticas, o canal é variante no tempo, $r(n)$ é não estacionário e, portanto, $\mathbf{R}$ e $\mathbf{p}_{\Delta}$ não podem ser estimados com exatidão em cada instante de tempo.

Para contornar esse problema, o algoritmo LMS, foi proposto. Em vez de considerar a função custo exata, o LMS usa uma aproximação instantânea dada por

$$
\widehat{C}(n)=e^{2}(n)
$$

e atualiza os coeficientes do equalizador usando a seguinte equação

$$
\mathbf{w}(n)=\mathbf{w}(n-1)-\mu \nabla_{\mathbf{w}} \widehat{C}(n)
$$

sendo $\mu$ um passo de adaptação e $\nabla_{\mathbf{w}} \widehat{C}(n)$ o vetor gradiente instantâneo da função custo $\widehat{C}(n)$ a ser minimizada, dado por

$$
\nabla_{\mathbf{w}} \widehat{C}(n)=-2 e(n) \mathbf{r}(n)
$$

Com essa aproximação, obtém-se a equação de atualização de coeficientes do LMS

$$
\mathbf{w}(n)=\mathbf{w}(n-1)+\mu e(n) \mathbf{r}(n),
$$

$\operatorname{com} \mathbf{w}(-1)=\mathbf{0}$.

O algoritmo LMS é um dos algoritmos mais utilizados em filtragem adaptativa devido ao baixo custo computacional, robustez e a grande variedade de resultados analíticos presentes na literatura. A partir de uma análise de segunda ordem, é possível mostrar que o LMS converge na média quadrática para a solução de Wiener, se [Farhang-Boroujeny, 1998]

$$
0<\mu<\frac{2}{3 \lambda_{\max }}<\frac{2}{3 M \sigma_{r}^{2}},
$$

em que $\lambda_{\max }$ é o máximo autovalor de $\mathbf{R}$ e $\sigma_{r}^{2}$ é a variância do sinal de entrada $r(n)$.

É bem conhecido na literatura sobre filtros adaptativos que um problema do algoritmo LMS é relativo à escolha do passo de adaptação $\mu$ a fim de obter uma boa velocidade de convergência, um valor de erro quadrático médio aceitável em regime e até mesmo garantir a estabilidade do algoritmo, já que o máximo valor do passo de adaptação depende de estatísticas do sinal 
de entrada [Havkin, 2002; Saved, 2008]. Algoritmos que utilizam passo de adaptação variável fazem essa escolha de maneira mais apropriada e podem apresentar desempenho superior em relação às versões não normalizadas, principalmente quando as estatísticas do sinal de entrada mudam rapidamente. Esse é o caso do algoritmo NLMS [Havkin, 2002; Saved, 2008], proposto como uma versão do LMS com o seguinte passo de adaptação:

$$
\mu(n)=\frac{\widetilde{\mu}}{\delta+\|\mathbf{r}(n)\|^{2}},
$$

com $0<\widetilde{\mu}<2$, sendo $\delta$ uma constante positiva pequena usada para evitar a divisão por zero e $\|\cdot\|$ representando a norma euclideana. Assim, a equação de atualização dos coeficientes com o NLMS é dada por

$$
\mathbf{w}(n)=\mathbf{w}(n-1)+\frac{\widetilde{\mu}}{\delta+\|\mathbf{r}(n)\|^{2}} e(n) \mathbf{r}(n) .
$$

O passo de adaptação variante no tempo $\mu(n)$ depende inversamente da potência instantânea do vetor regressor de entrada $\mathbf{r}(n)$, o que faz com que o NLMS se adapte às variações nas estatísticas do sinal.

É importante notar que o algoritmo NLMS pode ser calculado de diversas maneiras. A maneira mais usual é por meio do cálculo do passo de adaptação $\mu(n)$ que faz com que o erro de estimação a posteriori

$$
e_{p}(n)=s(n-\Delta)-\mathbf{r}^{\mathrm{T}}(n) \mathbf{w}(n)
$$

seja igual a zero a cada iteração do algoritmo Farhang-Boroujenv, 1998; Nascimento e Silva, 2014]. Assim, usando (3.16) com $\mu(n)$ em vez de $\mu$ em (3.20), obtém-se

$$
\begin{aligned}
e_{p}(n) & =s(n-\Delta)-\mathbf{r}^{\mathrm{T}}(n)[\mathbf{w}(n-1)+\mu(n) e(n) \mathbf{r}(n)] \\
& =e(n)\left[1-\mu(n) \mathbf{r}^{\mathrm{T}}(n) \mathbf{r}(n)\right] .
\end{aligned}
$$

Para impor $e_{p}(n)=0$ a cada iteração $n$, deve-se escolher

$$
\mu(n)=\frac{1}{\|\mathbf{r}(n)\|^{2}}
$$

Por fim, para evitar a divisão por zero em (3.22) e controlar a velocidade de convergência, é comum incluir um fator de regularização $\delta$ e um passo de adaptação $\widetilde{\mu}$, o que leva a (3.18) e a equação de atualização (3.19).

Outra abordagem bastante utilizada é a interpretação do NLMS como um algoritmo do tipo quasi-Newton, o que explica a sua rápida convergência quando comparado ao LMS [Saved, 2008]. 


\subsection{Estabilidade do NLMS}

Usando (3.19) e (3.7), a equação de adaptação do NLMS pode ser reescrita como

$$
\begin{aligned}
\mathbf{w}(n)= & {\left[\mathbf{I}-\frac{\widetilde{\mu}}{\delta+\|\mathbf{r}(n)\|^{2}} \mathbf{r}(n) \mathbf{r}^{\mathrm{T}}(n)\right] \mathbf{w}(n-1) } \\
& +\widetilde{\mu} s(n-\Delta) \frac{\mathbf{r}(n)}{\delta+\|\mathbf{r}(n)\|^{2}}
\end{aligned}
$$

sendo I a matriz identidade de dimensão $M \times M$. A matriz entre colchetes tem $M-1$ autovalores unitários e um autovalor igual a Saved [2008]

$$
\lambda_{1}=1-\widetilde{\mu} \frac{\|\mathbf{r}(n)\|^{2}}{\delta+\|\mathbf{r}(n)\|^{2}} .
$$

Notando que

$$
0 \leq \frac{\|\mathbf{r}(n)\|^{2}}{\delta+\|\mathbf{r}(n)\|^{2}}<1
$$

e para $\|\mathbf{r}(n)\|^{2} \gg \delta,\|\mathbf{r}(n)\|^{2} /\left(\delta+\|\mathbf{r}(n)\|^{2}\right) \approx 1$, a fim de se garantir que $\left|\lambda_{1}\right|<1$, deve-se escolher $\widetilde{\mu}$ no intervalo

$$
0<\widetilde{\mu}<2
$$

A norma da segunda parcela do lado direito de (3.23) é limitada, isto é,

$$
0 \leq \widetilde{\mu}|s(n-\Delta)| \frac{\|\mathbf{r}(n)\|}{\delta+\|\mathbf{r}(n)\|^{2}} \leq \widetilde{\mu} \frac{\sqrt{\delta}}{2 \delta}<\infty
$$

Portanto, usando resultados de estabilidade exponencial (determinísticos) do algoritmo LMS [Sethares, 1992], conclui-se que o NLMS é estável se $\widetilde{\mu}$ for escolhido no intervalo (3.26), ou seja, para esses valores de $\widetilde{\mu}$, o algoritmo não diverge [Haykin, 2002].

\subsection{Resultados de simulação}

A fim de mostrar o comportamento do algoritmo NLMS, foi considerada a transmissão de uma sequência binária $s(n) \in\{-1,+1\}$ através dos canais listados na Tabela 3.1, juntamente com as respectivas funções de transferência. Esses resultados servem de base de comparação para a equalização de sistemas que usam caos discutidos nos próximos capítulos.

Inicialmente, foi considerada a transmissão através do Canal 1 (IIR) na ausência de ruído. Na simulação, foi considerado atraso nulo $(\Delta=0)$ e foram utilizados equalizadores com $M=2$ coeficientes. É importante ressaltar que, para obter um bom comportamento do algoritmo 
Tabela 3.1: Canais de comunicação utilizados nas simulações.

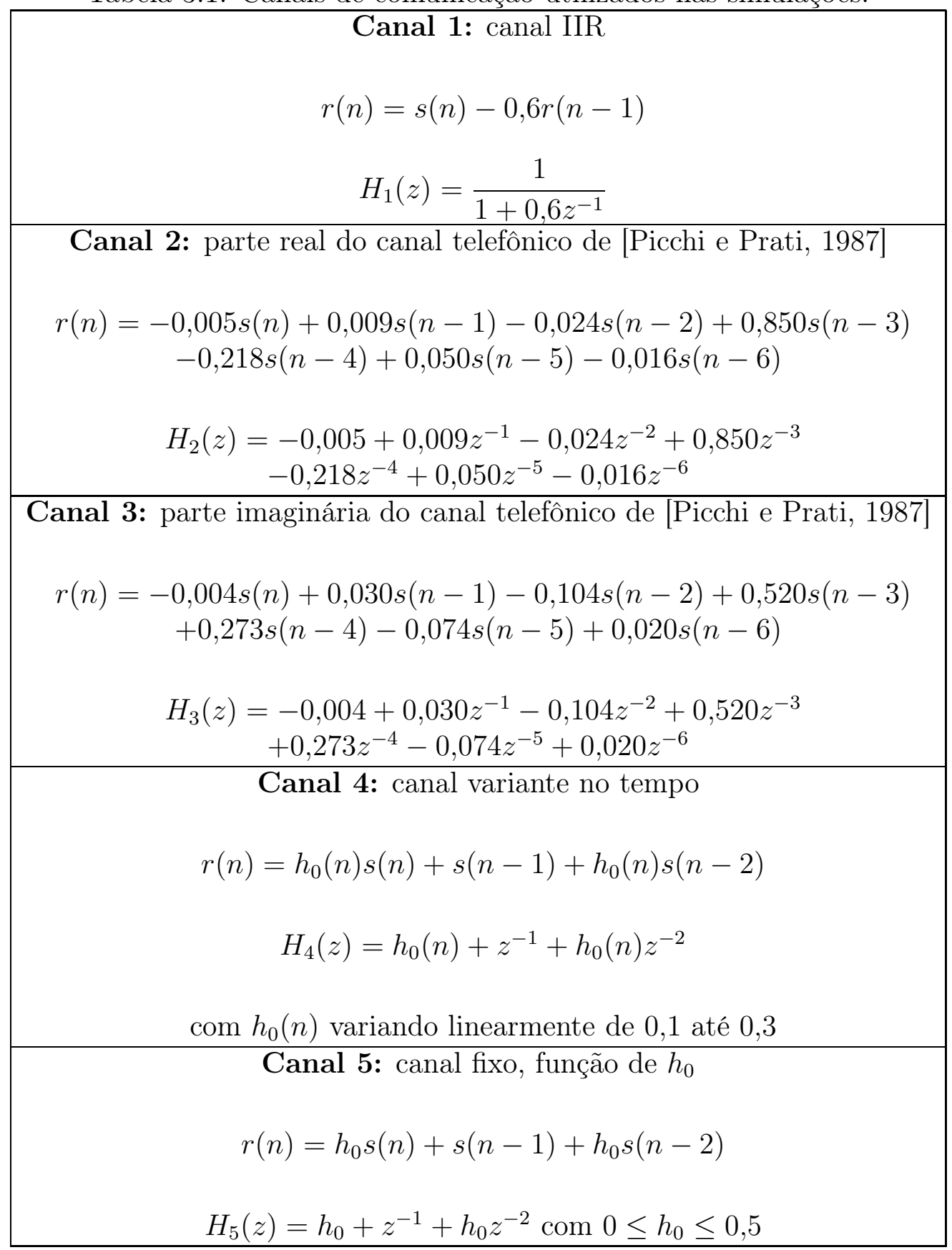

NLMS nesse caso, foi utilizado um fator de regularização $\delta$ com valor alto. Isso é necessário pois o termo $\|\mathbf{r}(n)\|^{2}$ tem uma probabilidade grande de se tornar próximo de zero quando são utilizados poucos coeficientes, o que pode causar instabilidade.

Como medida de desempenho, foi utilizado o erro médio quadrático em excesso (Excess 
Mean-Square Error - EMSE) definido como

$$
\mathrm{EMSE} \triangleq \mathrm{E}\left\{e_{a}^{2}(n)\right\}
$$

sendo

$$
e_{a}(n)=\mathbf{r}^{\mathrm{T}}(n)\left[\mathbf{w}_{\mathrm{o}}-\mathbf{w}(n-1)\right]
$$

o erro a priori e wo a solução de Wiener dada por (3.8) [Havkin, 2002; Saved, 2008]. Como a maioria dos filtros adaptativos convergem na média para a solução de Wiener, ela é considerada como uma referência para a medida de desempenho dos algoritmos. O EMSE mede quanto a função custo $C(n)$ excede o seu mínimo devido à adaptação. Se o algoritmo convergir para a solução de Wiener, o EMSE deverá ser nulo. Entretanto, na prática, os coeficientes dos filtros adaptativos nunca são exatamente iguais aos valores ótimos e o EMSE mede o efeito dessa diferença [Haykin, 2002; Sayed, 2008]. Como usual na área, apresenta-se o EMSE em decibéis, sendo $\operatorname{EMSE}(\mathrm{dB})=10 \log (\mathrm{EMSE})$.

A saída do equalizador NLMS e o erro após o decisor (ambos para uma única realização) são mostrados nas Figuras 3.4 (b) e (c). A média dos coeficientes e o EMSE ao longo das iterações, estimados a partir de uma média de conjunto de 1000 realizações, são mostrados respectivamente nas Figuras 3.4 (d) e (e). Como esperado, o algoritmo NLMS obtém uma boa estimativa da sequência transmitida, convergindo na média para a solução de Wiener $\mathbf{w}_{\mathrm{o}}=\left[\begin{array}{ll}1 & 0,6\end{array}\right]^{\mathrm{T}}$, cujos coeficientes são mostrados na Figura $3.4 \mathrm{f}(\mathrm{d})$ por meio de linhas tracejadas. Para efeito de comparação, também é mostrado na Figura 3.4 (a) o sinal recebido $r(n)$. Pode-se notar que o equalizador tem um papel importante no sistema de comunicação já que se ele não for utilizado, a mensagem não é recuperada. Em contrapartida, usando o equalizador NLMS, o EMSE diminui a cada iteração, indicando que os coeficientes do equalizador estão cada vez mais próximos dos coeficientes da solução ótima de Wiener, possibilitando a recuperação da mensagem transmitida usando um decisor, conforme mostrado na Figura 3.4.(c).

Como o Canal 1 é IIR, um filtro FIR pode fazer com que seja obtida equalização perfeita na ausência de ruído. Para mostrar o comportamento do NLMS em um cenário mais prático, é considerado o caso de uma variação abrupta de canal, com $s(n)$ inicialmente transmitido através de um canal modelado como a parte real do canal telefônico de [Picchi e Prati, 1987] (Canal 2 da Tabela 3.1). Em seguida, em $n=5 \times 10^{3}$, o canal é alterado de forma abrupta para a parte imaginária do mesmo canal telefônico (Canal 3 da Tabela 3.1). Para ambos os canais, é utilizado um equalizador com $M=12$ coeficientes e um atraso de $\Delta=7$ amostras. Na Figura 3.5, são mostrados os resultados para esse cenário. Como pode ser observado, o algoritmo NLMS converge para a solução de Wiener [Saved, 2008], cujos coeficientes são mostrados pelas linhas tracejadas na Figura 3.5.(d). Após a variação abrupta do canal, a solução 

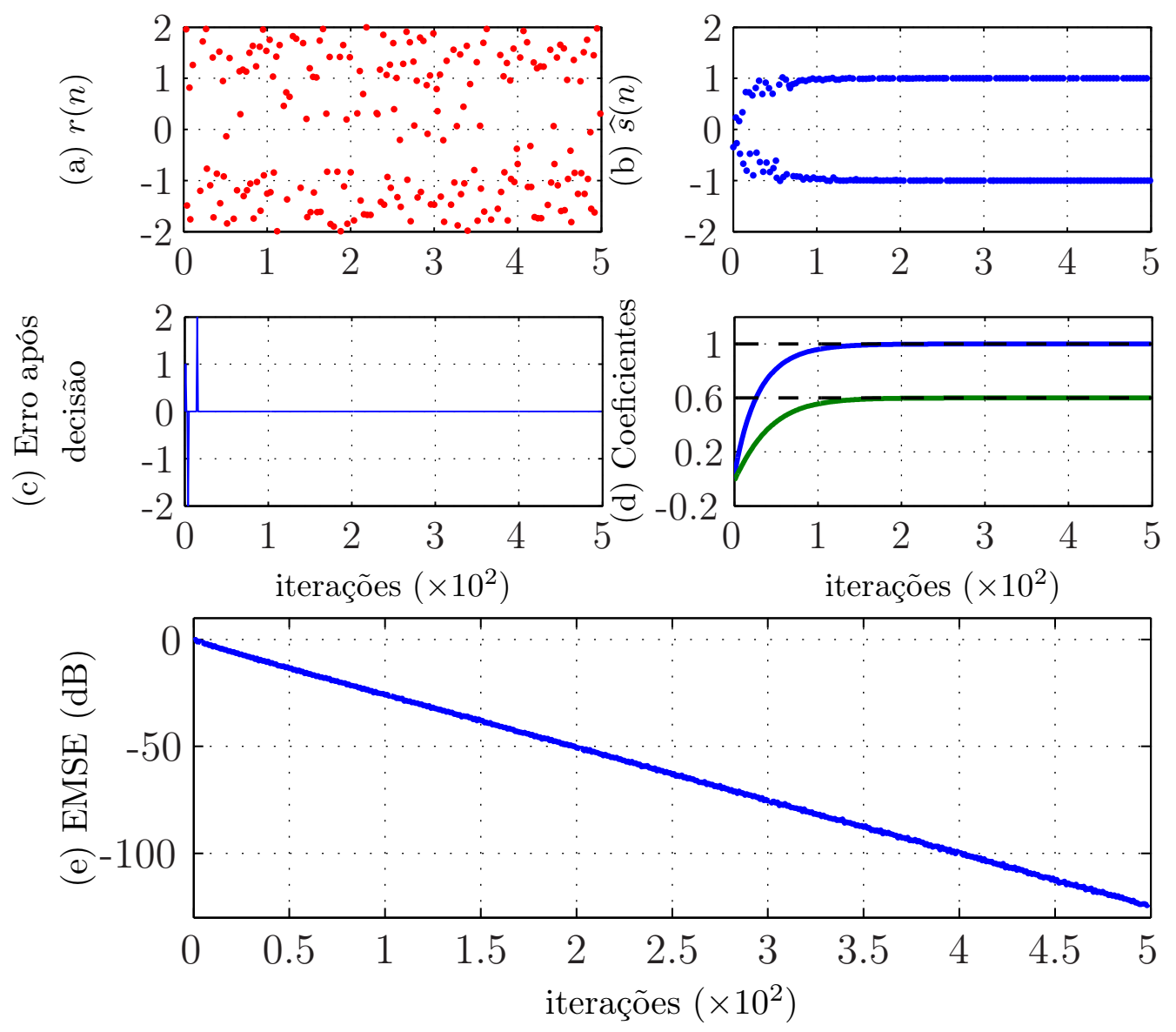

Figura 3.4: Sequência recuperada (a) sem equalizador e (b) com uma realização do NLMS $(\widetilde{\mu}=0,1 ; \delta=0,5 ; M=2 ; \Delta=0)$; (c) Erro após decisão; (d) Média dos coeficientes do NLMS e solução de Wiener (linhas tracejadas); (e) EMSE estimado; média de 1000 realizações; Canal 1.

ótima de Wiener é alterada e o algoritmo NLMS é capaz de acompanhar essa variação, atingindo o estado estacionário novamente. O equalizador tem um papel importante em mitigar a interferência intersimbólica, obtendo um EMSE em regime de aproximadamente -58 dB para o Canal 2 e um EMSE em regime de aproximadamente $-40 \mathrm{~dB}$ para o Canal 3.

Para verificar o comportamento do equalizador na presença de um canal variante no tempo, foi considerada a transmissão de $s(n)$ por meio do Canal 4 da Tabela 3.1, na ausência de ruído, com $h_{0}(n)$ variando linearmente de 0,1 até 0,3 em $n=0$ e $n=3 \times 10^{3}$, respectivamente. Os resultados para esse cenário são mostrados na Figura 3.6. Nesse caso, a solução ótima de Wiener é variante no tempo, conforme mostrado por meio das linhas tracejadas na Figura 3.6.(d). Como pode ser observado, o algoritmo NLMS é capaz de adaptar os coeficientes conforme o canal varia, obtendo uma boa estimativa da solução de Wiener instantânea.

Outra medida de desempenho utilizada em aplicações de equalização é a taxa de erro de 

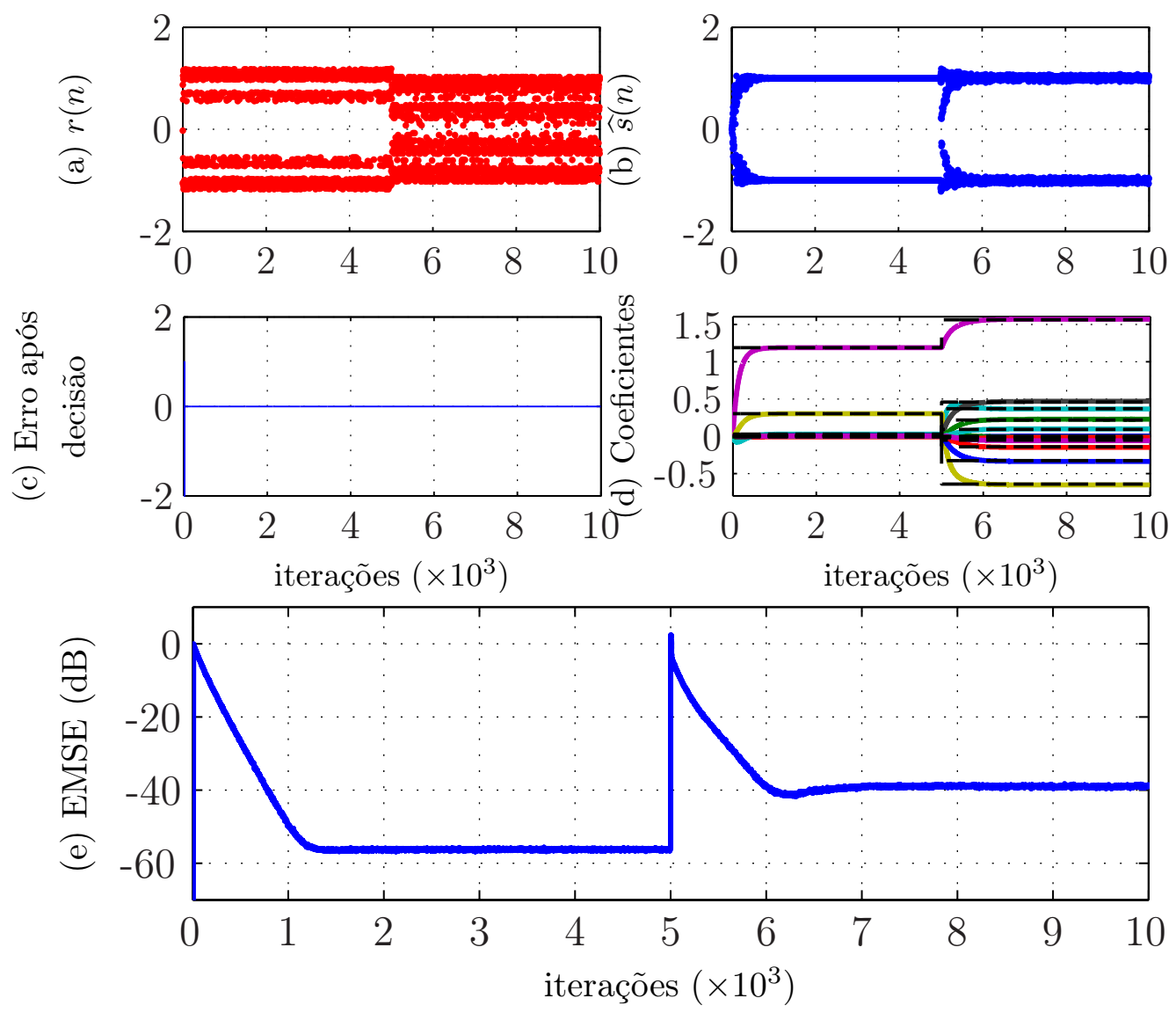

Figura 3.5: Sequência recuperada (a) sem equalizador e (b) com uma realização do NLMS $\left(\widetilde{\mu}=0,1 ; \delta=10^{-5} ; M=12 ; \Delta=7\right)$; (c) Erro após decisão; (d) Média dos coeficientes do NLMS e solução de Wiener (linhas tracejadas); (e) EMSE estimado; média de 1000 realizações; variação abrupta do Canal 2 para o Canal 3 em $n=5 \times 10^{3}$.

bit (Bit Error Rate - BER) Haykin, 2000]. Para medir o desempenho do sistema em um cenário com ruído, foi adicionado ruído branco gaussiano ao sinal na saída do Canal 5, com $h_{0}=0,25$ e foram obtidas curvas de BER em função da relação sinal-ruído (Signal to Noise Ratio - (SNR). A SNR é calculada como

$$
\mathrm{SNR}=10 \log _{10}\left(\frac{\sigma_{\breve{r}}^{2}}{\sigma_{\eta}^{2}}\right)
$$

sendo que $\sigma_{\breve{r}}^{2}$ representa a potência do sinal $\breve{r}(n)=r(n)-\eta(n)$ e é apresentada usualmente em decibéis, sendo $\mathrm{SNR}(\mathrm{dB})=10 \log (\mathrm{SNR})$. As curvas de BER foram estimadas depois da convergência do NLMS, contando o número de erros ao comparar $s(n-\Delta)$ com a sequência obtida na saída de um decisor aplicado à $\widehat{s}(n)$. Foram desprezados $1 \times 10^{5}$ bits devido à convergência inicial e utilizados $7 \times 10^{5}$ para o cálculo da BER. Os resultados obtidos são 

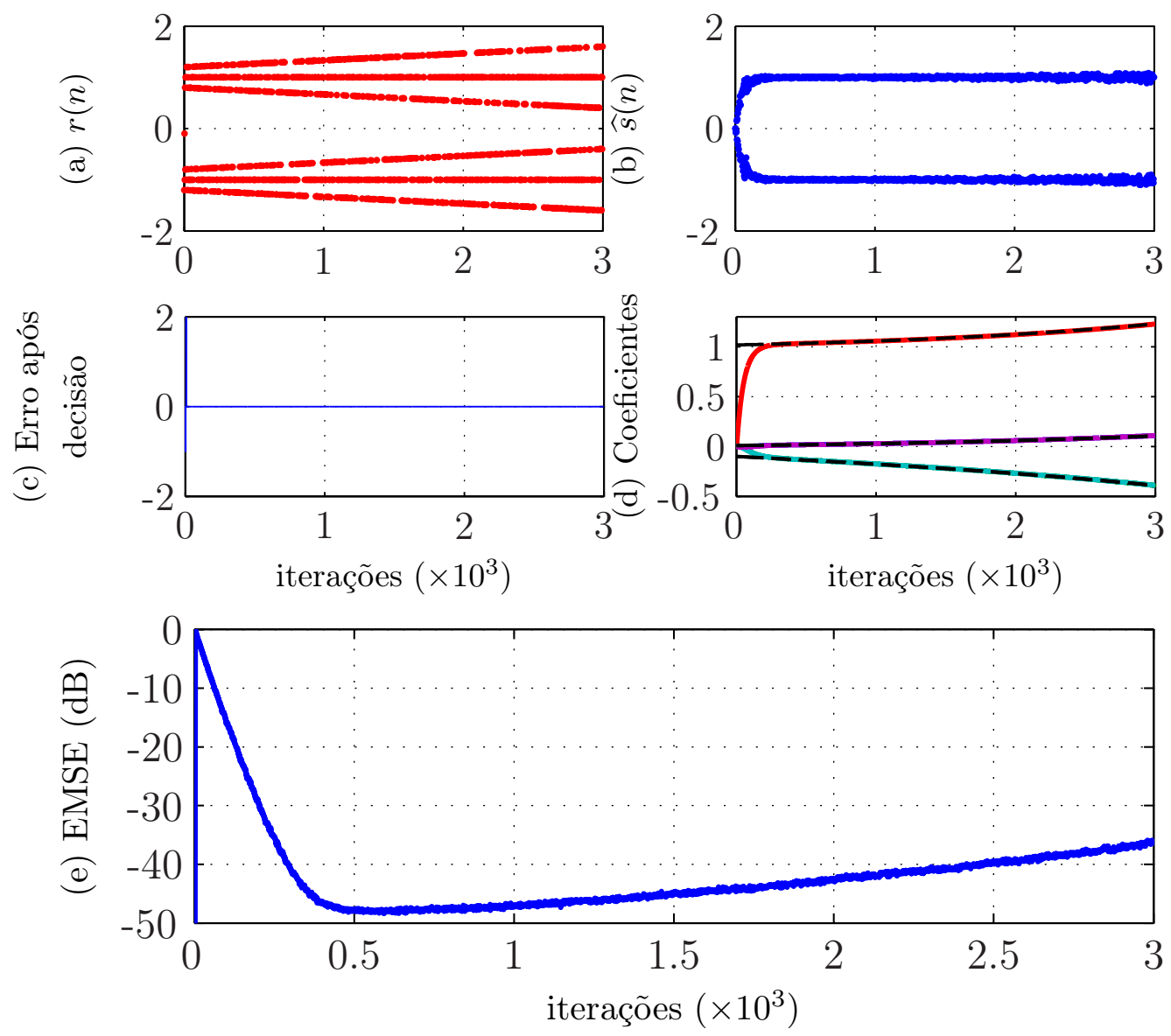

Figura 3.6: Sequência recuperada (a) sem equalizador e (b) com uma realização do NLMS $\left(\widetilde{\mu}=0,1 ; \delta=10^{-5} ; M=5 ; \Delta=3\right)$; (c) Erro após decisão; (d) Média dos coeficientes do NLMS e solução de Wiener (linhas tracejadas); (e) EMSE estimado; média de 1000 realizações; Canal 4, variante no tempo.

mostrados na Figura 3.7. Para fins de comparação, também foram incluídas curvas de BER para o canal AWGN ideal, obtidas com o sistema mostrado na Figura 3.1 sem o equalizador. Essas curvas de BER servem como referência para equalização em um cenário dispersivo e com ruído. Quanto mais próximo o valor da $\mathrm{BER}$ obtido em um canal não ideal e com ruído estiver do valor da BER em um canal AWGN, mais eficiente é o equalizador, em termos da eliminação da [SI] Também é mostrada na Figura 3.7, os resultados obtidos considerando o Canal 5 sem o equalizador. Pode-se observar que, para SNRs muito baixas, entre 0 e $7 \mathrm{~dB}$, os resultados obtidos com todas as soluções são semelhantes. Conforme o valor da SNR aumenta, a BER obtida com o algoritmo NLMS fica próxima ao valor obtido pela solução de Wiener, sendo ambos os valores superiores ao valor obtido no caso do canal AWGN. Para valores de SNR acima de $16 \mathrm{~dB}$, o algoritmo NLMS obteve equalização quasi-perfeita $\left(\mathrm{BER}<10^{-5}\right.$ ) enquanto, sem o equalizador, foi possível obter $\mathrm{BER}<10^{-5}$ para valores de $\mathrm{SNR}$ acima de $19 \mathrm{~dB}$. 


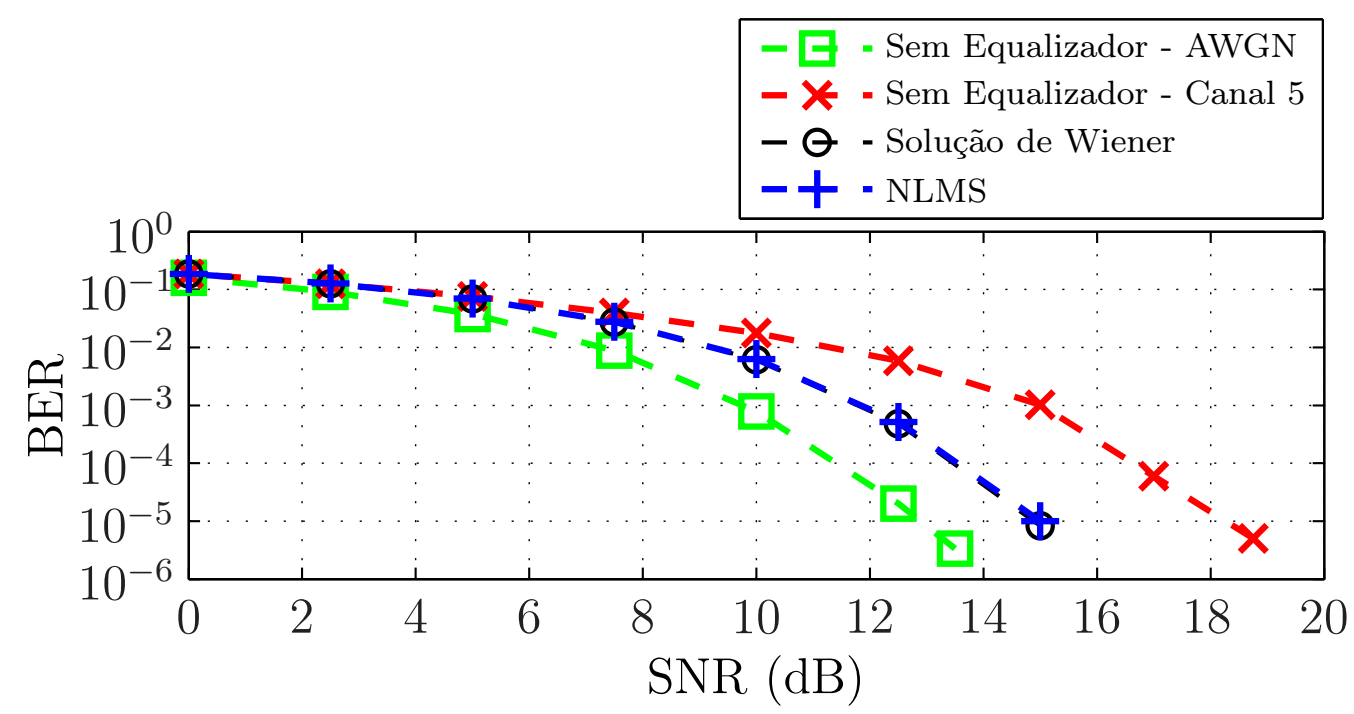

Figura 3.7: Taxa de erro de bit para o canal AWGN não dispersivo e para o Canal 5 com $h_{0}=0,25$, em função da relação sinal-ruído (SNR); Equalização com NLMS com $\widetilde{\mu}=0,01$; $\delta=10^{-5} ; M=21 ; \Delta=11$.

\subsection{Conclusões}

De forma geral, pode-se dizer que o tema equalização de sistemas de comunicação é uma área de pesquisa madura, com muitos resultados publicados no contexto de equalização supervisionada e também no contexto de equalização autodidata. O algoritmo LMS e sua versão normalizada estão dentre os algoritmos mais utilizados no caso supervisionado, possuindo muitos resultados publicados na literatura, relativos a análises de desempenho, estabilidade e velocidade de convergência [Sayed, 2008].

Neste capítulo, foram apresentados conceitos de equalização adaptativa. Foi apresentado o algoritmo NLMS e o intervalo para escolha do passo de adaptação para evitar a divergência. Por meio de simulações, foi mostrado que o algoritmo é capaz de equalizar o canal de comunicação em diferentes cenários.

Nos Capítulos 4 e 5, são propostos algoritmos para equalização no contexto de sistemas de comunicação que utilizam sinais caóticos, com base no algoritmo NLMS, Utilizando a modulação caótica baseada no sincronismo de Wu e Chua [1993], são consideradas duas funções de codificação da mensagem, sendo uma baseada na multiplicação da mensagem por um dos estados do GSC e a outra baseada na soma da mensagem em um dos estados do GSC, 


\section{Capítulo 4}

\section{Equalização aplicada a sincronismo caótico - codificação com multiplicação}

Neste capítulo, são propostos algoritmos adaptativos para a equalização de canais em sistemas de comunicação que utilizam sinais caóticos. Inicialmente, é apresentado o sistema de comunicação baseado em caos incluindo um equalizador adaptativo. Em seguida, é considerada a função de codificação dada pela multiplicação do estado $x_{i}(n)$ pela mensagem $m(n)$ e, usando essa função, um algoritmo baseado no NLMS é apresentado juntamente com suas condições de estabilidade. Nos geradores de sinais caóticos, são considerados os mapas de Hénon e de Ikeda, para os quais são apresentadas as condições para o sincronismo caótico e resultados de simulação em diferentes cenários. Por fim, são mostrados alguns detalhes sobre o sistema com o mapa de Ikeda quanto à presença de caos no sinal transmitido.

\subsection{Sistema de comunicação baseado em caos com equali- zador}

Na Figura 4.1é mostrado o sistema de comunicação baseado em caos descrito na Seção 1.2 com um equalizador adaptativo. No esquema, uma mensagem binária $m(n) \in\{-1,1\}$ é codificada usando um componente do vetor de estados $\mathbf{x}(n)$ do sistema mestre, por meio de uma função de codificação

$$
s(n)=c\left(x_{i}(n), m(n)\right),
$$

de forma que seja possível recuperá-la usando a função de codificação inversa em relação à $m(n)$, ou seja,

$$
m(n)=c^{-1}\left(x_{i}(n), s(n)\right) .
$$




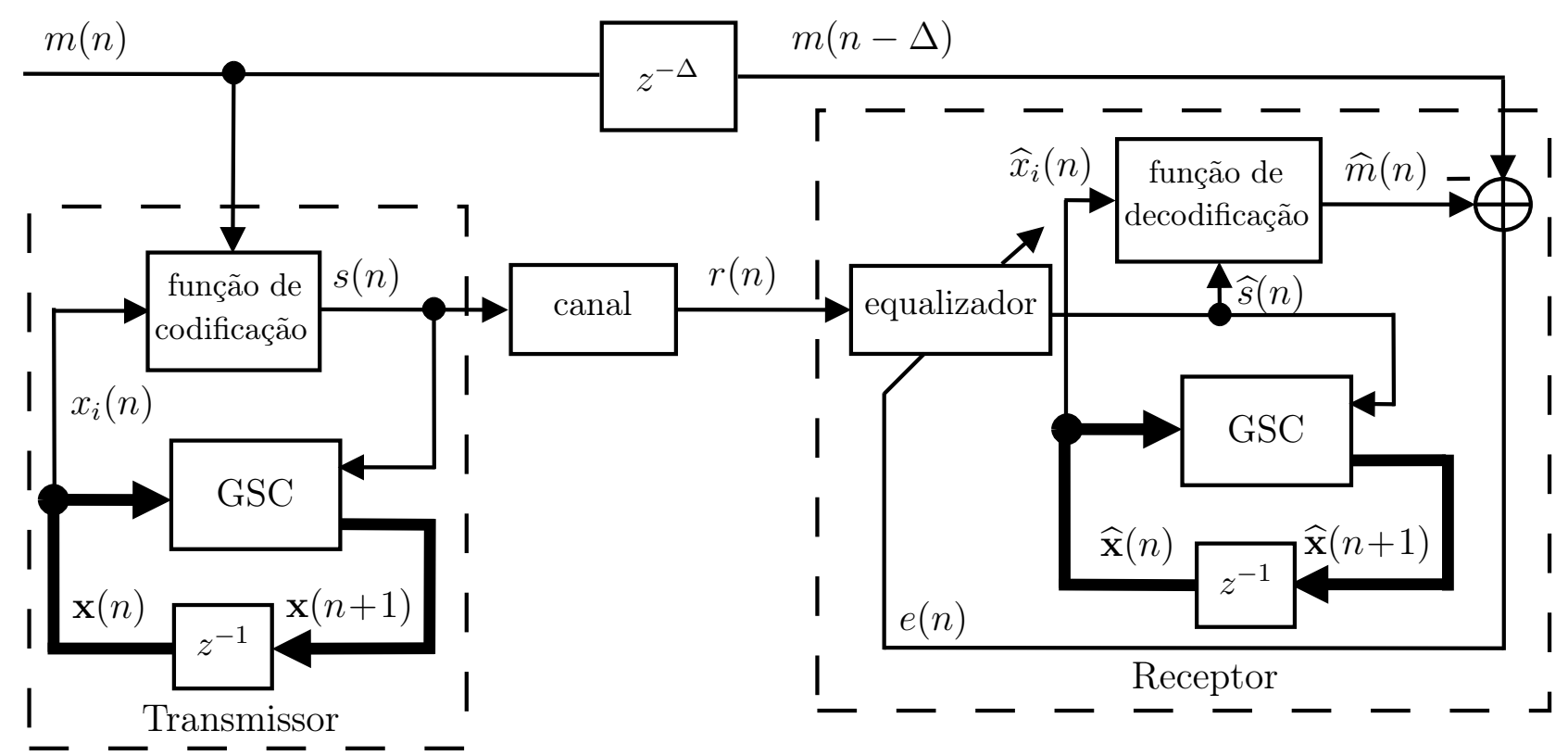

Figura 4.1: Sistema de comunicação baseado em caos com um equalizador no caso supervisionado.

Após a codificação da mensagem, o sinal $s(n)$ é realimentado no GSC e transmitido por um canal de comunicação modelado por um filtro com função de transferência $H(z)$ e ruído aditivo branco gaussiano $\eta(n)$. Para compensar os efeitos do canal e permitir o sincronismo caótico nesse caso, é utilizado um equalizador adaptativo com $M$ coeficientes, com vetor regressor de entrada, vetor de coeficientes e saída dados por (3.4), (3.5) e (3.6), que são repetidas aqui por conveniência, ou seja

$$
\begin{aligned}
\mathbf{r}(n) & =\left[\begin{array}{llll}
r(n) r(n-1) & \cdots & r(n-M+1)
\end{array}\right]^{\mathrm{T}}, \\
\mathbf{w}(n-1) & =\left[\begin{array}{llll}
w_{0}(n-1) & w_{1}(n-1) & \cdots & w_{M-1}(n-1)
\end{array}\right]^{\mathrm{T}}
\end{aligned}
$$

e

$$
\widehat{s}(n)=\mathbf{r}^{\mathrm{T}}(n) \mathbf{w}(n-1) .
$$

O equalizador deve mitigar a ISI introduzida pelo canal e recuperar a mensagem codificada $s(n)$ com um atraso de $\Delta$ amostras. Nesse caso, as equações que governam o sistema global são dadas por

$$
\begin{aligned}
& \mathbf{x}(n+1)=\mathbf{A x}(n)+\mathbf{b}+\mathbf{f}(s(n)) \\
& \widehat{\mathbf{x}}(n+1)=\mathbf{A} \widehat{\mathbf{x}}(n)+\mathbf{b}+\mathbf{f}(\widehat{s}(n))
\end{aligned}
$$


Se o transmissor e o receptor sincronizarem identicamente Boccaletti et al., 2002: Pecora et al., 1997], isto é, se $\widehat{\mathbf{x}}(n) \rightarrow \mathbf{x}(n)$, usando a saída do equalizador e a estimativa de $x_{i}(n)$, o sinal de informação pode ser decodificado por

$$
\widehat{m}(n) \triangleq c^{-1}\left(\widehat{x}_{i}(n), \widehat{s}(n)\right) \rightarrow m(n),
$$

sendo $\widehat{x}_{i}(n)$, o $i$-ésimo componente do vetor de estados $\widehat{\mathbf{x}}(n)$. Dessa forma, o erro de estimação

$$
e(n)=m(n-\Delta)-\widehat{m}(n)
$$

pode ser utilizado no critério de equalização. Vale notar que, apesar da utilização da mesma notação, o sinal $e(n)$ aqui definido é diferente daquele definido no Capítulo 3, por (3.7) já que, no sistema baseado em caos, é necessário considerar a decodificação da mensagem. A mesma observação vale para a função custo $\widehat{C}(n)$ utilizada neste capítulo, já que essa depende do sinal $e(n)$.

Assim que o equalizador for capaz de mitigar a ISI e o sincronismo entre os sistemas mestre e escravo for obtido, $m(n)$ pode ser utilizado para transmitir informação entre os sistemas, sendo $\widehat{m}(n)$ a mensagem decodificada. Nesse caso, o sistema deve ser utilizado no modo de decisão direta, como mostrado na Figura 4.2. Apesar do chaveamento entre os dois modos de operação ser necessário em aplicações práticas, nas simulações realizadas, considera-se apenas o modo de treinamento.

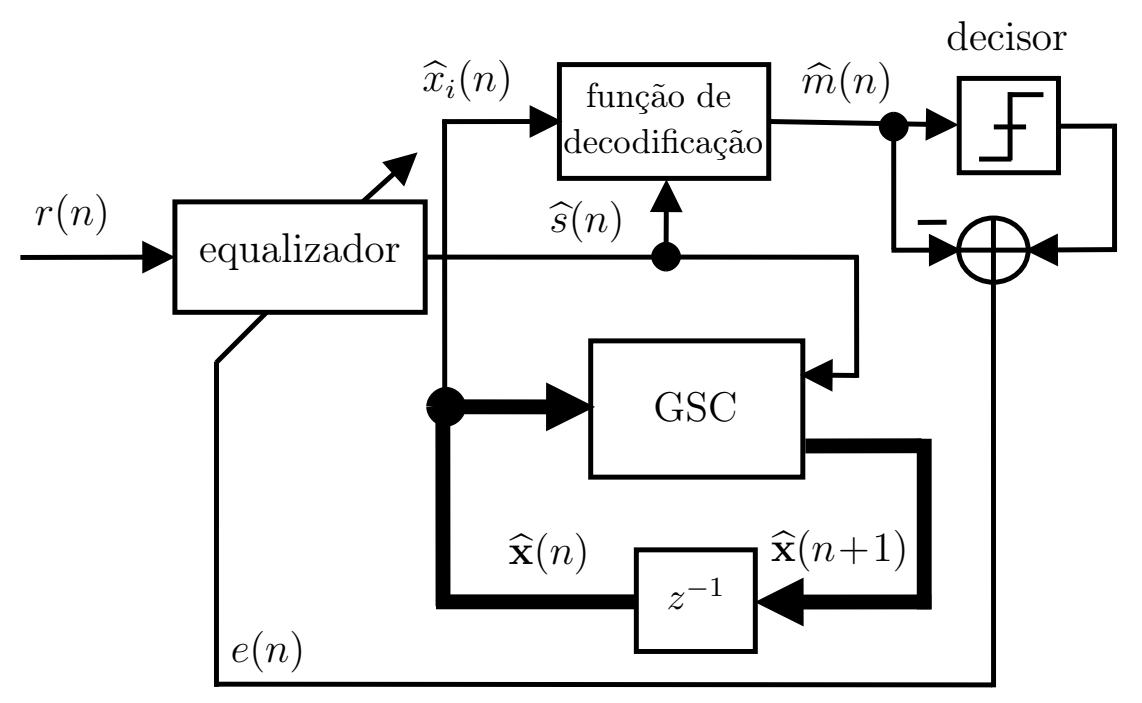

Figura 4.2: Receptor do sistema de comunicação baseado em caos com um equalizador adaptativo no modo de decisão direta.

Neste capítulo, é considerada a função de codificação $c\left(x_{i}(n), m(n)\right)$ obtida pelo produto 
entre a mensagem $m(n)$ e o $i$-ésimo componente do vetor de estados $x_{i}(n)$, ou seja

$$
s(n)=x_{i}(n) \cdot m(n)
$$

de forma que a mensagem $m(n)$ possa ser recuperada usando a função inversa em relação a $m(n)$, ou seja,

$$
\widehat{m}(n)=\frac{\widehat{s}(n)}{\widehat{x}_{i}(n)} \rightarrow m(n) .
$$

Essa função de codificação, além de ser simples, apresenta uma propriedade interessante quando utilizada com o sistema de Hénon, conforme será comentado na Seção 4.3 .

\subsection{O algoritmo NLMS caótico}

A fim de obter uma versão do algoritmo LMS para adaptar o equalizador do esquema mostrado na Figura 4.1, é definida a seguinte função custo instantânea:

$$
\widehat{C}(n)=e^{2}(n)=[m(n-\Delta)-\widehat{m}(n)]^{2} .
$$

Calculando o gradiente de $\widehat{C}(n)$ com relação ao vetor de coeficientes $\mathbf{w}(n-1)$, obtém-se

$$
\boldsymbol{\nabla}_{\mathbf{w}} \widehat{C}(n)=2 e(n) \frac{\partial e(n)}{\partial \mathbf{w}(n-1)}=-2 e(n) \frac{\partial \widehat{m}(n)}{\partial \mathbf{w}(n-1)} .
$$

Considerando-se que $\widehat{x}_{i}(n) \neq 0$ para todo $n$ e levando-se em conta o equalizador no esquema da Figura 4.1, (4.5) pode ser reescrita como

$$
\widehat{m}(n)=\frac{\widehat{s}(n)}{\widehat{x}_{i}(n)}=\frac{\mathbf{r}^{\mathrm{T}}(n) \mathbf{w}(n-1)}{\widehat{x}_{i}(n)} .
$$

Usando (4.11) e considerando que $\widehat{x}_{i}(n)$ não depende de $\mathbf{w}(n-1)$, chega-se a

$$
\nabla_{\mathbf{w}} \widehat{C}(n)=-2 \frac{e(n)}{\widehat{x}_{i}(n)} \frac{\partial \widehat{s}(n)}{\partial \mathbf{w}(n-1)}=-2 \frac{e(n)}{\widehat{x}_{i}(n)} \mathbf{r}(n) .
$$

De fato, existe uma dependência de $\widehat{x}_{i}(n)$ em relação à $\mathbf{w}(n-1)$. De (4.4), nota-se que $\widehat{x}_{i}(n)$ depende de $\widehat{\mathbf{x}}(n-1)$ e de $\widehat{s}(n-1)$. Como $\widehat{s}(n-1)=\mathbf{r}^{\mathrm{T}}(n-1) \mathbf{w}(n-2), \widehat{x}_{i}(n)$ claramente depende de $\mathbf{w}(n-2)$. Assim, a dependência de $\widehat{x}_{i}(n)$ em relação à $\mathbf{w}(n-1)$ pode ser expressa 
usando a regra da cadeia, ou seja,

$$
\frac{\partial \widehat{x}_{i}(n)}{\partial \mathbf{w}(n-1)}=\frac{\partial \mathbf{w}(n-2)}{\partial \mathbf{w}(n-1)} \frac{\partial \widehat{x}_{i}(n)}{\partial \mathbf{w}(n-2)}
$$

Entretanto, o cálculo da matriz $\frac{\partial \mathbf{w}(n-2)}{\partial \mathbf{w}(n-1)}$ requer outras aproximações e leva a um algoritmo mais complicado, para o qual não é possível chegar a um intervalo para a escolha do passo de adaptação. Sendo assim, decidiu-se desprezar a dependência de $\widehat{x}_{i}(n)$ em relação a $\mathbf{w}(n-1)$.

Assim, usando a equação de atualização dos coeficientes do LMS, dada por (3.14), na página 27] e usando (4.12), chega-se à equação de adaptação do algoritmo LMS caótico (cLMS) 1 , dada por

$$
\mathbf{w}(n)=\mathbf{w}(n-1)+\mu \frac{e(n)}{\widehat{x}_{i}(n)} \mathbf{r}(n) .
$$

A fim de se obter uma versão normalizada do cLMS $\times$, de forma semelhante a (3.20), é definido o erro a posteriori como

$$
e_{p}(n)=m(n-\Delta)-\frac{\mathbf{r}^{\mathrm{T}}(n) \mathbf{w}(n)}{\widehat{x}_{i}(n)} .
$$

Usando-se (4.14) com $\mu(n)$ em vez de $\mu, e_{p}(n)$ pode ser reescrito como

$$
\begin{aligned}
e_{p}(n) & =m(n-\Delta)-\frac{\mathbf{r}^{\mathrm{T}}(n)\left[\mathbf{w}(n-1)+\mu(n) \frac{e(n)}{\widehat{x}_{i}(n)} \mathbf{r}(n)\right]}{\widehat{x}_{i}(n)} \\
& =e(n)\left[1-\mu(n) \frac{\|\mathbf{r}(n)\|^{2}}{\widehat{x}_{i}^{2}(n)}\right] .
\end{aligned}
$$

Para se garantir que $e_{p}(n)=0$ a cada iteração $n$, deve-se fazer

$$
\mu(n)=\frac{\widehat{x}_{i}^{2}(n)}{\|\mathbf{r}(n)\|^{2}}
$$

Introduzindo-se um passo de adaptação fixo $\widetilde{\mu}$ para controlar a velocidade de convergência e um fator de regularização $\delta$ para evitar a divisão por zero no cálculo de $\mu(n)$ e substituindo-se o passo de adaptação resultante em (4.14), obtém-se a equação de atualização do cNLMS $\times$,

\footnotetext{
${ }^{1} \mathrm{O}$ termo caótico é usado para os algoritmos apenas para distingui-los das versões originais dos algoritmos LMS e NLMS (veja, por exemplo, [Haykin, 2002] e [Saved, 2008]). A utilização desse termo não implica que os algoritmos tenham um comportamento caótico. A notação $\times$ é utilizada para diferenciar o algoritmo proposto neste capítulo do algoritmo proposto no Capítulo 5, que utiliza a soma na função de codificação.
} 
isto é,

$$
\mathbf{w}(n)=\mathbf{w}(n-1)+\frac{\widetilde{\mu}}{\delta+\|\mathbf{r}(n)\|^{2}} \widehat{x}_{i}(n) e(n) \mathbf{r}(n) .
$$

Vale notar que o cNLMS $\times$ não depende apenas da estimativa do erro $e(n)$ mas também de $\widehat{x}_{i}(n)$. Como $\widehat{x}_{i}(n)$ depende de forma não linear de $\widehat{s}(n-1)$, o cNLMS $\times$ é uma versão não linear do NLMS, Além disso, o sincronismo entre os sistemas mestre e escravo depende da eliminação da interferência intersimbólica, que é o papel do equalizador no sistema.

A divisão por zero é evitada no cálculo de $\widehat{m}(n)$ fazendo

$$
\widehat{m}(n)=\operatorname{sign}\left[\widehat{s}(n) \widehat{x}_{i}(n)\right]
$$

quando $\left|\widehat{x}_{i}(n)\right|<\varepsilon$, sendo $\varepsilon$ uma constante positiva pequena e

$$
\operatorname{sign}[x]=\left\{\begin{array}{rl}
-1, & x<0 \\
1, & x \geq 0
\end{array} .\right.
$$

Para garantir a estabilidade do algoritmo e evitar estimativas erradas quando $\widehat{x}_{i}(n)$ for muito grande, é introduzido um limite superior para $\widehat{x}_{i}(n)$, isto é, se $\left|\widehat{x}_{i}(n)\right|>X$, impõe-se $\widehat{x}_{i}(n) \leftarrow X \operatorname{sign}\left[\widehat{x}_{i}(n)\right]$, sendo $X$ uma constante positiva. Fazendo $X=100$, não foi observada degradação no desempenho do algoritmo em diversos cenários de simulação.

\subsubsection{Condições de estabilidade}

Usando (4.6), a equação de adaptação do cNLMS, pode ser reescrita como

$$
\begin{aligned}
\mathbf{w}(n)= & {\left[\mathbf{I}-\frac{\widetilde{\mu}}{\delta+\|\mathbf{r}(n)\|^{2}} \mathbf{r}(n) \mathbf{r}^{\mathrm{T}}(n)\right] \mathbf{w}(n-1) } \\
& +\widetilde{\mu} \widehat{x}_{i}(n) m(n-\Delta) \frac{\mathbf{r}(n)}{\delta+\|\mathbf{r}(n)\|^{2}}
\end{aligned}
$$

A matriz entre colchetes é idêntica à obtida na Seção 3.3 (página 29), possuindo $M-1$ autovalores unitários e um autovalor igual a

$$
\lambda_{1}=1-\widetilde{\mu} \frac{\|\mathbf{r}(n)\|^{2}}{\delta+\|\mathbf{r}(n)\|^{2}} .
$$

Assim, escolhendo o passo de adaptação no intervalo

$$
0<\widetilde{\mu}<2,
$$


é possível garantir que $\left|\lambda_{1}\right|<1$.

Considerando que $\widehat{x}_{i}(n)$ é limitado em $X$, a norma da segunda parcela do lado direito de (4.21) fica limitada, isto é,

$$
0 \leq \widetilde{\mu}\left|\widehat{x}_{i}(n)\right||m(n-\Delta)| \frac{\|\mathbf{r}(n)\|}{\delta+\|\mathbf{r}(n)\|^{2}} \leq \widetilde{\mu} X \frac{\sqrt{\delta}}{2 \delta}<\infty .
$$

Portanto, de forma semelhante à mostrada na Seção 3.3, conclui-se que o algoritmo cNLMS, não diverge se $\widetilde{\mu}$ for escolhido no intervalo (4.23) [Havkin, 2002].

\subsection{Sistema com o mapa de Hénon}

Nesta seção, é considerada a utilização do mapa de Hénon Hénon, 1976] em ambos GSCs da Figura 4.1. Como a parcela não linear do mapa de Hénon é função do estado $x_{1}(n)$, esse deve ser o estado utilizado para a codificação da mensagem. Dessa forma, as equações que governam o sistema dinâmico global têm a seguinte forma

$$
\begin{aligned}
& \mathbf{x}(n+1)=\mathbf{A} \mathbf{x}(n)+\mathbf{b}+\mathbf{f}(s(n)), \\
& \widehat{\mathbf{x}}(n+1)=\mathbf{A} \widehat{\mathbf{x}}(n)+\mathbf{b}+\mathbf{f}(\widehat{s}(n)),
\end{aligned}
$$

sendo $\mathbf{x}(n) \triangleq\left[\begin{array}{ll}x_{1}(n) & x_{2}(n)\end{array}\right]^{\mathrm{T}}, \quad \widehat{\mathbf{x}}(n) \triangleq\left[\begin{array}{ll}\widehat{x}_{1}(n) & \widehat{x}_{2}(n)\end{array}\right]^{\mathrm{T}}$,

$$
\mathbf{A}=\left[\begin{array}{ll}
0 & 1 \\
\beta & 0
\end{array}\right], \quad \mathbf{b}=\left[\begin{array}{l}
1 \\
0
\end{array}\right], \quad \mathbf{f}(s(n))=\left[\begin{array}{c}
-\alpha s^{2}(n) \\
0
\end{array}\right]
$$

e $\alpha$ e $\beta$ constantes reais que representam parâmetros do mapa.

Em [Eisencraft et al., 2009], foi mostrado que, sob condições ideais de canal, isto é, quando $r(n) \equiv s(n)$ e sem o equalizador, o sincronismo entre os sistemas mestre e escravo é obtido se todos os autovalores de $\mathbf{A}$ estiverem dentro do círculo unitário no plano complexo. Portanto, como no caso considerado, os autovalores de $\mathbf{A}$ são $\pm \sqrt{\beta}$, conclui-se que, sob condições ideais, ocorre o sincronismo entre mestre e escravo para $|\beta|<1$. Assim, usando (4.5), $\widehat{m}(n) \rightarrow m(n)$.

O sinal $s(n)$ é obtido usando a função de codificação [Candido et al., 2013; Feki et al., 2003.

$$
s(n)=c\left(x_{1}(n), m(n)\right)=x_{1}(n) \cdot m(n),
$$

que leva à função de decodificação

$$
\widehat{m}(n)=\frac{\widehat{s}(n)}{\widehat{x}_{1}(n)} .
$$


Essa escolha particular associada ao mapa de Hénon tem uma propriedade interessante. Considerando uma mensagem binária e polar $(m(n)= \pm 1$ ), pode-se observar usando (4.27) que $s^{2}(n)=x_{1}^{2}(n)$. Assim, (4.24) não depende de $m(n)$ e a mensagem não interfere nos GSCs, Com isso, o sinal transmitido será de fato caótico, desde que o sinal gerado pelo GSC seja caótico.

Assim, com base nos resultados apresentados na Seção 4.2, é proposto o algoritmo mostrado na Tabela 4.1.

Tabela 4.1: Algoritmo cNLMS $\times$ considerando o mapa de Hénon.

\begin{tabular}{|c|}
\hline $\begin{array}{l}\text { Inicializar o algoritmo com: } \\
\mathbf{w}(-1)=\mathbf{0}, \quad \widehat{\mathbf{x}}(0)=[0,1-0,1]^{\mathrm{T}} \\
\mathbf{A}=\left[\begin{array}{ll}0 & 1 \\
\beta & 0\end{array}\right], \quad \mathbf{b}=\left[\begin{array}{l}1 \\
0\end{array}\right] \\
\alpha, \beta: \text { parâmetros do mapa de Hénon } \\
\delta, \varepsilon: \text { constantes positivas pequenas } \\
X: \text { constante positiva grande } \\
0<\widetilde{\mu}<2\end{array}$ \\
\hline 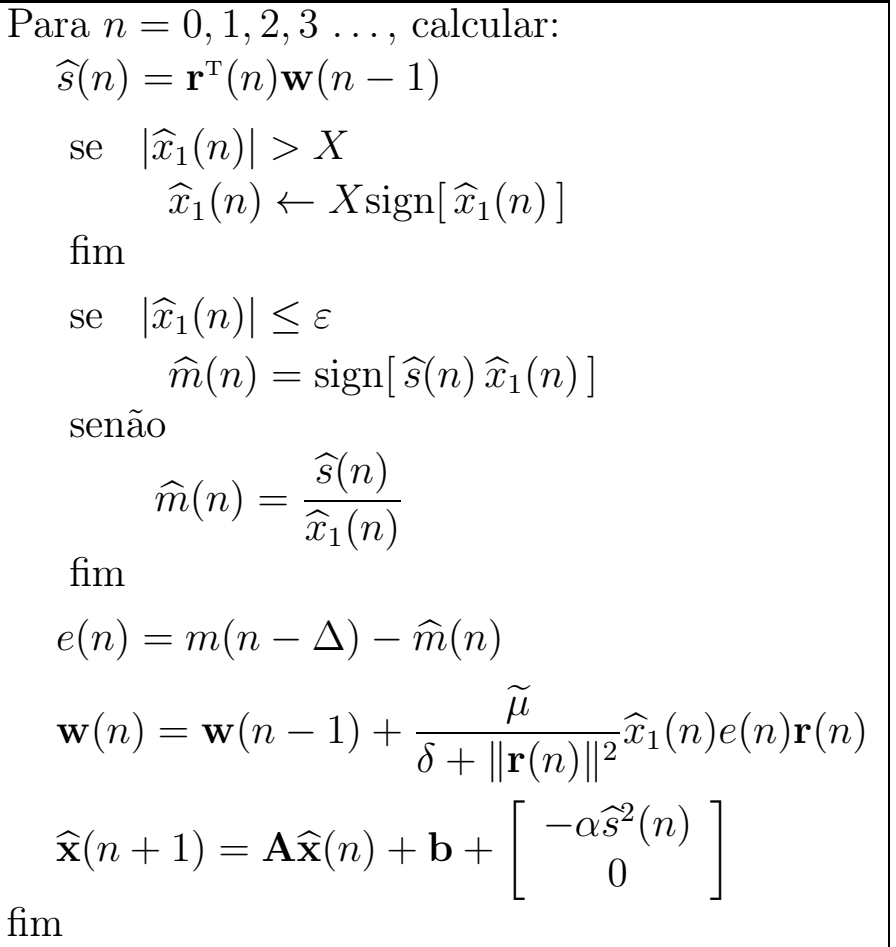 \\
\hline
\end{tabular}

\subsubsection{Resultados de simulação}

Para verificar o comportamento do algoritmo cNLMS, no sistema com o mapa de Hénon, foram feitas simulações considerando os parâmetros $\alpha=1,4$ e $\beta=0,3$ [Hénon, 1976]. Os 
vetores de estados (4.24) e (4.25) foram inicializados com $\mathbf{x}(0)=\mathbf{0}$ e $\widehat{\mathbf{x}}(0)=\left[\begin{array}{ll}0,1 & -0,1\end{array}\right]^{\mathrm{T}}$, respectivamente. Outras inicializações também permitem resultados igualmente bons em termos de sincronismo quando o equalizador é capaz de mitigar a interferência intersimbólica. Além disso, os equalizadores foram inicializados com $\mathbf{w}(0)=\mathbf{0}$ e, para efeito de comparação, também foi considerado o sistema mostrado na Figura 4.1 sem a inclusão do equalizador, com $\widehat{s}(n)=r(n)$. Os canais de comunicação utilizados estão listados na Tabela 3.1, na página 30.

Como medidas de desempenho, foram utilizados o EMSE, obtido por (3.28) e a BER, As curvas de BER foram estimadas depois da convergência do cNLMS, contando o número de erros ao comparar $m(n-\Delta)$ com a sequência obtida na saída de um decisor aplicado à $\widehat{m}(n)$. Foram desprezados $6 \times 10^{5}$ bits devido à convergência inicial e utilizados $7 \times 10^{5}$ para o cálculo da BER, Nesse caso, a BER obtida com a solução ótima de Wiener é considerada como referência para o esquema proposto.

Inicialmente foi considerado que $m(n) \equiv 1 \mathrm{e}$, consequentemente, $s(n)=x_{1}(n)$ e a transmissão através do Canal 1 na ausência de ruído. Como o Canal 1 é \R e o equalizador é um filtro FIR, é possível obter equalização perfeita. Apesar de não haver transmissão de informação entre os sistemas mestre e escravo nesse caso, o resultado da simulação mostra que o equalizador tem um papel importante quanto à possibilidade de sincronismo entre mestre e escravo, como descrito a seguir.

O efeito do canal pode ser observado comparando os atratores reconstruídos, usando $s(n)$ e $r(n)$. Devido ao efeito do canal, as características do sinal $s(n)=x_{1}(n)$ são distorcidas, como pode ser observado ao se comparar os atratores das Figuras 4.3 -(a) e 4.3 -(b). Na Figura 4.3.(c), é possível notar que o equalizador é capaz de eliminar o efeito do canal, recuperando um atrator semelhante ao original.

A mensagem $\widehat{m}(n)$, estimada usando o equalizador cNLMS, é mostrada na Figura 4.4 (b). A média dos dois coeficientes e o EMSE ao longo das iterações, estimados a partir de uma média de 1000 realizações são mostrados respectivamente nas Figuras 4.4 (c) e (e). Pode-se notar que os coeficientes do cNLMS, convergem para a solução ótima de Wiener, indicada pelas linhas tracejadas na Figura 4.4f(c). Assim, pode-se concluir que o equalizador está funcionando conforme o esperado dado que essa solução elimina a interferência intersimbólica, permitindo a sincronização dos mapas de Hénon, o que pode ser confirmado pela Figura 4.4 (d), já que para $n>2000$, o gráfico de $x_{1}(n)$ vs. $\widehat{x}_{1}(n)$ se aproxima de uma reta (pontos azuis na figura). O sincronismo não ocorre caso o equalizador não esteja presente como pode ser visto na Figura 4.4-(a).

Nas simulações seguintes, é considerada a transmissão de uma sequência binária equiprovável $m(n) \in\{-1,1\}$. Levando em conta novamente o Canal 1 , com $\Delta=0$, na ausência de ruído, a mensagem estimada utilizando o equalizador cNLMS $\times$ e o erro após o decisor (ambos 

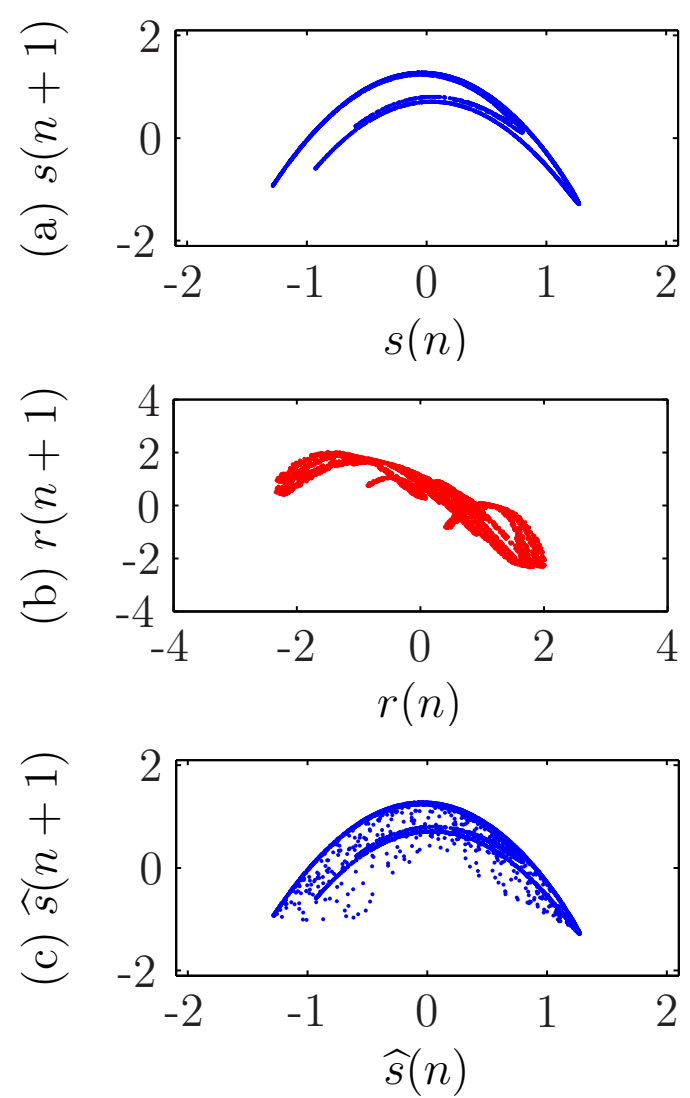

Figura 4.3: Atrator reconstruído usando: (a) sinal transmitido, (b) sinal recebido e (c) sinal recuperado com o $\mathrm{cNLMS}_{\times}$para $m(n) \equiv 1 ; M=2 ; \Delta=0$; Canal 1.

para uma única realização) são mostrados nas Figuras 4.5-(b) e (c). A média dos dois coeficientes e o EMSE ao longo das iterações, estimados por uma média de 1000 realizações, são mostrados respectivamente nas Figuras 4.5-(d) e (e). Novamente, o algoritmo cNLMS $\times$ converge para a solução ótima de Wiener e o equalizador é capaz de recuperar adequadamente a sequência transmitida, o que pode ser confirmado por meio dos erros após o decisor mostrados na Figura 4.5. (c). A comunicação não é possível na ausência do equalizador, como mostrado na Figura 4.5. (a).

O efeito do canal de comunicação também pode ser observado por meio do atrator reconstruído usando o sinal transmitido e o sinal recebido, conforme mostrado nas Figuras 4.6 (a) e 4.6-(b). Devido ao efeito do canal, as características do sinal transmitido são fortemente afetadas, como pode ser observado na Figura 4.6-(b). Na Figura 4.6-(c), pode-se notar que o equalizador é capaz de eliminar o efeito do canal, recuperando um atrator semelhante ao original.

A fim de verificar o comportamento do equalizador no caso de uma variação abrupta do 

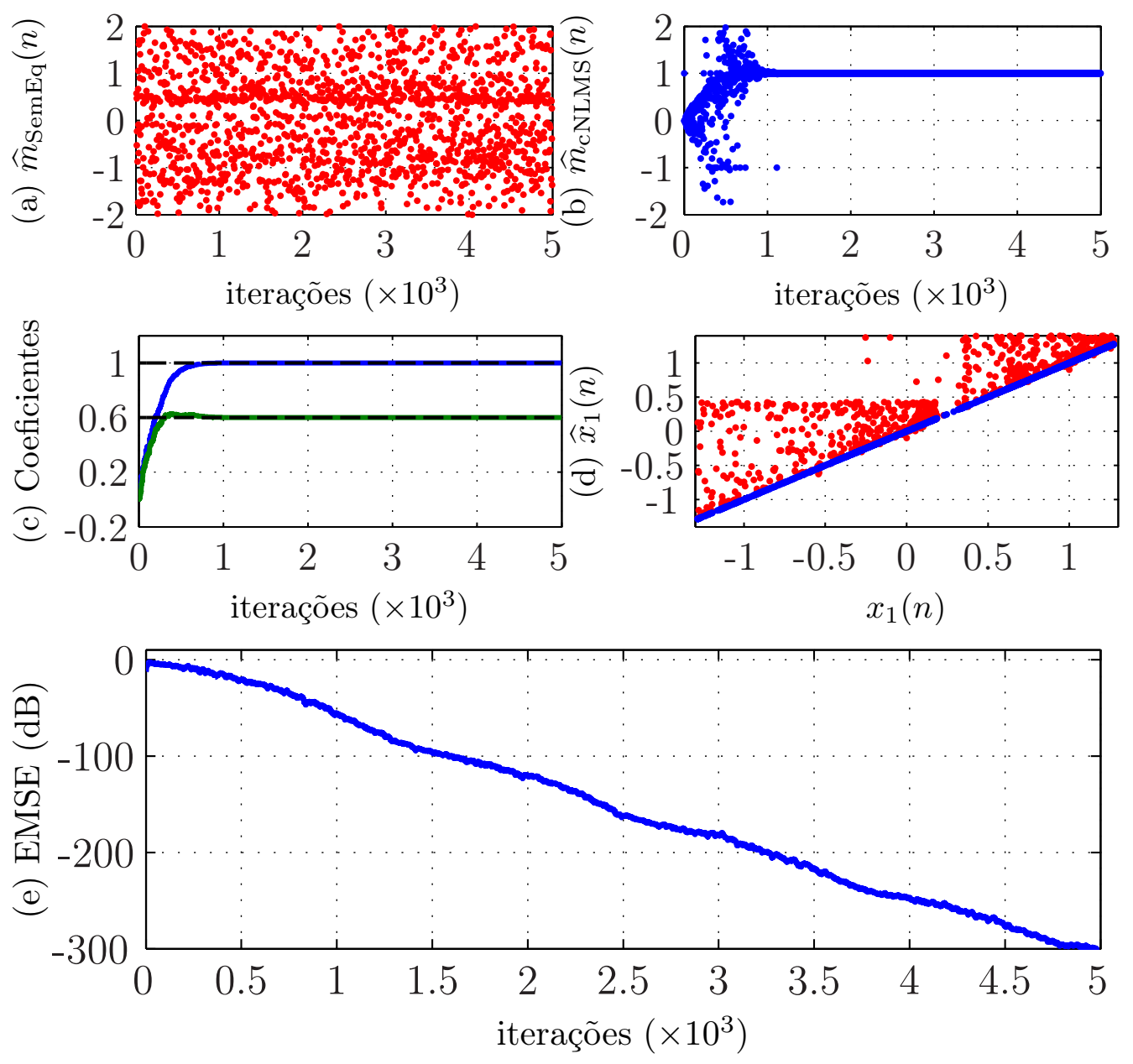

Figura 4.4: Sequência recuperada com o sistema utilizando o mapa de Hénon e codificação com multiplicação (a) sem equalizador e (b) com uma realização do $\operatorname{cNLMS}_{\times}\left(\widetilde{\mu}=0,01 ; \delta=10^{-5}\right.$; $\varepsilon=0,1 ; M=2 ; \Delta=0$ ); (c) Média dos coeficientes do cNLMS $_{\times}$e solução de Wiener (linhas tracejadas); (d) $x_{1}(n)$ vs. $\widehat{x}_{1}(n)$ : pontos vermelhos para $0<n \leq 2000$ e pontos azuis para $n>2000$ (e) EMSE estimado; média de 1000 realizações; Canal 1.

canal, $s(n)$ é inicialmente transmitido através do Canal 2 e, em $n=30 \times 10^{3}$, o canal é alterado de forma abrupta para o Canal 3. Para ambos os canais, é utilizado um equalizador com $M=12$ coeficientes e um atraso de $\Delta=7$ amostras.

Os resultados para esse cenário são mostrados na Figura 4.7. Como pode ser observado, o cNLMS $\times$ converge para a solução de Wiener [Saved, 2008], cujos coeficientes são mostrados pelas linhas tracejadas na Figura 4.7f(d). Vale notar que o cNLMS $\times$ é capaz de acompanhar a variação abrupta no canal, atingindo o estado estacionário novamente. Nessa configuração, o equalizador tem um papel importante em mitigar a interferência intersimbólica antes da variação abrupta do canal, já que o desempenho do sistema sem o equalizador é muito pre- 

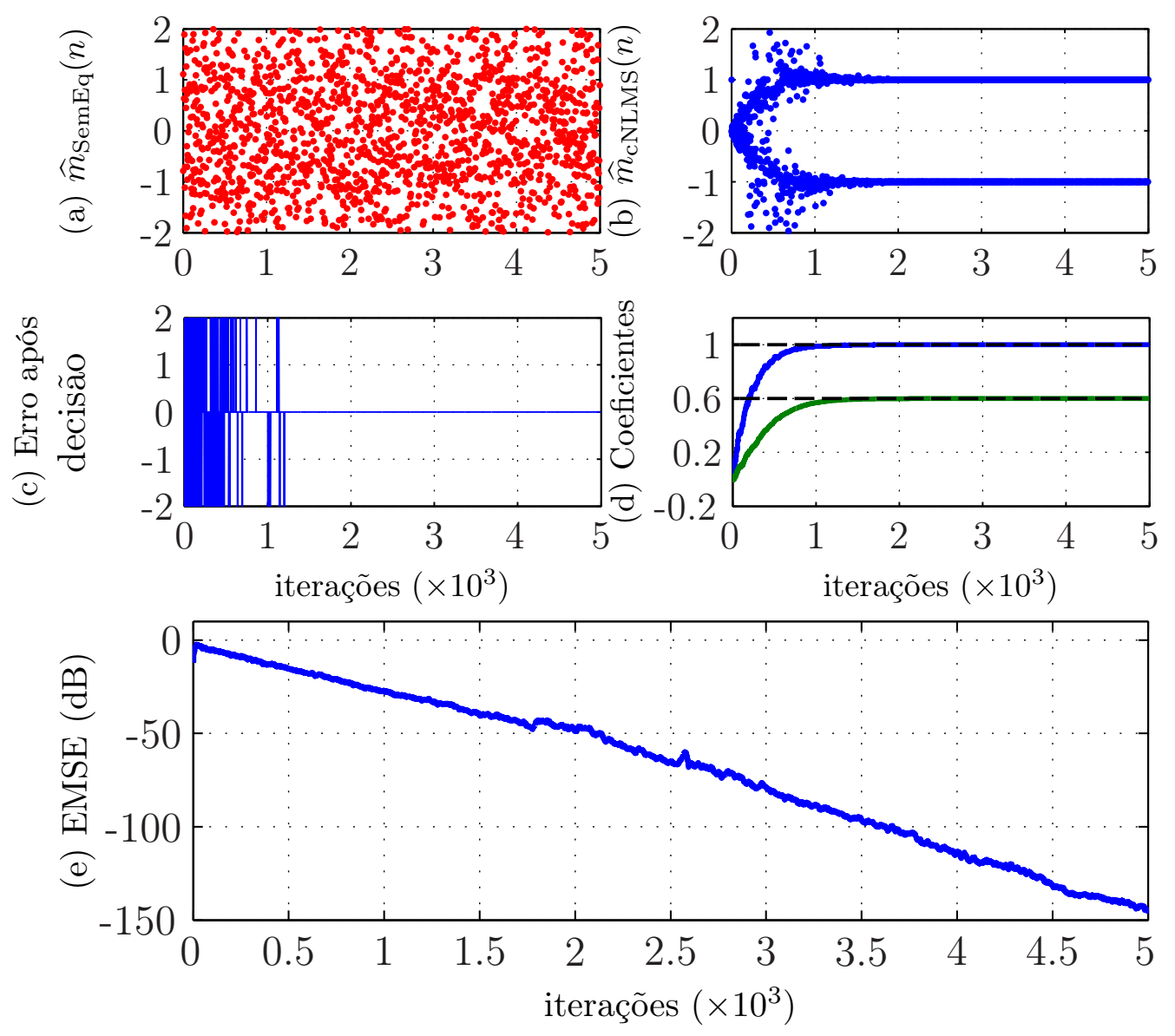

Figura 4.5: Sequência recuperada com o sistema utilizando o mapa de Hénon e codificação com multiplicação (a) sem equalizador e (b) com uma realização do $\operatorname{cNLMS}_{\times}\left(\widetilde{\mu}=0,01 ; \delta=10^{-5}\right.$; $\varepsilon=0,1 ; M=2 ; \Delta=0$ ); (c) Erro após decisão; (d) Média dos coeficientes do cNLMS $\times$ e solução de Wiener (linhas tracejadas); (e) EMSE estimado; média de 1000 realizações; Canal 1.

judicado como pode ser observado na Figura 4.7-(a). Entretanto, após a variação abrupta do canal, a solução encontrada com $M=12$ não é boa o suficiente e acarreta muitos erros após a decisão, como pode ser visto na Figura 4.7.(c). Para que seja possível recuperar a mensagem após a variação do canal, é necessário aumentar o número de coeficientes do equalizador. Na Figura 4.8, são mostrados os resultados obtidos considerando o mesmo cenário mas utilizando um equalizador com $M=25$ coeficientes e considerando um atraso de $\Delta=12$ amostras. Como pode ser notado, o aumento no número de coeficientes possibilita a recuperação adequada da mensagem após a variação abrupta do canal. Comparando esses resultados com o resultado obtido com a variação abrupta do canal para o caso do sistema de comunicação convencional, mostrado na Figura 3.5 na página [33, é possível notar que o EMSE não serve como parâmetro de comparação entre os sistemas baseados em caos e os sistemas convencionais. Para o caso 

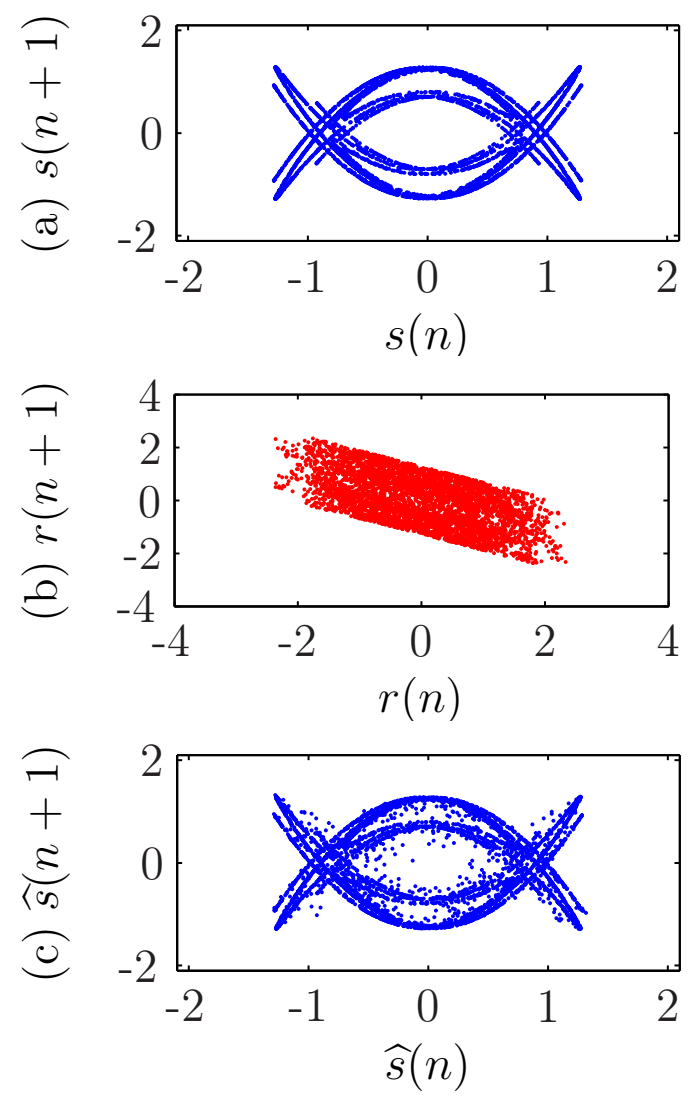

Figura 4.6: Atrator reconstruído usando: (a) sinal transmitido, (b) sinal recebido e (c) sinal recuperado com o $\mathrm{cNLMS}_{\times}$para a sequência $m(n)$ binária, aleatória equiprovável (parâmetros iguais aos da Figura 4.5).

do Canal 3, por exemplo, ambos os sistemas obtiveram EMSE de aproximadamente $-40 \mathrm{~dB}$ (Figuras 3.5-(e) e 4.7-(e)). No entanto, a mensagem recuperada no caso do sistema baseado em caos é claramente mais distorcida do que a mensagem recuperada no caso do sistema convencional (Figuras 3.5-(b) e 4.7-(b)). Isso ocorre pois o EMSE mede a diferença entre a saída do equalizador e a saída obtida utilizando o equalizador ótimo. No caso do sistema baseado em caos, é necessário decodificar a mensagem a partir da saída do equalizador. Assim, mesmo com um nível menor de EMSE, que corresponde a uma diferença menor entre os coeficientes do equalizador e os coeficientes ótimos, o efeito da codificação da mensagem pode fazer com que a mensagem recuperada apresente uma distorção maior.

Para verificar o comportamento do equalizador na presença de um canal variante no tempo, como feito no Capítulo 3, foi considerada a transmissão de $s(n)$ através do Canal 4, na ausência de ruído, com $h_{0}(n)$ variando linearmente de 0,1 até 0,3 entre $n=0$ e $n=3 \times 10^{3}$. Na Figura 4.9, são mostrados os resultados para esse cenário. É possível notar que o equalizador 

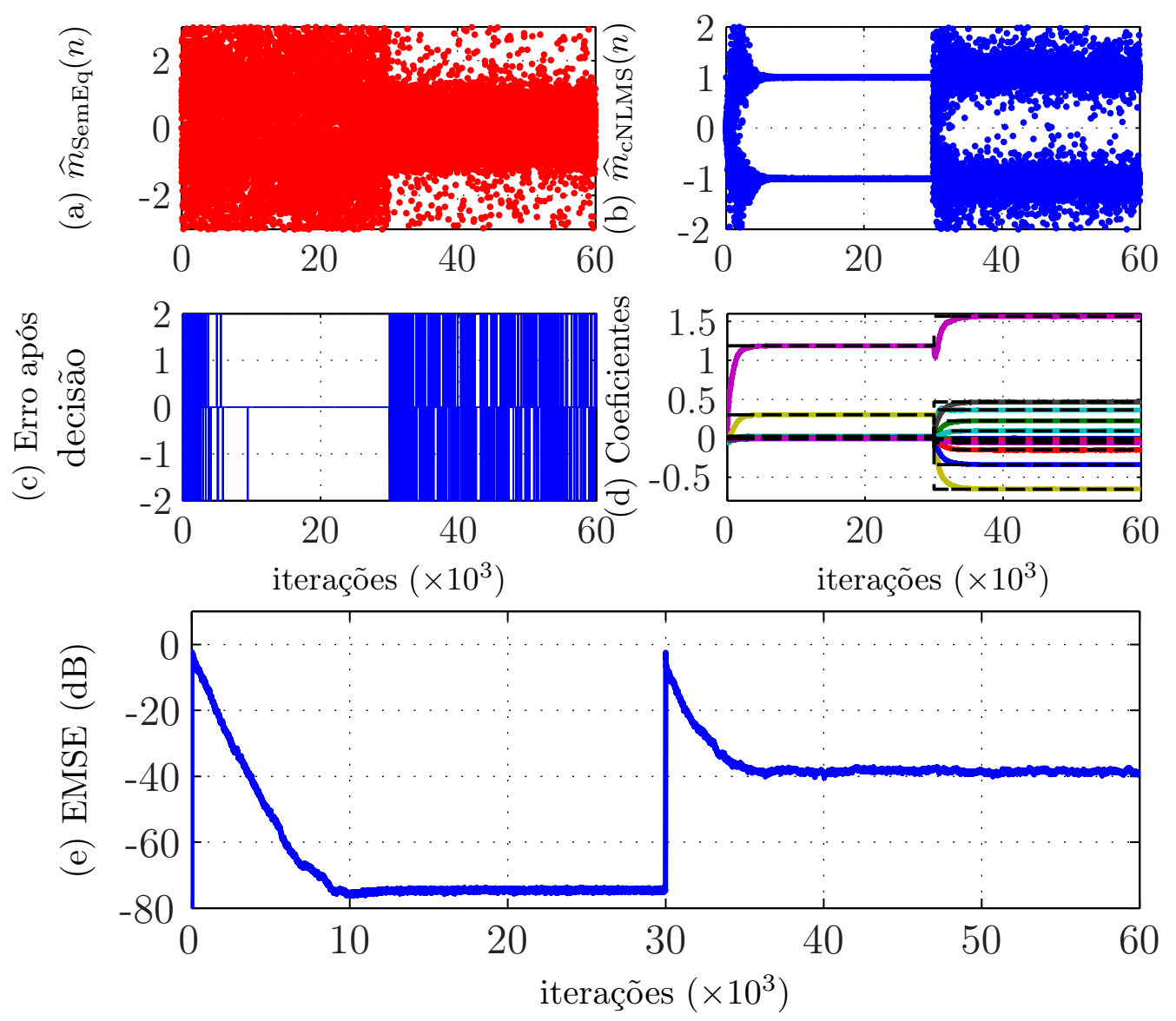

Figura 4.7: Sequência recuperada com o sistema utilizando o mapa de Hénon e codificação com multiplicação (a) sem equalizador e (b) com o $\operatorname{cNLMS}_{\times}\left(\widetilde{\mu}=0,1 ; \delta=10^{-5} ; \varepsilon=0,1\right.$; $M=12 ; \Delta=7$ ); (c) Erro após decisão; (d) Média dos coeficientes do cNLMS $_{\times}$e solução de Wiener (linhas tracejadas); (e) EMSE estimado; média de 1000 realizações; variação abrupta do Canal 2 para o Canal 3 em $n=30 \times 10^{3}$.

é capaz de adaptar os coeficientes conforme o canal varia, obtendo uma boa estimativa da solução de Wiener instantânea, mostrada pelas linhas tracejadas na Figura 4.9. (d).

Para mostrar a sensibilidade da modulação caótica à interferência intersimbólica, foram obtidas curvas de BER do sistema considerando o Canal 5, para diversos valores de $h_{0}$, na ausência de ruído. Foi utilizado um equalizador com $M=21$ coeficientes e foi considerado um atraso $\Delta=11$. As curvas são mostradas na Figura 4.10. É importante notar que no caso sem equalizador, o atraso é causado apenas pelo canal. Assim, foi feita a comparação da sequência recuperada com $m(n-\Delta)$, considerando $\Delta=1$, nesse caso. Quanto menor o valor de $h_{0}$, menor a interferência intersimbólica introduzida pelo canal. É possível notar que o cNLMS, é praticamente capaz de eliminar os efeitos do canal, obtendo equalização quasi-perfeita $\left(\mathrm{BER}<10^{-5}\right)$ para $0 \leq h_{0} \leq 0,2$, enquanto a solução de Wiener é capaz de 

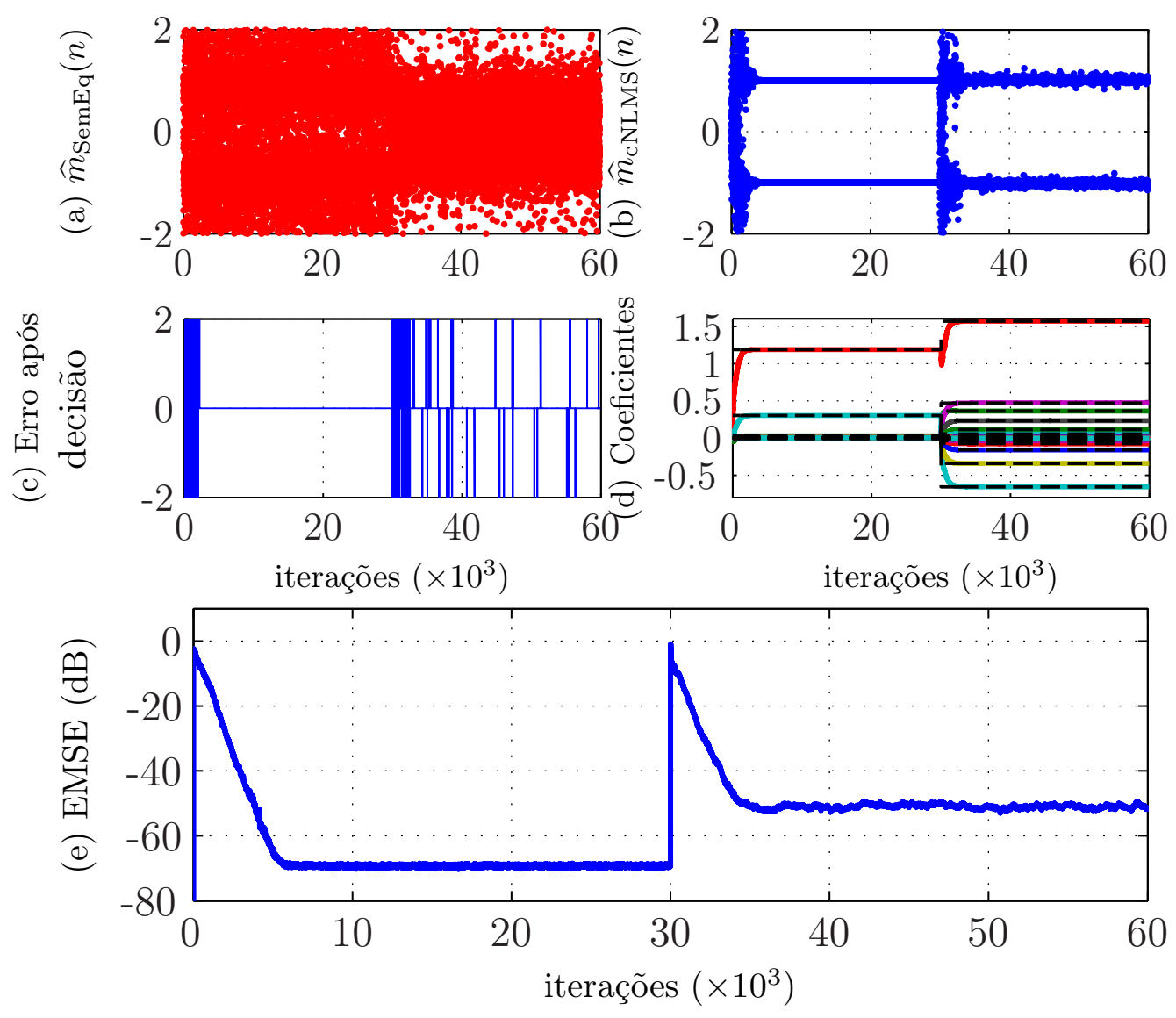

Figura 4.8: Sequência recuperada com o sistema utilizando o mapa de Hénon e codificação com multiplicação (a) sem equalizador e (b) com o $\operatorname{cNLMS}_{\times}\left(\widetilde{\mu}=0,25 ; \delta=10^{-5} ; \varepsilon=0,1\right.$; $M=25 ; \Delta=12$ ); (c) Erro após decisão; (d) Média dos coeficientes do cNLMS $\times$ e solução de Wiener (linhas tracejadas); (e) EMSE estimado; média de 1000 realizações; variação abrupta do Canal 2 para o Canal 3 em $n=30 \times 10^{3}$.

obter equalização quasi-perfeita para $0 \leq h_{0} \leq 0,25$. A diferença entre o cNLMS e a solução de Wiener é devida ao passo de adaptação $(\mu=0,05)$ considerado nas simulações. É bem conhecido que em todos os algoritmos adaptativos existe um compromisso entre o valor do passo de adaptação e o desempenho, de modo que quanto menor o passo de adaptação, menor o EMSE em regime (e a BER $)$ e, consequentemente, menor a diferença entre os coeficientes do filtro em regime e a solução ótima de Wiener [Haykin, 2002; Sayed, 2008]. Entretanto, quanto menor o passo de adaptação, menor a velocidade de convergência do algoritmo. Dessa forma, usar um passo de adaptação muito pequeno pode fazer com que o algoritmo não seja capaz de acompanhar as variações no canal. Ambas as soluções têm desempenho melhor do que o caso sem equalizador, para $0<h_{0}<0,5$. Para $h_{0}=0$, o canal é ideal e o equalizador não é necessário. Vale notar que uma pequena imperfeição no canal (por exemplo, $h_{0}=0,05$ ), é 

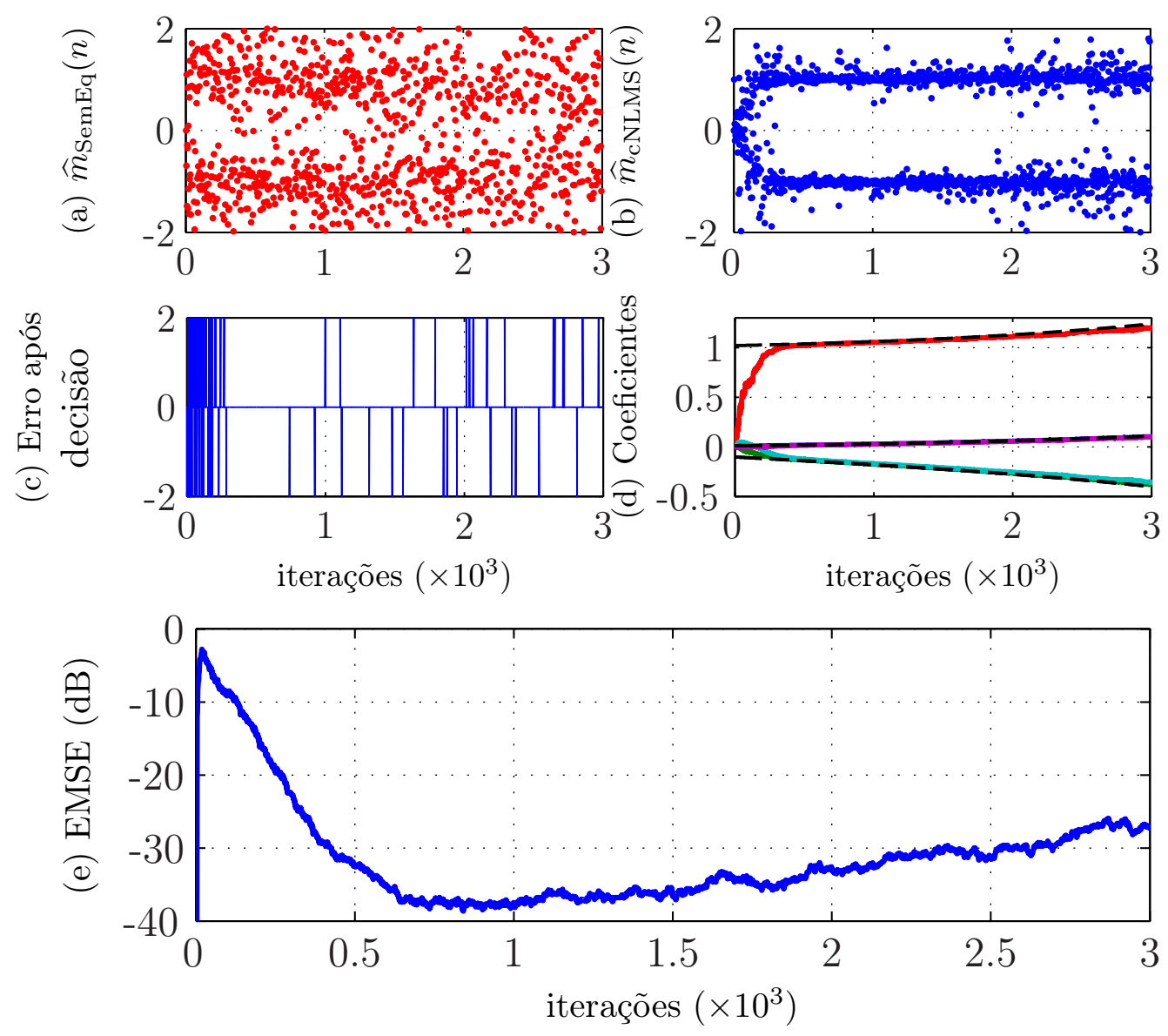

Figura 4.9: Sequência recuperada com o sistema utilizando o mapa de Hénon e codificação com multiplicação (a) sem equalizador e (b) com o $\operatorname{cNLMS}_{\times}\left(\widetilde{\mu}=0,1, \delta=10^{-5}, \varepsilon=0,1\right.$; $M=5 ; \Delta=3$ ); (c) Erro após decisão; (d) Média dos coeficientes do cNLMS $\times$ e solução de Wiener (linhas tracejadas); (e) EMSE estimado; média de 1000 realizações; Canal 4, variante no tempo.

suficiente para distorcer completamente a mensagem transmitida, sendo o equalizador essencial para permitir a comunicação. Para $h_{0}=0,5$, o canal apresenta um nulo espectral e, em vez de um equalizador linear transversal, é necessário utilizar um DFE para eliminar os efeitos do canal [Havkin, 2000; Saved, 2008].

Para mostrar a sensibilidade do sincronismo caótico com relação ao ruído, foi adicionado ruído branco gaussiano ao sinal na saída do Canal 5 de modo a obter uma SNR de 60 dB. As curvas de BER para esse caso são mostradas na Figura 4.11. Como o equalizador somente tenta eliminar a ISI, as taxas de erro de bit são maiores do que as obtidas na Figura 4.10, principalmente quando a ISI] é pequena. Mesmo para o canal ideal $\left(h_{0}=0\right)$, a recuperação perfeita da mensagem não é possível e a BER obtida é de aproximadamente $8 \times 10^{-4}$. Considerando novamente o Canal 5 , com $h_{0}(n)=0,25$, foram obtidas curvas de BER em função da SNR, 


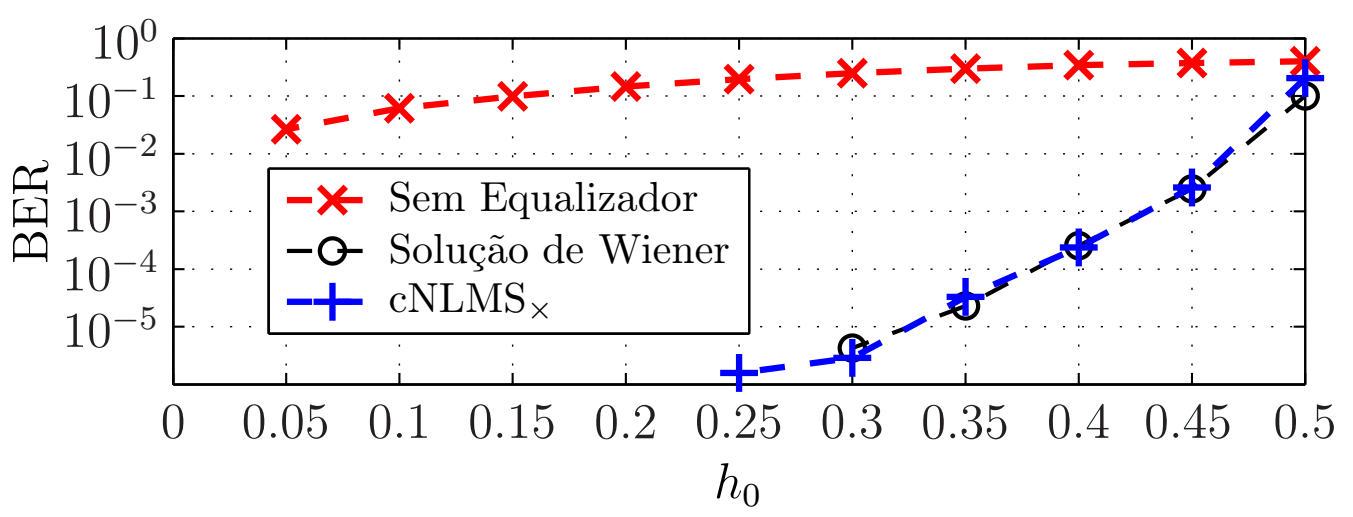

Figura 4.10: Taxa de erro de bit para o Canal 5 em função de $h_{0}$ na ausência de ruído; Sistema utilizando o mapa de Hénon e codificação com multiplicação; $\operatorname{cNLMS}_{\times} \operatorname{com} \widetilde{\mu}=0,05 ; \delta=10^{-5}$; $\varepsilon=0,1 ; M=21 ; \Delta=11$.

conforme mostrado na Figura 4.12, Para fins de comparação, também foram incluídas curvas de BER para o canal AWGN não dispersivo, obtidas com o sistema mostrado na Figura 4.1 sem o equalizador. Pode-se observar que a BER obtida com o algoritmo cNLMS $\times$ é próxima ao valor obtido pela solução de Wiener, sendo ambos os valores superiores ao valor obtido no caso da canal AWGN. Novamente, a ausência do equalizador em um canal dispersivo leva a taxas de erro proibitivas. Dadas as altas BER obtidas na presença de ruído, é importante ressaltar que para permitir a comunicação baseada em caos usando o sistema da Figura 4.1, o transmissor deve codificar o sinal usando um código corretor de erros antes da transmissão [Haykin, 2000].

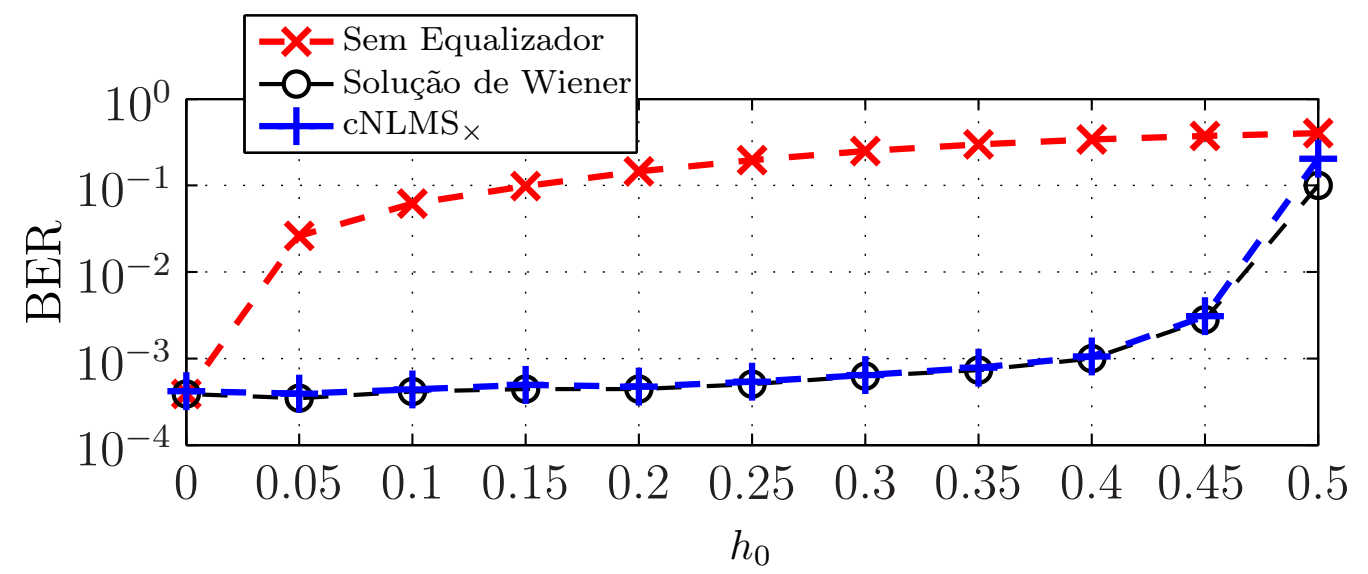

Figura 4.11: Taxa de erro de bit para o Canal 5 em função de $h_{0}$ com SNR $=60$ dB; Sistema utilizando o mapa de Hénon e codificação com multiplicação; $\operatorname{cNLMS}_{\times} \operatorname{com} \widetilde{\mu}=0,05 ; \delta=10^{-5}$; $\varepsilon=0,1 ; M=21 ; \Delta=11$. 


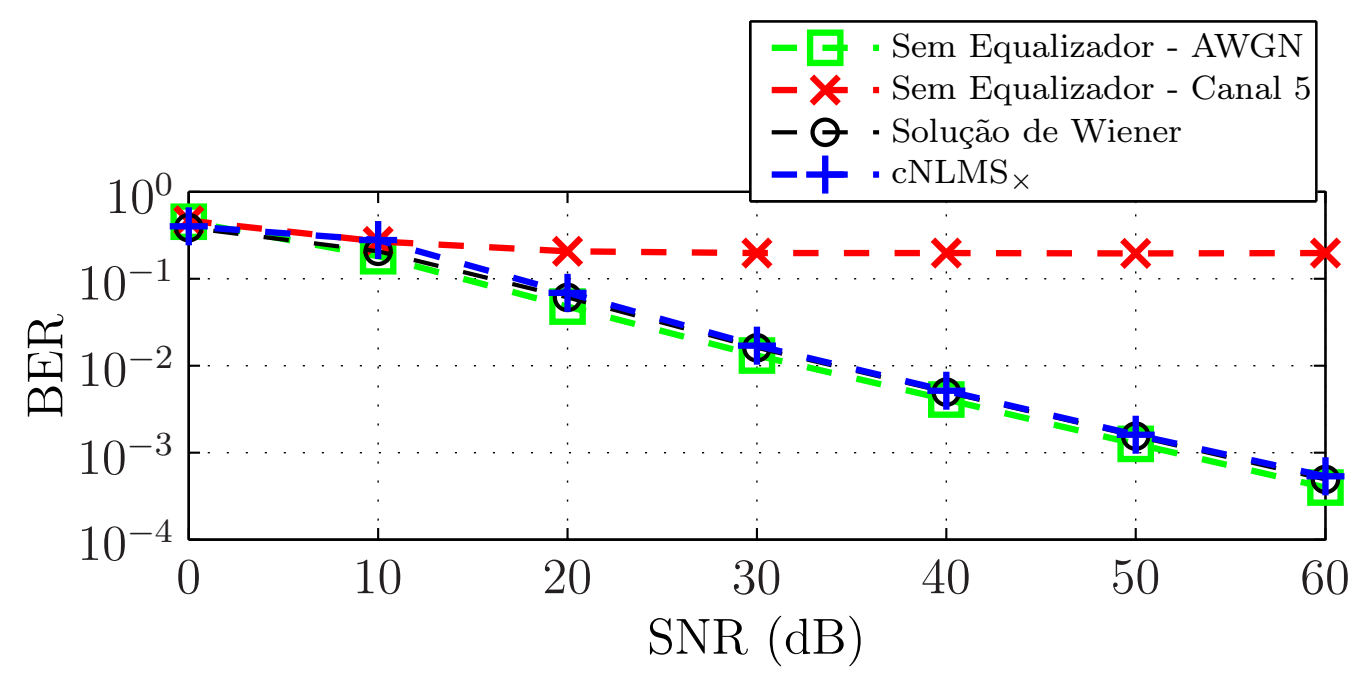

Figura 4.12: Taxa de erro de bit para o canal AWGN não dispersivo e para o Canal 5 com $h_{0}=0,25$, em função da relação sinal-ruído (SNR); Sistema utilizando o mapa de Hénon e codificação com multiplicação; $\operatorname{cNLMS}_{\times} \operatorname{com} \widetilde{\mu}=0,05 ; \delta=10^{-5} ; \varepsilon=0,1 ; M=21 ; \Delta=11$.

\subsection{Sistema com o mapa de Ikeda}

Nesta seção, é proposto um algoritmo de equalização adaptativa para o sistema de comunicação baseado em caos utilizando o mapa de Ikeda [Alligood et al., 1997; Ikeda, 1979] nos GSCS. Primeiramente, é mostrado que é possível obter sincronismo entre os sistemas mestre e escravo utilizando o mapa de Ikeda. Em seguida, com base no algoritmo mostrado na Seção 4.2, é proposta uma versão para a utilização com o mapa de Ikeda e são mostrados resultados de simulação. Por fim, é feito um estudo quanto à geração de sinais caóticos pelo sistema proposto e são mostrados alguns problemas quanto ao sincronismo no sistema com o mapa de Ikeda quando esse gera sinais caóticos.

Como mostrado na Seção 2.3.2, o mapa de Ikeda é um mapa bidimensional dado por

$$
\mathbf{x}(n+1)=\left[\begin{array}{l}
x_{1}(n+1) \\
x_{2}(n+1)
\end{array}\right]=\left[\begin{array}{l}
C_{2} x_{1}(n) \cos \theta(n)-C_{2} x_{2}(n) \sin \theta(n)+R \\
C_{2} x_{1}(n) \sin \theta(n)+C_{2} x_{2}(n) \cos \theta(n)
\end{array}\right]
$$

sendo

$$
\theta(n)=C_{1}-\frac{C_{3}}{1+x_{1}^{2}(n)+x_{2}^{2}(n)}
$$

e $C_{1}, C_{2}, C_{3}$ e $R$ constantes reais.

Considerando-se a função de codificação dada pela multiplicação entre o estado $x_{2}(n)$ e a mensagem binária $m(n)$, de forma análoga à (4.27), ou seja 


$$
s(n)=c\left(x_{2}(n), m(n)\right)=m(n) \cdot x_{2}(n) .
$$

As equações que governam o sistema de comunicação baseado em (4.29) podem ser reescritas em uma forma parecida à de (1.8) e (1.9) como

$$
\begin{aligned}
& \mathbf{x}(n+1)=\mathbf{A}_{t}(n) \mathbf{x}(n)+\left[\begin{array}{ll}
R & 0
\end{array}\right]^{\mathrm{T}}, \\
& \widehat{\mathbf{x}}(n+1)=\mathbf{A}_{r}(n) \widehat{\mathbf{x}}(n)+\left[\begin{array}{ll}
R & 0
\end{array}\right]^{\mathrm{T}},
\end{aligned}
$$

sendo

$$
\begin{gathered}
\mathbf{A}_{t}(n)=C_{2}\left[\begin{array}{rr}
\cos \theta_{t}(n) & -\sin \theta_{t}(n) \\
\sin \theta_{t}(n) & \cos \theta_{t}(n)
\end{array}\right]\left[\begin{array}{rr}
1 & 0 \\
0 & m(n)
\end{array}\right] \\
\mathbf{A}_{r}(n)=C_{2}\left[\begin{array}{rr}
\cos \theta_{r}(n) & -\sin \theta_{r}(n) \\
\sin \theta_{r}(n) & \cos \theta_{r}(n)
\end{array}\right]\left[\begin{array}{rc}
1 & 0 \\
0 & \widehat{m}(n)
\end{array}\right] \\
\theta_{t}(n)=C_{1}-\frac{C_{3}}{1+x_{1}^{2}(n)+s^{2}(n)} \\
\theta_{r}(n)=C_{1}-\frac{C_{3}}{1+\widehat{x}_{1}^{2}(n)+\widehat{s}^{2}(n)}
\end{gathered}
$$

e $\widehat{s}(n)=\widehat{m}(n) \widehat{x}_{2}(n)$. É importante notar que, diferentemente do sistema de comunicação baseado no mapa de Hénon, as matrizes $\mathbf{A}_{t}$ e $\mathbf{A}_{r}$ não são constantes e incluem a função de codificação. Além disso, no caso do mapa de Ikeda, é utilizado o estado $x_{2}(n)$ no lugar de $x_{1}(n)$ para a codificação da mensagem pois essa escolha leva a melhores resultados quanto à equalização do canal, conforme será mostrado por meio de simulação.

A dinâmica do erro de sincronismo é dada por

$$
\mathbf{e}(n+1)=\left[\mathbf{A}_{r}(n)-\mathbf{A}_{t}(n)\right] \mathbf{e}(n) .
$$

Garantir a estabilidade exponencial de (4.38) é uma condição suficiente (mas não necessária) para o sincronismo completo entre os sistemas mestre e escravo. Da teoria de sistemas lineares, (4.38) é exponencialmente estável se existir uma constante $0 \leq \rho<1$ de forma que o máximo valor absoluto dos autovalores de $\left[\mathbf{A}_{r}(n)-\mathbf{A}_{t}(n)\right]$ satisfaça [Rugh, 1996]

$$
\prod_{n=N_{1}}^{N_{2}}\left|\lambda_{\max }(n)\right| \leq \rho^{N_{2}-N_{1}+1} \text { para todo } N_{2} \text { e } N_{1} \text { tais que } N_{2} \geq N_{1}
$$


sendo $\left|\lambda_{\max }(n)\right| \triangleq \max \left\{\left|\lambda_{1}(n)\right|,\left|\lambda_{2}(n)\right|\right\}$ e $\lambda_{i}(n), i=1,2$ os autovalores de $\left[\mathbf{A}_{r}(n)-\mathbf{A}_{t}(n)\right]$. Em outras palavras, se $\left|\lambda_{\max }(n)\right|<1$ para todo $n \geq N_{1}$, os sistemas mestre e escravo sincronizam completamente em um sistema de comunicação baseado no mapa de Ikeda.

Provar que $\left|\lambda_{\max }(n)\right|<1$ para todo $n>N_{1}$ não é uma tarefa simples e são necessárias algumas hipóteses sobre a mensagem transmitida e recuperada, mesmo quando o canal é ideal. Isso ocorre porque no sistema com o mapa de Ikeda, $\mathbf{A}_{t}(n)$ e $\mathbf{A}_{r}(n)$ dependem de $m(n)$ e $\widehat{m}(n)$, respectivamente. Dessa forma, são mostradas a seguir algumas simulações numéricas para mostrar que o sincronismo entre os sistemas mestre e escravo pode ser obtido quando o canal é ideal, considerando os parâmetros usuais do mapa de Ikeda, dados por (2.16), na página 19.

Considerando uma mensagem binária, aleatória e equiprovável $m(n) \in\{-1,+1\}$ e inicializando os vetores de estados com $\mathbf{x}(0)=\mathbf{0}$ e $\widehat{\mathbf{x}}(0)=[0,1-0,1]^{\mathrm{T}}$, foram feitas $L=10^{4}$ realizações independentes das Equações (4.32) e (4.33). Para cada iteração $n$, o valor de $\left|\lambda_{\max }(n)\right|$ foi observado ao longo das $L$ realizações. Na Figura 4.13 -(a), é mostrado o valor máximo de $\left|\lambda_{\max }(n)\right|$ para cada iteração entre as $L$ realizações e na Figura 4.13-(b) é mostrado um histograma de $\left|\lambda_{\max }(n)\right|$ na iteração $n=30$. Do histograma, é possível notar que o máximo valor absoluto dos autovalores pode ser maior do que um na iteração $n=30$ mas isso ocorre com uma frequência muito baixa (apenas 16 vezes em $10^{4}$ realizações). Conforme $n$ aumenta, a frequência da ocorrência de $\left|\lambda_{\max }(n)\right|>1$ diminui e após 64 iterações, $\max _{L}\left\{\left|\lambda_{\max }(n)\right|\right\}$ converge para um valor menor do que um. Assim, (4.39) é satisfeita e é obtido o sincronismo entre os sistemas mestre e escravo. Por meio de simulações com diferentes inicializações, foi possível notar que esse é o comportamento típico quando os sistemas mestre e escravo são inicializados dentro da mesma bacia de atração.

(a)

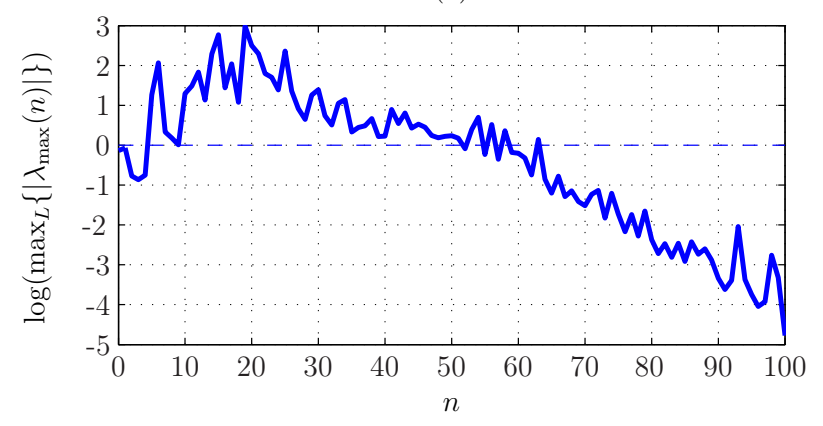

(b)

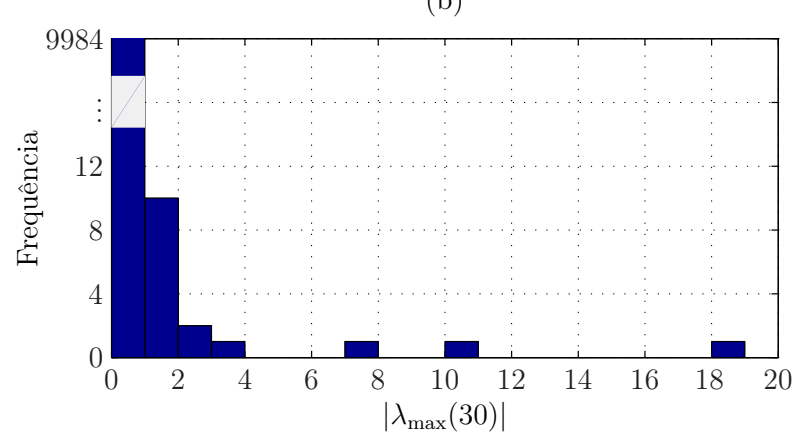

Figura 4.13: (a) Logaritmo do máximo valor de $\left|\lambda_{\max }(n)\right|$ entre $L=10^{4}$ realizações independentes e (b) histograma do máximo valor absoluto dos autovalores de $\mathbf{A}_{r}(n)-\mathbf{A}_{t}(n)$ em $n=30$, considerando uma mensagem binária equiprovável. Inicialização com $\mathbf{x}(0)=\left[\begin{array}{ll}0 & 0\end{array}\right]^{\mathrm{T}} \mathrm{e}$ $\widehat{\mathbf{x}}(0)=[0,1-0,1]^{\mathrm{T}}$. 
Dada a possibilidade de sincronismo entre os sistemas mestre e escravo e, utilizando o algoritmo calculado na Seção 4.2, considerando a função de codificação (4.31), foi proposto o algoritmo mostrado na Tabela 4.2 .

Tabela 4.2: Algoritmo $\mathrm{cNLMS}_{\times}$considerando o mapa de Ikeda.

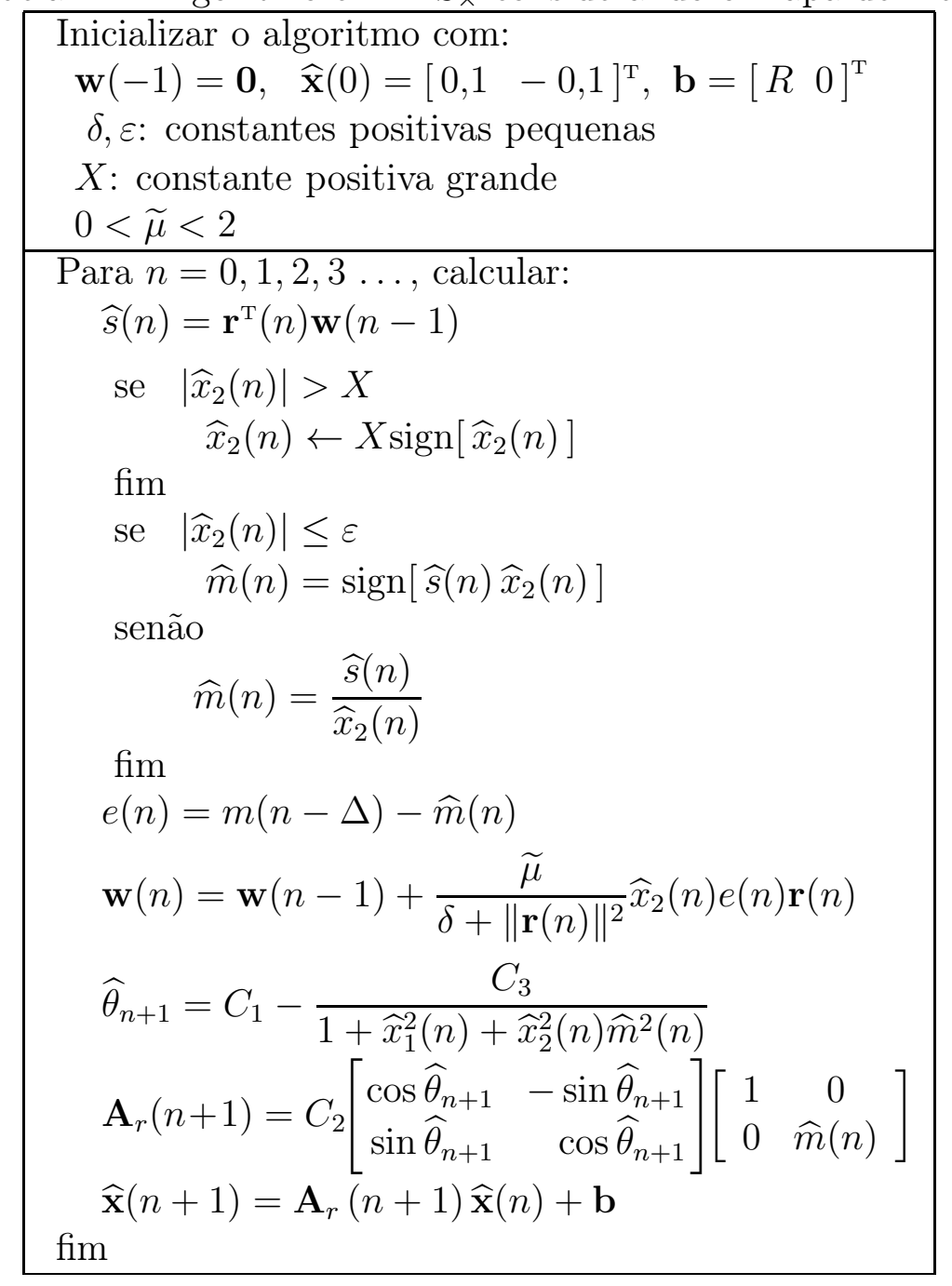

\subsubsection{Resultados de simulação}

Nas simulações, foi considerado o mapa de Ikeda com parâmetros (2.16). Os vetores de estados de (4.32) e (4.33) foram inicializados com $\mathbf{x}(0)=\mathbf{0}$ e $\widehat{\mathbf{x}}(0)=\left[\begin{array}{ll}0,1 & -0,1\end{array}\right]^{\mathrm{T}}$, respectivamente. Outras inicializações também permitem resultados semelhantes desde que o equalizador seja capaz de mitigar razoavelmente bem a interferência intersimbólica. Além disso, foi considerada a transmissão de uma mensagem binária $m(n) \in\{-1,1\}$ e o equalizador foi inicializado com $\mathbf{w}(0)=\mathbf{0}$. Para fins de comparação, também foi considerado o sistema 
sem a presença do equalizador, para o qual $\widehat{s}(n)=r(n)$.

Inicialmente, é considerado que o sinal $s(n)$ seja transmitido pelo Canal 1 (IIR) da Tabela 3.1 com SNR de $30 \mathrm{~dB}$ e atraso $\Delta=0$. A mensagem estimada utilizando o equalizador com o algoritmo cNLMS $x$ e o erro após a decisão (ambos para uma realização) são mostrados nas Figuras. 4.14t(b) e (c). A média de conjunto dos dois coeficientes e o EMSE ao longo das iterações, estimado por uma média de 1000 realizações, são mostrados respectivamente nas Figuras 4.14 (d) e (e). É possível notar que o cNLMS/ converge para a solução ótima, cujos coeficientes são mostrados pelas linhas tracejadas na Figura 4.14 (d). Assim, pode-se concluir que o equalizador está funcionando conforme o esperado dado que essa solução elimina a interferência intersimbólica, permitindo o sincronismo entre mestre e escravo, o que pode ser confirmado por meio dos erros obtidos após a decisão, mostrados na Figura 4.14-(c). O sincronismo não ocorre caso o equalizador não esteja presente como pode ser visto na Figura 4.14_(a).
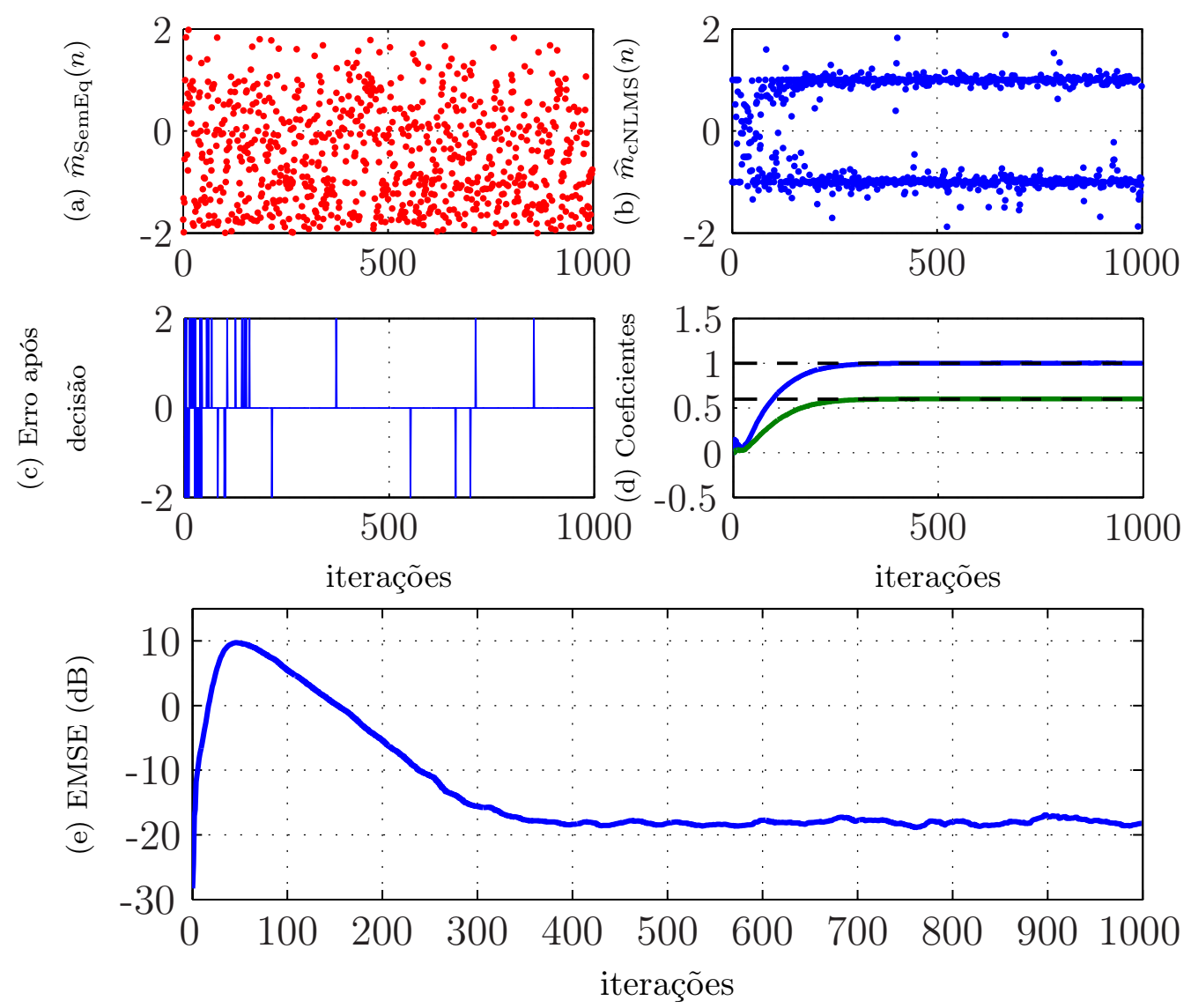

Figura 4.14: Sequência recuperada com o sistema utilizando o mapa de Ikeda com a codificação da mensagem com multiplicação usando o estado $x_{2}(n)$ (a) sem equalizador e (b) com uma realização do $\operatorname{cNLMS}_{\times}\left(\widetilde{\mu}=0,1 ; \delta=10^{-2} ; \varepsilon=0,1 ; M=2 ; \Delta=0\right) ;$ (c) Erro após decisão; (d) Média dos coeficientes do $\mathrm{NLLMS}_{\times}$e solução de Wiener (linhas tracejadas); (e) EMSE estimado; média de 1000 realizações; Canal 1; SNR $=30 \mathrm{~dB}$. 
Na Figura 4.15, são mostrados os resultados obtidos para a mesma situação mas utilizando o estado $x_{1}(n)$ no lugar de $x_{2}(n)$ para a codificação da mensagem e a geração do sinal $s(n)$. É possível notar que, apesar de haver sincronismo entre os sistemas mestre e escravo, a mensagem recuperada $\widehat{m}(n)$, mostrada na Figura 4.15-(b) possui uma variância bem maior do que a do caso anterior, o que acarreta um maior número de erros após a decisão, conforme pode ser visto na Figura 4.15-(c). Aparentemente, isso ocorre pois a média dos coeficientes não converge exatamente para a solução ótima, conforme mostrado na Figura 4.15-(d).
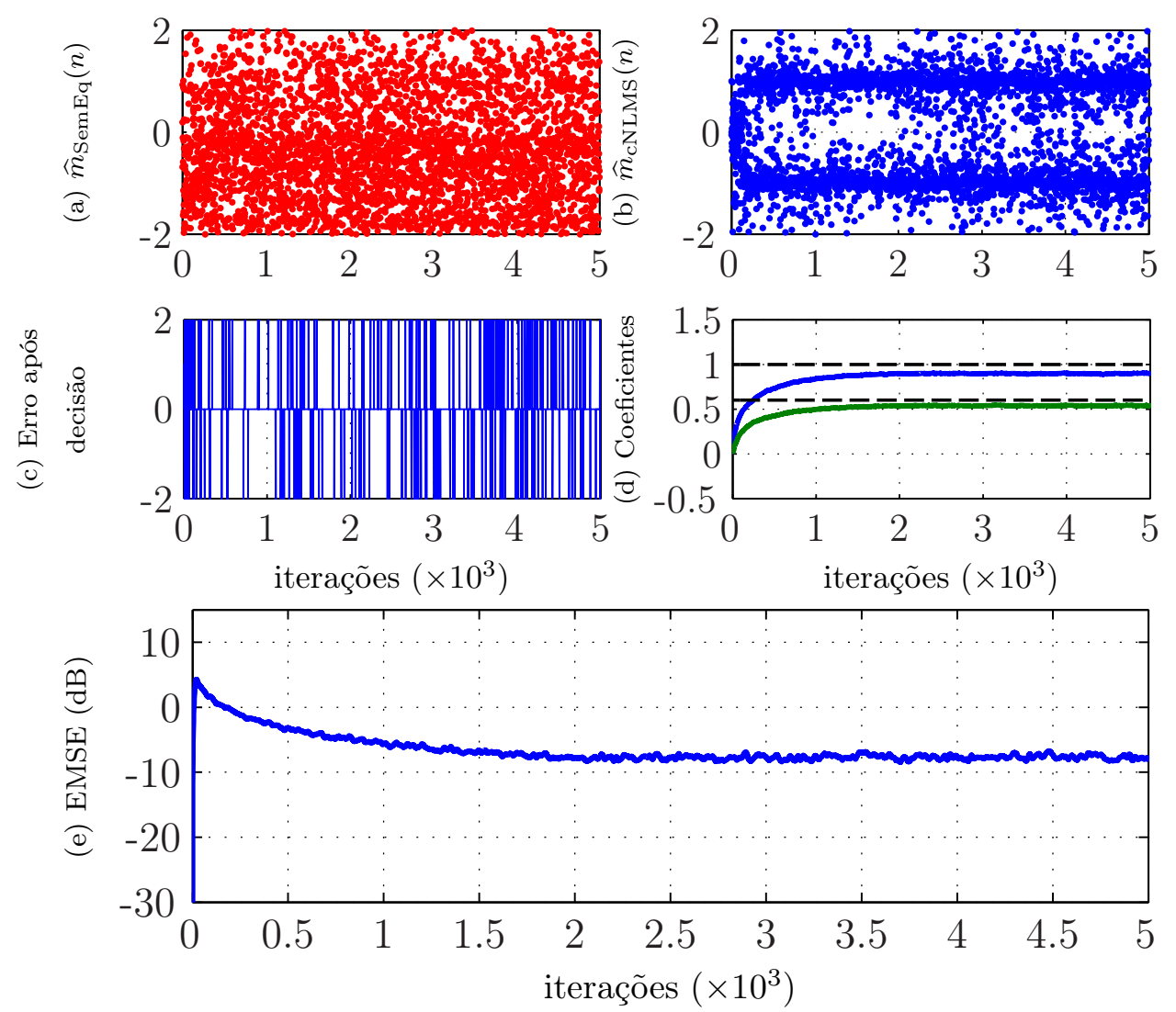

Figura 4.15: Sequência recuperada com o sistema utilizando o mapa de Ikeda com a codificação da mensagem com multiplicação usando o estado $x_{1}(n)$ (a) sem equalizador e (b) com uma realização do $\mathrm{cNLMS}_{\times}\left(\widetilde{\mu}=0,1 ; \delta=10^{-2} ; \varepsilon=0,1 ; M=2 ; \Delta=0\right) ;$ (c) Erro após decisão; (d) Média dos coeficientes do $\mathrm{NLLMS}_{\times}$e solução de Wiener (linhas tracejadas); (e) EMSE estimado; média de 1000 realizações; Canal 1; SNR $=30 \mathrm{~dB}$.

No sistema com o mapa de Ikeda, é possível obter resultados com desempenho semelhante ao apresentado na Figura 4.14 com os outros canais da Tabela 3.1 quando se utiliza o estado $x_{2}(n)$ para codificar a mensagem. No entanto, o sistema com o mapa de Ikeda apresenta um problema relativo à geração de sinais com $\overline{\mathrm{DSCI}}$, como comentado na seção seguinte. 


\subsubsection{Sobre a geração de sinais com DSCI no sistema com o mapa de Ikeda}

Apesar do bom do funcionamento do sistema com o mapa de Ikeda quando se utiliza o estado $x_{2}(n)$ para codificar a mensagem, é necessário tomar um cuidado adicional, uma vez que esse mapa apresenta mais de um atrator com bacias de atração próximas: um ponto fixo e um atrator caótico [Alligood et al., 1997]. Essa estrutura em particular pode eventualmente gerar alguns inconvenientes para o projeto de sistemas de comunicação eficientes baseados em caos, como a geração de sinais aperiódicos mas sem DSCI. Dessa forma, uma análise mais detalhada envolvendo a presença de atratores coexistentes e as suas consequências é mostrada a seguir por meio de simulações.

Considerando a multiplicação como função de codificação e uma mensagem binária, é mostrado a seguir um exemplo para ilustrar que a órbita do sinal gerado pode sair da bacia de atração do regime caótico para o sistema descrito por (4.32) e (4.33). Na Figura 4.16, são mostradas uma parte da mensagem $m(n)$, a parte correspondente do sinal $s(n)$ e o espaço de fases $x_{1}(n)$ por $x_{2}(n)$. A área destacada em amarelo na Figura 4.16-(c) corresponde à bacia de atração para o atrator caótico composto por pontos pretos e vermelhos dentro da área amarela na figura. Dependendo do valor de $x_{2}(n)$, quando este é multiplicado por -1 , pode-se observar dois comportamentos distintos:

i) se $\left[x_{1}(n), x_{2}(n)\right]^{\mathrm{T}}$ for um dos pontos pretos do atrator caótico mostrado na figura, a órbita permanece na área amarela e $s(n)$ permanece caótico ou;

ii) se $\left[x_{1}(n), x_{2}(n)\right]^{\mathrm{T}}$ for um dos pontos vermelhos dentro do atrator caótico mostrado na figura, a coordenada $\left[x_{1}(n),-x_{2}(n)\right]^{\mathrm{T}}$ fica fora da bacia de atração representada pela área amarela e, portanto, a órbita deixa o regime caótico.

Por exemplo, na iteração $n_{1},\left[x_{1}(n), x_{2}(n)\right]^{\mathrm{T}}$ é um dos pontos pretos mostrados na Figura 4.16 . (c) e a codificação de $m\left(n_{1}\right)=-1$ não perturba o regime caótico. Em contrapartida, na iteração, $n_{2},\left[x_{1}(n), x_{2}(n)\right]^{\mathrm{T}}$ é um dos pontos vermelhos mostrados na Figura 4.16-(c) e a codificação de $m\left(n_{2}\right)=-1$ leva a órbita a convergir para o ponto fixo, indicado pela cruz na figura. Vale notar que, uma vez que a órbita deixa a bacia de atração do regime caótico, ela não retorna. A cada vez que ocorre um -1 no sinal $m(n)$, a órbita apenas oscila em torno do ponto fixo, gerando um sinal como o mostrado na Figura 4.16子(b). Esses sinais não são caóticos.

A DSCI também pode ser testada por meio dos expoentes de Lyapunov, como descrito na Seção 2.2. No sistema aqui considerado, há uma mensagem binária $m(n)$ que afeta o 

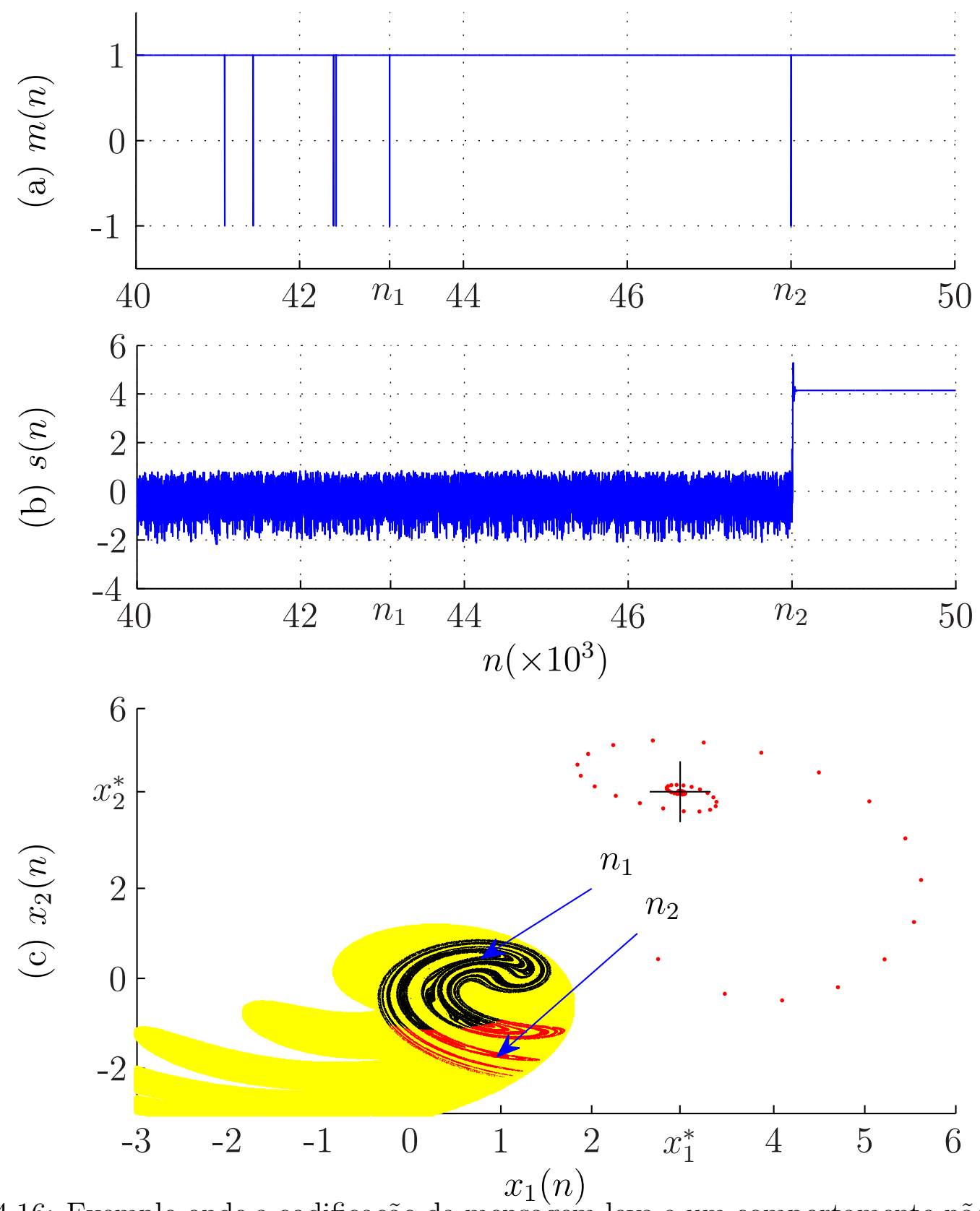

Figura 4.16: Exemplo onde a codificação da mensagem leva a um comportamento não caótico: (a) Trecho da mensagem a ser codificada; (b) Trecho do sinal obtido após a codificação da mensagem; (c) Espaço de fases $\left(x_{1}(n)\right.$ por $\left.x_{2}(n)\right)$ convergindo para o ponto fixo indicado pela cruz; Mapa de Ikeda.

sistema dinâmico. Nesse caso, para calcular numericamente os expoentes de Lyapunov, podese considerar o sinal $m(n)$ como um parâmetro variante no tempo. Fazendo isso, é possível verificar que os expoentes de Lyapunov para o sistema considerado são negativos, o que indica que não há DSCI. 
Para evitar a convergência do sistema para o ponto fixo, pode-se escolher uma outra função de codificação, de modo a garantir que a órbita não saia da bacia de atração no transmissor, o que permite a geração de sinais com DSCI, como mostrado no Apêndice A. Entretanto, o sistema com o mapa de Ikeda apresenta um problema de sincronismo quando o sinal transmitido tem a órbita dentro da bacia de atração e o receptor é inicializado fora da bacia de atração. Na Figura 4.17, é mostrado um resultado análogo ao da Figura 4.13-(a) mas considerando $m(n)=1$, o que garante que os sinais no transmissor permaneçam dentro da bacia de atração do regime caótico. Além disso, o receptor foi inicializado em $\widehat{\mathbf{x}}(0)=[22]^{\mathrm{T}}$, fora da bacia de atração do regime caótico. Como pode ser notado, o valor de $\left|\lambda_{\max }(n)\right|$ não converge para um valor menor que um ao longo das iterações, o que indica que os sistemas não sincronizam. Dado esse resultado, e, lembrando que o sistema não retorna à bacia de atração do regime caótico uma vez que tenha saído, pode-se concluir que haverá problemas com o sistema quando o transmissor tiver os sinais dentro da bacia de atração do regime caótico. Mesmo inicializando o receptor dentro da bacia de atração, o efeito do canal pode levá-lo a sair e convergir para o ponto fixo, fazendo com que o sistema perca o sincronismo e impossibilitando a recuperação.

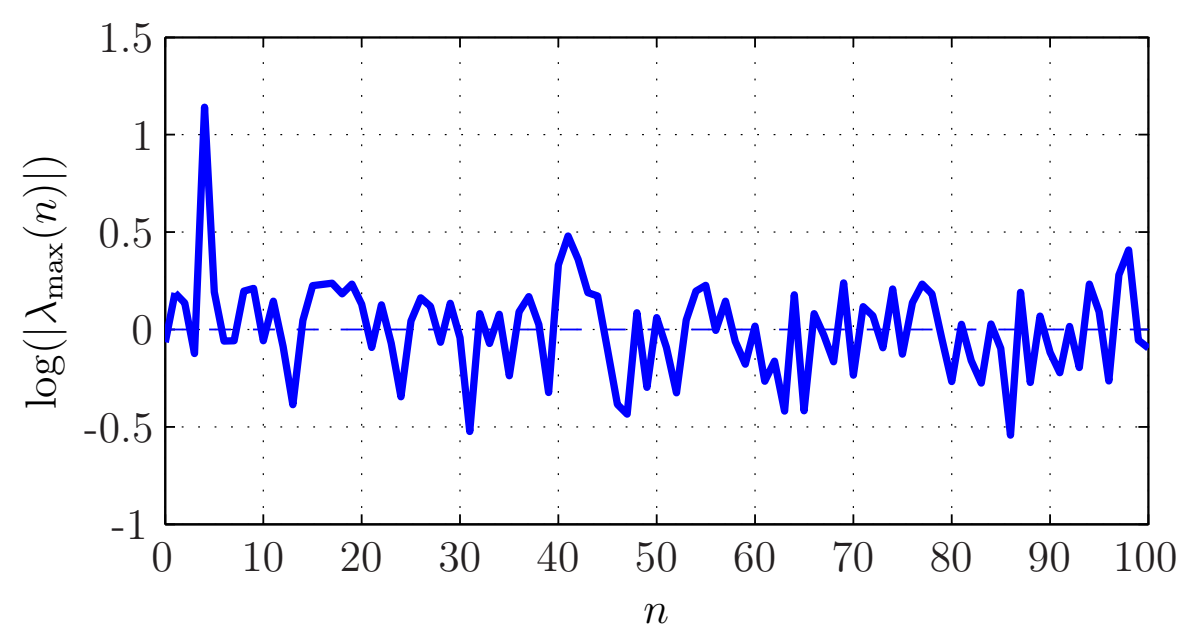

Figura 4.17: Logaritmo do valor de $\left|\lambda_{\max }(n)\right|$ em uma realização do sistema. Mensagem $m(n)=1$ e inicialização com $\mathbf{x}(0)=\left[\begin{array}{ll}0 & 0\end{array}\right]^{\mathrm{T}} ; \widehat{\mathbf{x}}(0)=\left[\begin{array}{ll}2 & 2\end{array}\right]^{\mathrm{T}}$.

\subsection{Conclusões}

Neste capítulo, foram apresentados os resultados obtidos com o sistema de comunicação baseado em caos considerando uma função de codificação que utiliza a multiplicação. Para a 
equalização do canal de comunicação foi utilizado um equalizador adaptado com um algoritmo baseado no NLMS,

Considerando o mapa de Ikeda, apesar do funcionamento do equalizador, foi mostrado que, devido à presença de um ponto fixo, o transmissor deixa de gerar sinais que apresentam DSCI quando utilizado com a função de codificação baseada na multiplicação. Apesar de ser possível corrigir o problema trocando a função de codificação, foi mostrado que a correção inviabiliza o uso do sistema pois o sincronismo pode ser perdido no caso de canais não ideais.

Já com o mapa de Hénon, foi possível verificar o funcionamento do equalizador, convergindo na média para a solução ótima de Wiener em todos os cenários considerados. Apesar do funcionamento do sistema, o desempenho ainda está muito aquém de um sistema de comunicação convencional, cujos resultados são mostrados no Capítulo 3. A fim de melhorar o desempenho do sistema, no próximo capítulo, é proposta uma outra função de codificação, baseada na soma. 


\section{Capítulo 5}

\section{Equalização aplicada a sincronismo caótico - codificação com soma}

O sistema que utiliza a codificação com a multiplicação e o mapa de Hénon, apesar de ter a vantagem de não interferir na dinâmica do GSC, apresenta taxas de erro de bit elevadas, principalmente na presença de ruído. A fim de obter uma codificação mais robusta em cenários com SNR baixa, é proposta neste capítulo uma outra função que utiliza a soma para codificar o sinal de mensagem no estado do GSC. Inicialmente, é apresentada a função de codificação proposta e são mostrados alguns detalhes quanto à geração de sinais caóticos pelo GSC. Usando a função de codificação, é proposto um algoritmo para equalização considerando apenas o mapa de Hénon, já que o mapa de Ikeda apresenta problemas no sincronismo, como mostrado na Seção 4.4.2. Em seguida, são apresentados alguns detalhes quanto à escolha dos parâmetros a serem utilizados na função de codificação com base no desempenho do algoritmo de equalização. Por fim, são mostrados resultados de simulação e as conclusões.

\subsection{A codificação com soma}

Uma ideia proposta em [Abib, 2013; Abib e Eisencraft, 2013] para a codificação da mensagem no estado do GSC é utilizar a função

$$
s(n)=(1-\gamma) x_{1}(n)+\gamma m(n),
$$

com a respectiva função de decodificação

$$
\widehat{m}(n)=\frac{\widehat{s}(n)-(1-\gamma) x_{1}(n)}{\gamma},
$$


sendo $0<\gamma \leq 1$ um parâmetro que controla a forma do sinal $s(n)$. Quando $\gamma \rightarrow 0$, $s(n)$ tende para o sinal $x_{1}(n)$ natural do mapa de Hénon e quando $\gamma \rightarrow 1, s(n)$ tende para mensagem $m(n)$. Quando $0<\gamma<1$, a dinâmica do mapa é alterada, pois $s(n)$ é realimentado no GSC. Com isso, $s(n)$ pode variar entre um sinal que apresenta DSCI ou não ou até mesmo divergir. Foi mostrado em [Abib, 2013; Abib e Eisencraft, 2013], que essa codificação pode ser mais robusta quanto ao ruído quando se utilizam valores de $\gamma$ mais elevados.

No entanto, em [Abib, 2013; Abib e Eisencraft, 2013], não houve a preocupação em verificar se os sinais gerados apresentavam DSCI e, um problema dessa função de codificação é que o transmissor só é capaz de gerar sinais que apresentam DSCI para valores pequenos de $\gamma$, pois nesse caso $s(n)$ se aproxima de $x_{1}(n)$. Para mostrar esse resultado, foi considerada uma forma mais geral de (5.1), dada por

$$
s(n)=\gamma_{1} x_{1}(n)+\gamma_{2} m(n),
$$

em que $0 \leq \gamma_{1} \leq 1$ e $0<\gamma_{2} \leq 1$. Nesse caso, a decodificação da mensagem é feita com

$$
\widehat{m}(n)=\frac{\widehat{s}(n)-\gamma_{1} x_{1}(n)}{\gamma_{2}}
$$

Na Figura 5.1, é mostrado o máximo expoente de Lyapunov obtido no transmissor, em função dos parâmetros $\gamma_{1}$ e $\gamma_{2}$, considerando uma mensagem $m(n)$ binária, aleatória e equiprovável. Para obter o máximo expoente de Lyapunov, utilizou-se o algoritmo descrito na Seção 2.2, considerando $m(n)$ como sendo um parâmetro variante no tempo. Para facilitar a visualização, a área onde o máximo expoente de Lyapunov é negativo, o que indica ausência de DSCI, foi indicada pela cor cinza. Para alguns valores de $\gamma_{1}$ e $\gamma_{2}$, ocorre a divergência no transmissor e, na figura, essa área foi deixada em branco. A área colorida se refere aos valores de $\gamma_{1}$ e $\gamma_{2}$ onde se obtém o máximo expoente de Lyapunov positivo, que indica a geração de sinais com DSCI. Para cada ponto da figura, foi considerada uma mensagem $m(n)$ diferente para o cálculo do máximo expoente de Lyapunov. Dessa forma, dado que a superfície indicada pela área colorida é contínua, pode-se dizer que o máximo expoente de Lyapunov varia pouco em função da mensagem equiprovável $m(n)$. Como pode ser notado na figura, quando $\gamma_{1}=1$ e $\gamma_{2}=0, s(n)=x_{1}(n)$ e $\kappa_{1}$ é aproximadamente 0,4 , que coincide com o máximo expoente de Lyapunov do mapa de Hénon original. Também foi indicada na figura a reta $\gamma_{1}+\gamma_{2}=1$, referente aos resultados obtidos quando se utiliza a função de codificação (15.1), que é um caso particular de (5.3). É possível notar que, ao codificar a mensagem com (5.1), os sinais gerados apresentam DSCI apenas quando $\gamma$ é muito pequeno, ou seja, quando o sinal codificado $s(n)$ é parecido com o sinal $x_{1}(n)$ natural do mapa de Hénon. A partir do resultado mostrado na 


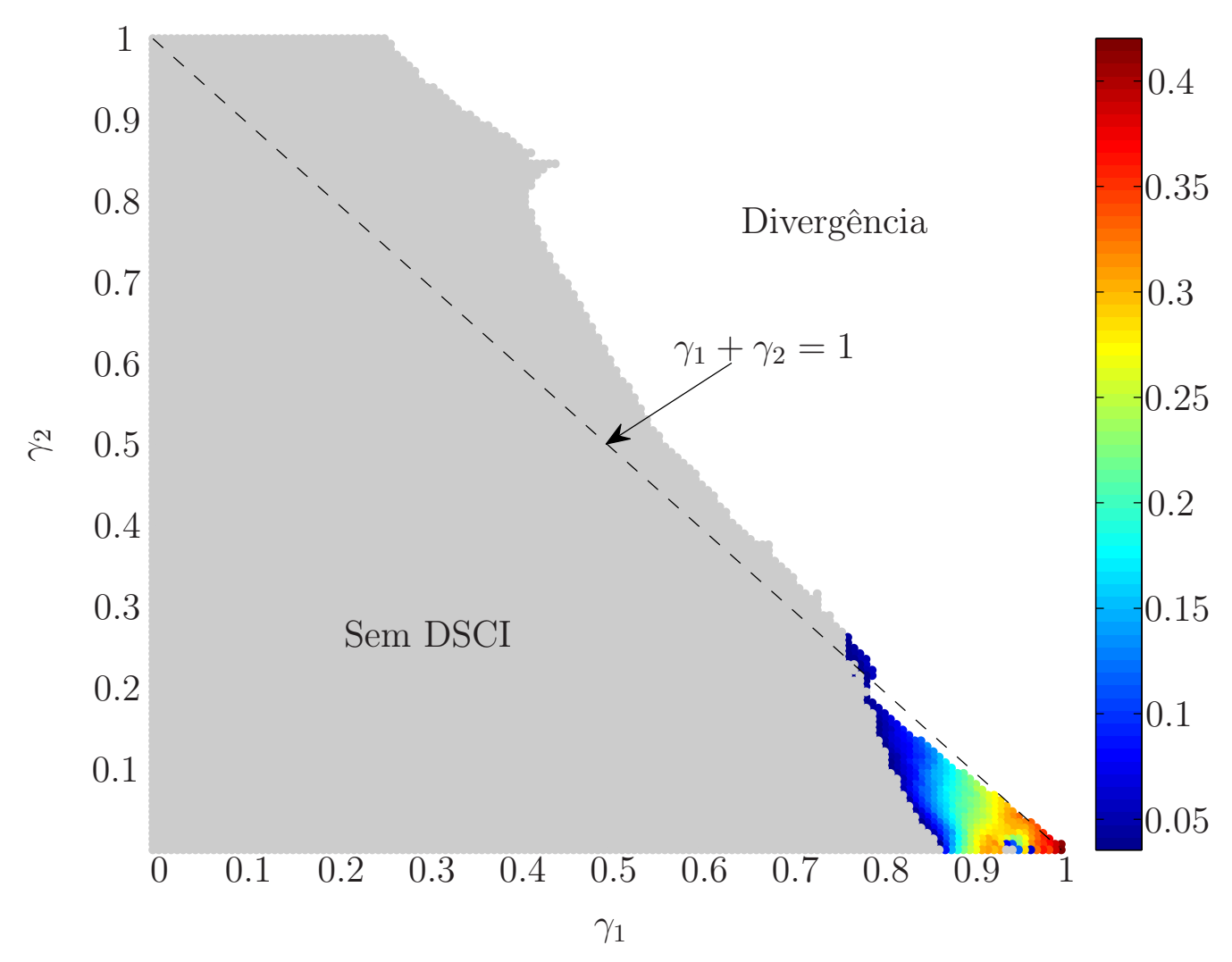

Figura 5.1: Máximo expoente de Lyapunov obtido no transmissor utilizando a função de codificação (5.3), em função dos parâmetros $\gamma_{1}$ e $\gamma_{2}$. A área cinza indica que o máximo expoente de Lyapunov é negativo. A área branca indica que houve divergência do transmissor.

figura, é possível notar que pode ser interessante considerar a utilização de valores de $\gamma_{1}>1$ e $\gamma_{2}<0$, o que é deixado como sugestão de trabalho futuro.

Escolher a função de codificação a ser utilizada é uma tarefa que envolve um compromisso entre vários fatores, já que a função de codificação modifica a dinâmica do mapa utilizado, e, dependendo da escolha, dificulta ou facilita a equalização. Utilizando (4.24) e (4.26) (página 42), a dinâmica do sistema com o mapa de Hénon pode ser escrita como

$$
\mathbf{x}(n+1)=\left[\begin{array}{ll}
0 & 1 \\
\beta & 0
\end{array}\right] \mathbf{x}(n)+\left[\begin{array}{l}
1 \\
0
\end{array}\right]+\left[\begin{array}{c}
-\alpha s^{2}(n) \\
0
\end{array}\right]
$$

Considerando que, com $s(n)=x_{1}(n)$, obtém-se o mapa de Hénon original, é interessante encontrar uma função de codificação que não modifique $s^{2}(n)$ em relação a $x_{1}^{2}(n)$ para manter a dinâmica original do mapa de Hénon. Desse ponto de vista, a multiplicação parece ser a função de codificação ideal para o caso de uma mensagem binária e polar mas apresenta problemas quanto ao desempenho do sistema na presença de ruído, como visto no Capítulo 4 . 
Para manter a dinâmica original do mapa de Hénon usando a função (5.1), baseada na soma, é necessário escolher o menor valor possível para $\gamma$. Isso dificulta a equalização, pois, ao utilizar um valor de $\gamma$ pequeno, uma pequena variação no sinal $\widehat{s}(n)$ causa uma grande variação no sinal $\widehat{m}(n)$, devido à divisão por $\gamma$ na função de decodificação (5.2). Para valores maiores de $\gamma$, há a perda da DSCI e a mensagem vai se tornando mais aparente.

Considerando a função de codificação (5.3), há um conjunto maior de possíveis valores dos parâmetros $\gamma_{1}$ e $\gamma_{2}$ que possibilitam a geração de sinais com DSCI No entanto, calculando-se um algoritmo baseado no NLMS para esse caso, foram feitos testes considerando o conjunto de parâmetros que geram sinais com DSCI e verificou-se que o algoritmo de equalização não apresenta um bom desempenho com essa codificação. Isso ocorre provavelmente devido à dinâmica não linear utilizada no sistema de comunicação, que faz com que a função custo fique com mínimos locais, o que pode dificultar a convergência para a solução ótima. No entanto, para explicar o motivo desse comportamento do algoritmo, é necessário fazer uma análise teórica do sistema, o que será feito em um trabalho futuro.

Uma forma de contornar o problema é considerar outras funções de codificação, a partir de (5.3). Assim, a fim de obter um sistema que permitisse a geração de sinais com DSCI para um conjunto maior de parâmetros $\gamma_{1}$ e $\gamma_{2}$, foi proposta a função de codificação

$$
s(n)=\gamma_{1} x_{1}(n)-\gamma_{2}[m(n)+1] \operatorname{sign}\left[\gamma_{1} x_{1}(n)\right]
$$

sendo sign[.] definida por (4.20), na página 41. Com essa função, $|s(n)|$ fica menor ou igual a $\left|x_{1}(n)\right|$, ao menos quando $\operatorname{sign}[s(n)]$ permanece igual ao $\operatorname{sign}\left[x_{1}(n)\right]$. Quando $m(n)=-1$,

$$
s(n)=\gamma_{1} x_{1}(n)
$$

e, escolhendo-se $0 \leq \gamma_{1} \leq 1$, obtém-se $|s(n)| \leq\left|x_{1}(n)\right|$. Quando $m(n)=1$,

$$
s(n)=\gamma_{1} x_{1}(n)-2 \gamma_{2} \operatorname{sign}\left[\gamma_{1} x_{1}(n)\right]
$$

Nesse caso, se $\operatorname{sign}[s(n)]$ permanecer igual ao $\operatorname{sign}\left[\gamma_{1} x_{1}(n)\right],|s(n)|<\left|x_{1}(n)\right|$. Caso contrário, quando $2 \gamma_{2}$ é maior que $\left|\gamma_{1} x_{1}(n)\right|, s(n)$ fica com sinal contrário ao de $\gamma_{1} x_{1}(n)$. Consequentemente, pode acontecer de $|s(n)|$ ficar maior que $\left|x_{1}(n)\right|$ mas $|s(n)|$ ainda é limitado por $2 \gamma_{2}$.

Na Figura 5.2, são apresentados resultados análogos aos da Figura 5.1 mas utilizando a função de codificação (5.6). Como pode ser observado, usando (5.6), é possível obter uma conjunto maior de valores de $\gamma_{1}$ e $\gamma_{2}$ que permitem a geração de sinais com DSCI. Além disso, nesse caso, há um subconjunto de valores de $\gamma_{1}$ e $\gamma_{2}$ que possibilitam o funcionamento 


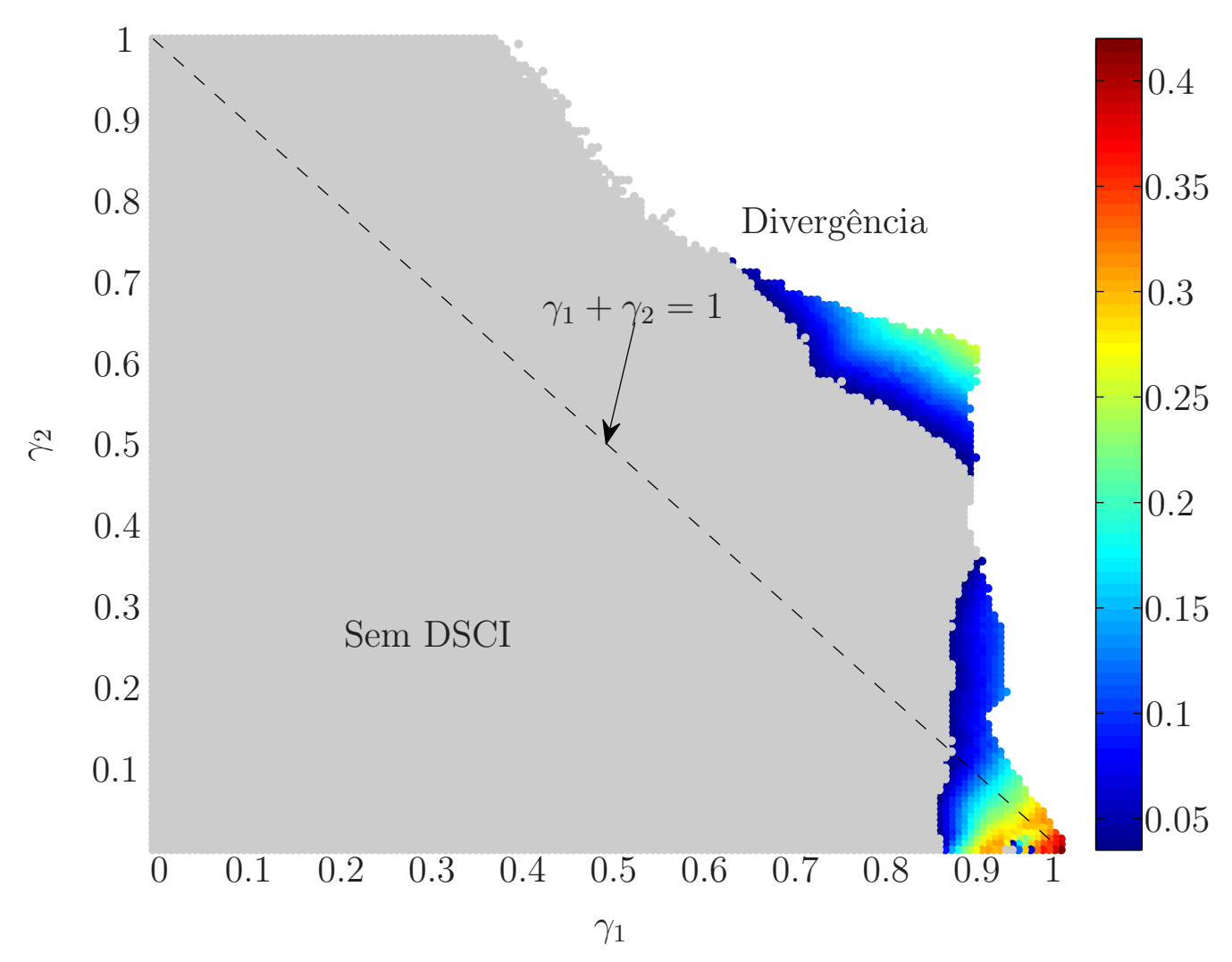

Figura 5.2: Máximo expoente de Lyapunov obtido no transmissor utilizando a função de codificação (5.6), em função dos parâmetros $\gamma_{1}$ e $\gamma_{2}$. A área cinza indica que o máximo expoente de Lyapunov é negativo. A área branca indica que houve divergência no transmissor.

adequado do equalizador conforme será mostrado na Seção 5.3 .

Os parâmetros $\gamma_{1}$ e $\gamma_{2}$ da função (5.6) podem ser variantes no tempo, desde que sejam conhecidos no receptor para permitir a recuperação correta da mensagem. Usar parâmetros variantes no tempo possibilita escolher conjuntos de parâmetros $\gamma_{1}$ e $\gamma_{2}$ e fazer o chaveamento entre eles de acordo com a situação. Por exemplo, utilizando a Figura 5.2, pode-se escolher valores de $\gamma_{1}$ e $\gamma_{2}$ para codificar a mensagem gerando um sinal $s(n)$ que apresenta as propriedades desejadas nos sistemas de comunicação baseados em caos, como a DSCI. Como um segundo conjunto de parâmetros, pode-se escolher $\gamma_{1}=0$ e $\gamma_{2}=1$, de forma a obter o sinal $s(n)$ sem a influência do GSC, o que é equivalente a utilizar um sistema de comunicação convencional, o que pode facilitar a equalização. Dados os dois conjuntos de parâmetros, um para a utilização do sistema de comunicação baseado em caos e o outro para a utilização do sistema de forma convencional, é possível fazer o chaveamento entre os dois modos de operação de acordo com o comportamento do canal. Considerando os parâmetros da função de codificação 
variantes no tempo, o sinal transmitido é dado por

$$
s(n)=\gamma_{1}(n) x_{1}(n)-\gamma_{2}(n)[m(n)+1] \operatorname{sign}\left[\gamma_{1}(n) x_{1}(n)\right]
$$

E, no receptor, a mensagem pode ser recuperada calculando

$$
\widehat{m}(n)=\frac{\gamma_{1}(n) \widehat{x}_{1}(n)-\widehat{s}(n)}{\gamma_{2}(n) \operatorname{sign}\left[\gamma_{1}(n) \widehat{x}_{1}(n)\right]}-1
$$

Vale notar que, para que esse esquema funcione corretamente, é necessário que o receptor conheça de antemão os parâmetros $\gamma_{1}(n)$ e $\gamma_{2}(n)$. No entanto, desde que haja um canal de retorno do receptor para o transmissor, pode ser utilizado um protocolo para a escolha entre os modos de operação, de forma semelhante à utilizada para a escolha da modulação em sistemas de transmissão de dados sem fio como o IEEE 802.11 (Wi-Fi) [Kurose e Ross, 2013]. Nas simulações utilizando parâmetros variantes no tempo, considera-se que o receptor conhece os parâmetros $\gamma_{1}(n)$ e $\gamma_{2}(n)$.

\section{$5.2 \mathrm{O}$ algoritmo $\mathrm{cNLMS}_{+}$}

O gradiente da função custo $\widehat{C}(n)$ (definida por (4.9) na página 39) em relação ao vetor de coeficientes $\mathbf{w}(n-1)$, é dado por

$$
\boldsymbol{\nabla}_{\mathbf{w}} \widehat{C}(n)=2 e(n) \frac{\partial e(n)}{\partial \mathbf{w}(n-1)}=-2 e(n) \frac{\partial \widehat{m}(n)}{\partial \mathbf{w}(n-1)} .
$$

Levando-se em conta o equalizador no sistema de comunicação, com saída $\widehat{s}(n)=\mathbf{r}^{\mathrm{T}}(n) \mathbf{w}(n-1)$, (5.10) pode ser reescrita como

$$
\widehat{m}(n)=\frac{\gamma_{1}(n) \widehat{x}_{1}(n)-\mathbf{r}^{\mathrm{T}}(n) \mathbf{w}(n-1)}{\gamma_{2}(n) \operatorname{sign}\left[\gamma_{1}(n) \widehat{x}_{1}(n)\right]}-1
$$

Usando (5.12) e assumindo que $\widehat{x}_{1}(n)$ não depende de $\mathbf{w}(n-1)$, chega-se a

$$
\boldsymbol{\nabla}_{\mathbf{w}} \widehat{C}(n)=-2 \frac{e(n)}{\gamma_{2}(n) \operatorname{sign}\left[\gamma_{1}(n) \widehat{x}_{1}(n)\right]}\left[-\frac{\partial \widehat{s}(n)}{\partial \mathbf{w}(n-1)}\right]=2 \frac{e(n)}{\gamma_{2}(n) \operatorname{sign}\left[\gamma_{1}(n) \widehat{x}_{1}(n)\right]} \mathbf{r}(n) .
$$

A partir do gradiente, chega-se à equação de adaptação do algoritmo LMS caótico para a codificação com soma $\left(\underline{\mathrm{cLMS}}_{+}\right)$, dada por

$$
\mathbf{w}(n)=\mathbf{w}(n-1)-\mu \frac{e(n)}{\gamma_{2}(n) \operatorname{sign}\left[\gamma_{1}(n) \widehat{x}_{1}(n)\right]} \mathbf{r}(n) .
$$


A fim de se obter uma versão normalizada do $\underline{\mathrm{CLMS}}_{+}$, é definido o erro a posteriori como

$$
e_{p}(n)=m(n-\Delta)-\frac{\gamma_{1}(n) \widehat{x}_{1}(n)-\mathbf{r}^{\mathrm{T}}(n) \mathbf{w}(n)}{\gamma_{2}(n) \operatorname{sign}\left[\gamma_{1}(n) \widehat{x}_{1}(n)\right]}+1
$$

Usando-se (5.14) com $\mu(n)$ em vez de $\mu, e_{p}(n)$ pode ser reescrito como

$$
\begin{aligned}
e_{p}(n) & =m(n-\Delta)-\frac{\gamma_{1}(n) \widehat{x}_{1}(n)-\mathbf{r}^{\mathrm{T}}(n)\left[\mathbf{w}(n-1)-\mu(n) \frac{e(n)}{\gamma_{2}(n) \operatorname{sign}\left[\gamma_{1}(n) \widehat{x}_{1}(n)\right]} \mathbf{r}(n)\right]}{\gamma_{2}(n) \operatorname{sign}\left[\gamma_{1}(n) \widehat{x}_{1}(n)\right]}+1 \\
& =e(n)\left[1-\mu(n) \frac{\|\mathbf{r}(n)\|^{2}}{\gamma_{2}^{2}(n) \operatorname{sign}^{2}\left[\gamma_{1}(n) \widehat{x}_{1}(n)\right]}\right] .
\end{aligned}
$$

Para se garantir que $e_{p}(n)=0$ a cada iteração $n$, deve-se fazer

$$
\mu(n)=\frac{\gamma_{2}^{2}(n) \operatorname{sign}^{2}\left[\gamma_{1}(n) \widehat{x}_{1}(n)\right]}{\|\mathbf{r}(n)\|^{2}}
$$

Introduzindo-se um passo de adaptação fixo $\widetilde{\mu}$ para controlar a velocidade de convergência e um fator de regularização $\delta$ para evitar a divisão por zero no cálculo de $\mu(n)$ e substituindo-se o passo de adaptação resultante em (5.14), obtém-se a equação de atualização do cNLMS $_{+}$, dada por

$$
\mathbf{w}(n)=\mathbf{w}(n-1)-\frac{\widetilde{\mu}}{\delta+\|\mathbf{r}(n)\|^{2}} \gamma_{2}(n) \operatorname{sign}\left[\gamma_{1}(n) \widehat{x}_{1}(n)\right] e(n) \mathbf{r}(n) .
$$

Vale notar que, com a função de codificação (5.9), um erro no sinal de $\operatorname{sign}\left[\gamma_{1}(n) \widehat{x}_{1}(n)\right]$ só acarreta erros na decodificação da mensagem para o caso de $m(n)=1$. Nesse caso, substituindo $\widehat{m}(n)=1$ em (5.10), obtém-se

$$
1=\frac{\gamma_{1}(n) \widehat{x}_{1}(n)-\widehat{s}(n)}{\gamma_{2}(n) \operatorname{sign}\left[\gamma_{1}(n) \widehat{x}_{1}(n)\right]}-1 \Rightarrow \operatorname{sign}\left[\gamma_{1}(n) \widehat{x}_{1}(n)\right]=\frac{\gamma_{1}(n) \widehat{x}_{1}(n)-\widehat{s}(n)}{2 \gamma_{2}(n)} .
$$

Então, substituindo (5.19) com o sinal trocado em (5.10), a mensagem recuperada seria

$$
\widehat{m}(n)=\frac{\gamma_{1}(n) \widehat{x}_{1}(n)-\widehat{s}(n)}{\gamma_{2}(n)\left[-\frac{\gamma_{1}(n) \widehat{x}_{1}(n)-\widehat{s}(n)}{2 \gamma_{2}(n)}\right]}-1=\frac{-2\left[\gamma_{1}(n) \widehat{x}_{1}(n)-\widehat{s}(n)\right]}{\gamma_{1}(n) \widehat{x}_{1}(n)-\widehat{s}(n)}-1=-3 .
$$

Assim, é possível identificar quando ocorre um erro na estimativa de $\operatorname{sign}\left[\gamma_{1}(n) \widehat{x}_{1}(n)\right]$, usando a estimativa da mensagem, que deveria ser 1 mas é decodificada como -3 . Para corrigir esse problema, quando $\widehat{m}(n)$ é decodificada no intervalo $-3,5<\widehat{m}(n)<-2,5$, considera-se $\widehat{m}(n) \leftarrow \widehat{m}(n)+4$.

Novamente, para garantir a estabilidade do algoritmo e evitar estimativas erradas quando 
$\widehat{x}_{1}(n)$ for muito grande, é introduzido um limite superior para $\widehat{x}_{1}(n)$, isto é, se $\left|\widehat{x}_{1}(n)\right|>X$, impõe-se $\widehat{x}_{1}(n) \leftarrow X \operatorname{sign}\left[\widehat{x}_{i}(n)\right]$, sendo $X$ uma constante positiva. Fazendo $X=100$, não foi observada degradação no desempenho do algoritmo em diversos cenários de simulação.

\subsubsection{Condições de estabilidade}

Usando (5.12), a equação de adaptação do $\mathrm{CNLMS}_{+}$pode ser reescrita como

$$
\begin{aligned}
\mathbf{w}(n)= & {\left[\mathbf{I}-\frac{\widetilde{\mu}}{\delta+\|\mathbf{r}(n)\|^{2}} \mathbf{r}(n) \mathbf{r}^{\mathrm{T}}(n)\right] \mathbf{w}(n-1) } \\
& -\widetilde{\mu} \gamma_{2}(n) \operatorname{sign}\left[\gamma_{1}(n) \widehat{x}_{1}(n)\right] m(n-\Delta) \frac{\mathbf{r}(n)}{\delta+\|\mathbf{r}(n)\|^{2}} \\
& +\widetilde{\mu} \gamma_{1}(n) \widehat{x}_{1}(n) \frac{\mathbf{r}(n)}{\delta+\|\mathbf{r}(n)\|^{2}} \\
& -\widetilde{\mu} \gamma_{2}(n) \operatorname{sign}\left[\gamma_{1}(n) \widehat{x}_{1}(n)\right] \frac{\mathbf{r}(n)}{\delta+\|\mathbf{r}(n)\|^{2}}
\end{aligned}
$$

Novamente, a matriz entre colchetes é idêntica à obtida na Seção 3.3. Assim, para permitir a convergência do algoritmo é necessário escolher o passo de adaptação no intervalo

$$
0<\widetilde{\mu}<2
$$

As normas da segunda, terceira e quarta parcelas do lado direito de (5.21) são limitadas isto é,

$$
\begin{gathered}
0 \leq \widetilde{\mu} \gamma_{2}(n)\left|\operatorname{sign}\left[\gamma_{1}(n) \widehat{x}_{1}(n)\right]\right||m(n-\Delta)| \frac{\|\mathbf{r}(n)\|}{\delta+\|\mathbf{r}(n)\|^{2}} \leq \widetilde{\mu} \gamma_{2}(n) \frac{\sqrt{\delta}}{2 \delta}<\infty, \\
0 \leq \widetilde{\mu} \gamma_{1}(n)\left|\widehat{x}_{1}(n)\right| \frac{\|\mathbf{r}(n)\|}{\delta+\|\mathbf{r}(n)\|^{2}} \leq \widetilde{\mu} \gamma_{1}(n) X \frac{\sqrt{\delta}}{2 \delta}<\infty
\end{gathered}
$$

e

$$
0 \leq \widetilde{\mu} \gamma_{2}(n)\left|\operatorname{sign}\left[\gamma_{1}(n) \widehat{x}_{1}(n)\right]\right| \frac{\|\mathbf{r}(n)\|}{\delta+\|\mathbf{r}(n)\|^{2}} \leq \widetilde{\mu} \gamma_{2}(n) \frac{\sqrt{\delta}}{2 \delta}<\infty .
$$

Portanto, de forma semelhante à mostrada na Seção 3.3, conclui-se que o algoritmo cNLMS não diverge se $\widetilde{\mu}$ for escolhido no intervalo (5.22) [Havkin, 2002].

Com base nesses resultados, é proposto ao algoritmo mostrado na Tabela 5.1 . 
Tabela 5.1: Algoritmo $\mathrm{cNLMS}_{+}$considerando o mapa de Hénon.

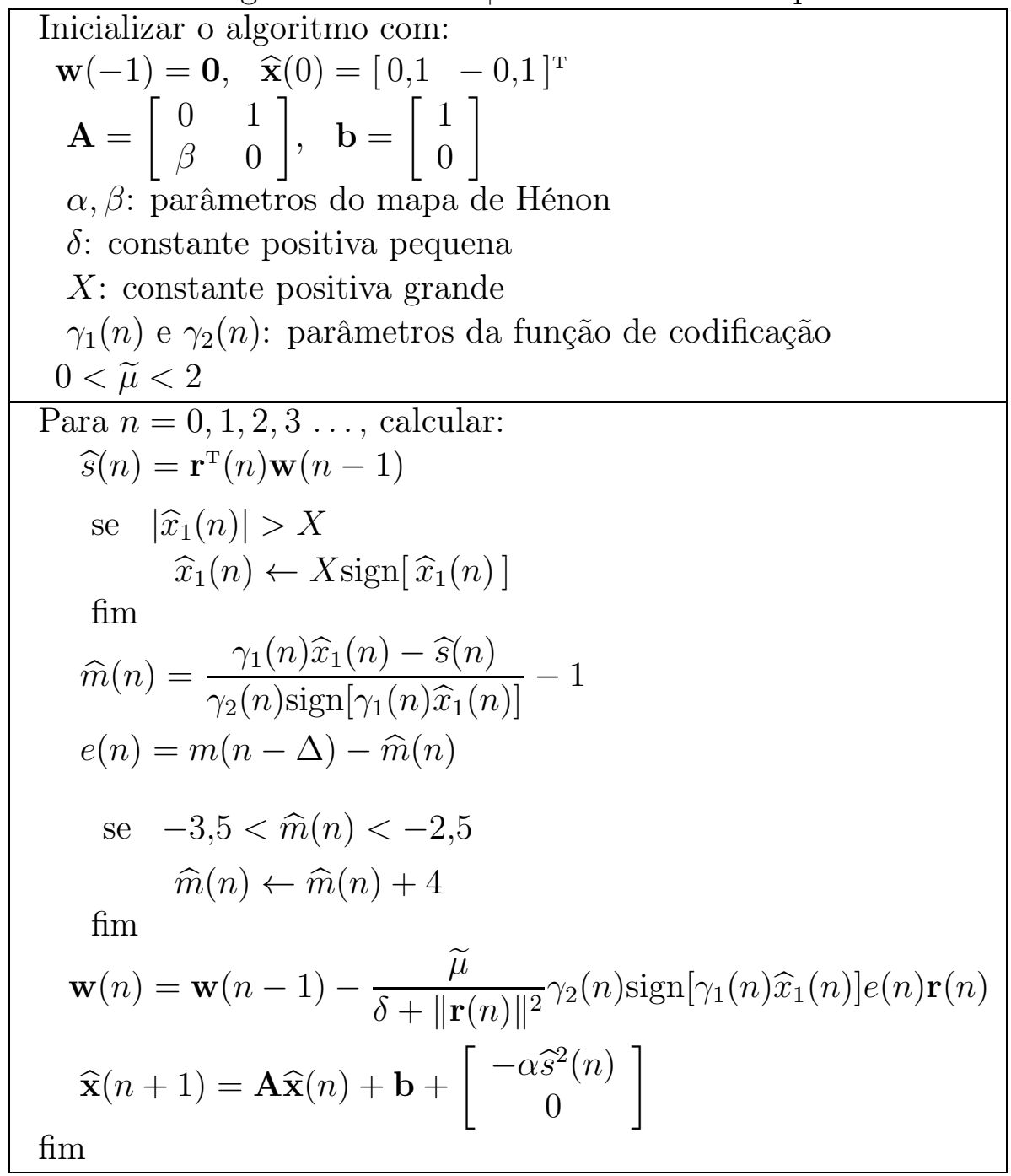

\subsection{A escolha dos parâmetros da codificação com soma}

Para que o sistema com o equalizador funcione corretamente, é necessário escolher os parâmetros $\gamma_{1}(n)$ e $\gamma_{2}(n)$ de forma adequada na função de codificação (5.9). Devido à dinâmica não linear utilizada no sistema de comunicação, a função custo fica com mínimos locais e, para alguns conjuntos de parâmetros, o equalizador não funciona corretamente. A fim de escolher os parâmetros de modo a gerar sinais com DSCI pelo transmissor, foi testado o sistema de comunicação com os parâmetros no intervalo mostrado na Figura 5.2, com o Canal 3 da Tabela 3.1 (página 30). Foi utilizado um equalizador com $M=12$ coeficientes e foi considerado o atraso de $\Delta=7$ amostras. Considerou-se que o equalizador funcionava corretamente quando o EMSE obtido era menor que $-20 \mathrm{~dB}$. Na Figura 5.3, é indicada a área referente ao subconjunto de $\gamma_{1}$ e $\gamma_{2}$ que permitiu a obtenção do EMSE menor que $-20 \mathrm{~dB}$ e a geração de sinais 
com DSCI. Dado esse resultado, uma possível escolha dos parâmetros para o funcionamento no regime caótico é

$$
\gamma_{1}(n)=0,9 \text { e } \gamma_{2}(n)=0,3
$$

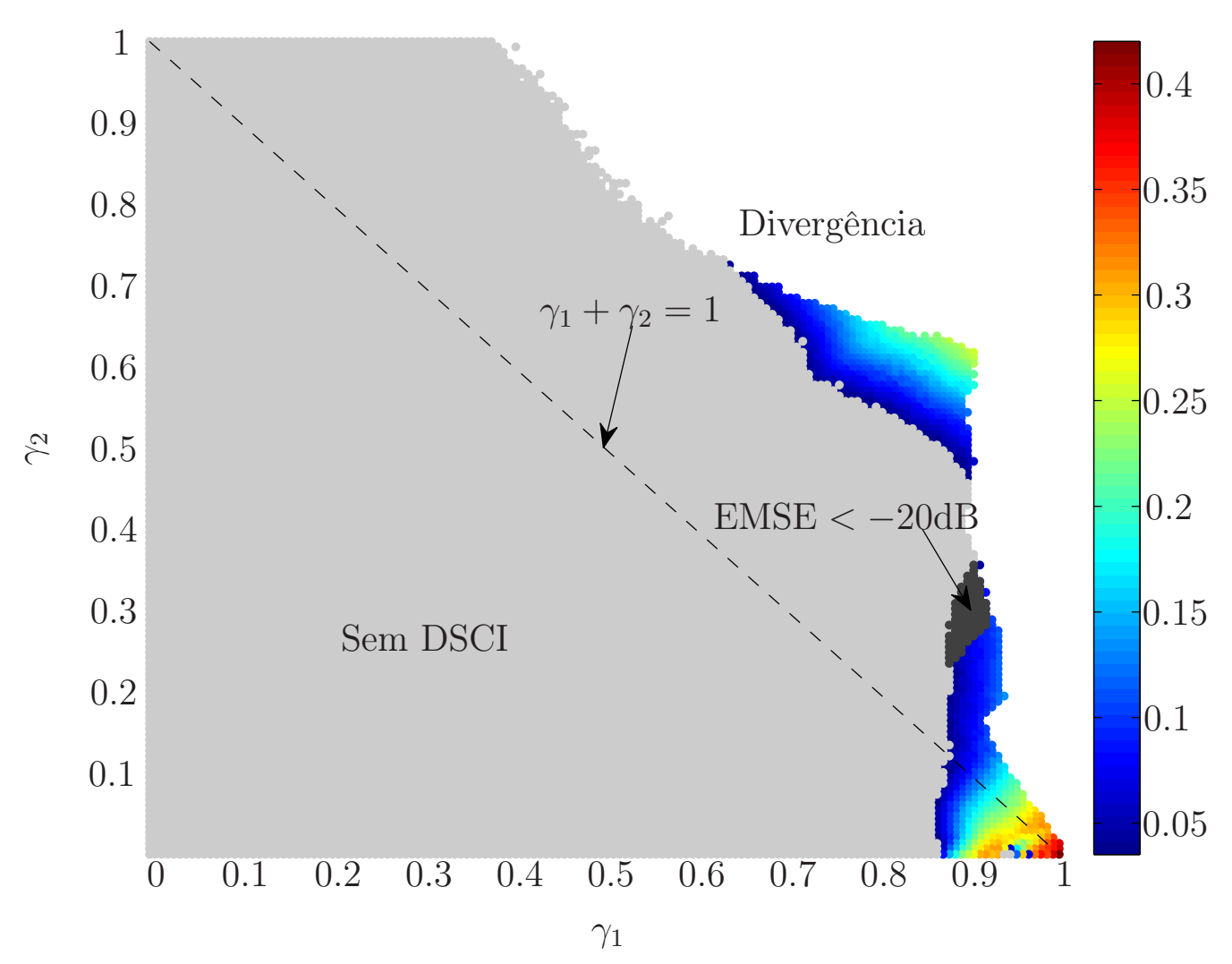

Figura 5.3: Indicação da área onde é possível equalizar o Canal 3 com a função de codificação (5.9) e obter EMSE $<-20 \mathrm{~dB}$ escolhendo $\gamma_{1}$ e $\gamma_{2}$ de forma a obter sinais com DSCI $(\widetilde{\mu}=0,02$; $\left.\delta=10^{-2} ; M=12 ; \Delta=7\right)$.

Considerando $\gamma_{1}(n)$ e $\gamma_{2}(n)$ constantes, com $\gamma_{2}=0,3$, na Figura 5.4 são mostrados o máximo expoente de Lyapunov e o diagrama de bifurcação do sinal $x_{1}(n)$ em função de $\gamma_{1}$. Na Figura 5.4-(a), é possível notar que o máximo expoente de Lyapunov fica positivo para valores de $\gamma_{1}$ a partir de aproximadamente 0,86 , o que coincide com o resultado mostrado na Figura 5.2. Apesar de não apresentar DSCI, o sinal $x_{1}(n)$ mostrado na Figura 5.4t(b) é aperiódico para os valores de $\gamma_{1}$ considerados. Entre $\gamma_{1}=0,5$ e $\gamma_{1}=0,8, x_{1}(n)$ parece ser periódico devido ao conjunto finito de linhas aparente na figura. Porém, essas linhas constituem um artefato devido à utilização de apenas 100 pontos de $x_{1}(n)$ para cada $\gamma_{1}$, a fim de facilitar a visualização. É possível perceber que essas linhas fazem parte de intervalos contínuos nas Figuras 5.5-(a) e (b), onde são mostrados os sinais $x_{1}(n)$ ao longo das iterações considerando $\gamma_{1}=0,05$ e $\gamma_{1}=0,6$. Na Figura 5.4 (c), é mostrado o detalhe do diagrama de 
bifurcação para 0,8 $<\gamma_{1}<0,93$ e, na Figura 5.5-(c) é mostrado o sinal $x_{1}(n)$ ao longo das iterações considerando $\gamma_{1}=0,92$. Pelo resultado do diagrama de bifurcação, é possível notar que $x_{1}(n)$ é aperiódico e, para $0<\gamma_{1}<0,86$ varia de forma suave conforme $\gamma_{1}$ varia. Para $\gamma_{1}>0,86$, uma pequena variação no valor de $\gamma_{1}$ gera um sinal $x_{1}(n)$ completamente diferente.

Um fato curioso acontece para $\gamma_{1} \approx 0,24$, quando $x_{1}(n)$ fica constante, mesmo com o sinal $m(n)$ sendo aleatório. Isso ocorre pois o valor de $s^{2}(n)$, que é realimentado na dinâmica do GSC, obtido com $m(n)=1$ fica igual ao valor obtido quando $m(n)=-1$. Considerando $x_{1}(n)>0$, usando $(5.9)$ e calculando

$$
\left.s^{2}(n)\right|_{m(n)=-1}=\left.s^{2}(n)\right|_{m(n)=1}
$$

obtém-se

$$
\left[\gamma_{1} x_{1}(n)\right]^{2}=\left[\gamma_{1} x_{1}(n)-2 \gamma_{2}\right]^{2}
$$

Considerando $\gamma_{2}=0,3$ e resolvendo (5.28) para $\gamma_{1} x_{1}(n)$, chega-se a $\gamma_{1} x_{1}(n)=0,3$. Assim, com $\gamma_{1}(n) \approx 0,24, x_{1}(n) \approx 1,25$, conforme mostrado na Figura 5.4-(b). Como $x_{1}(n)>0$, $\gamma_{1} x_{1}(n)=0,3$ e $\gamma_{2}=0,3$, usando (5.9),

$$
s(n)=\left\{\begin{array}{ll}
0,3 & \text { se } m(n)=-1 \\
-0,3 & \text { se } m(n)=1
\end{array},\right.
$$

ou seja, $s(n)$ será uma versão atenuada e invertida da mensagem $m(n)$.

Como comentado na Seção 5.1, é interessante considerar também um conjunto de parâmetros para que seja possível obter $s(n)$ sem a influência do GSC, fazendo $\gamma_{1}=0$. Na prática, é interessante escolher $\gamma_{2}$ de forma que a potência do sinal $s(n)$ gerado seja igual à potência do sinal gerado quando se utiliza o conjunto de parâmetros para o regime caótico.

Usando os parâmetros (5.26), $s(n)$ fica com potência igual a 0,21. Assim, considerando uma mensagem aleatória e equiprovável $m(n) \in\{-1,1\}$ e fazendo $\gamma_{1}=0$, pode-se obter $s(n)$ com potência igual a 0,21 , com

$$
\gamma_{1}(n)=0 \text { e } \gamma_{2}(n)=\sqrt{0,21}=0,46
$$

Nesse caso, o sinal $s(n)$ obtido fica composto apenas pela mensagem a ser transmitida, atenuada pelo fator $\gamma_{2}(n)$. 

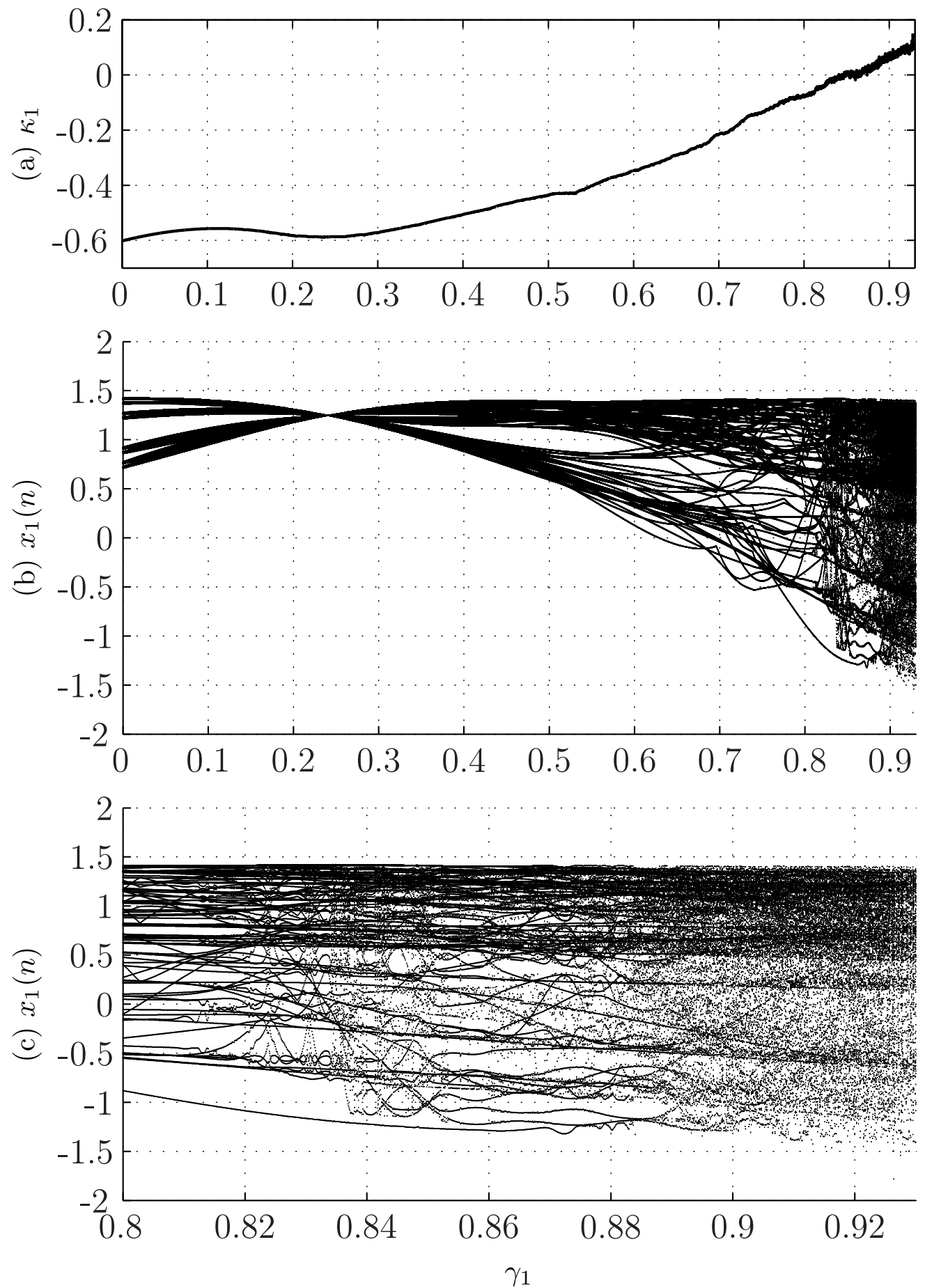

Figura 5.4: Transmissor com o mapa de Hénon e a codificação (5.6) com $\gamma_{2}=0,3$ : (a) Máximo expoente de Lyapunov $\kappa_{1}$ em função de $\gamma_{1}$, (b) diagrama de bifurcação considerando os últimos 100 valores de $x_{1}(n)$ para $0<\gamma_{1}<0,93$ e (c) detalhe de (b) para $0,8<\gamma_{1}<0,93$. 

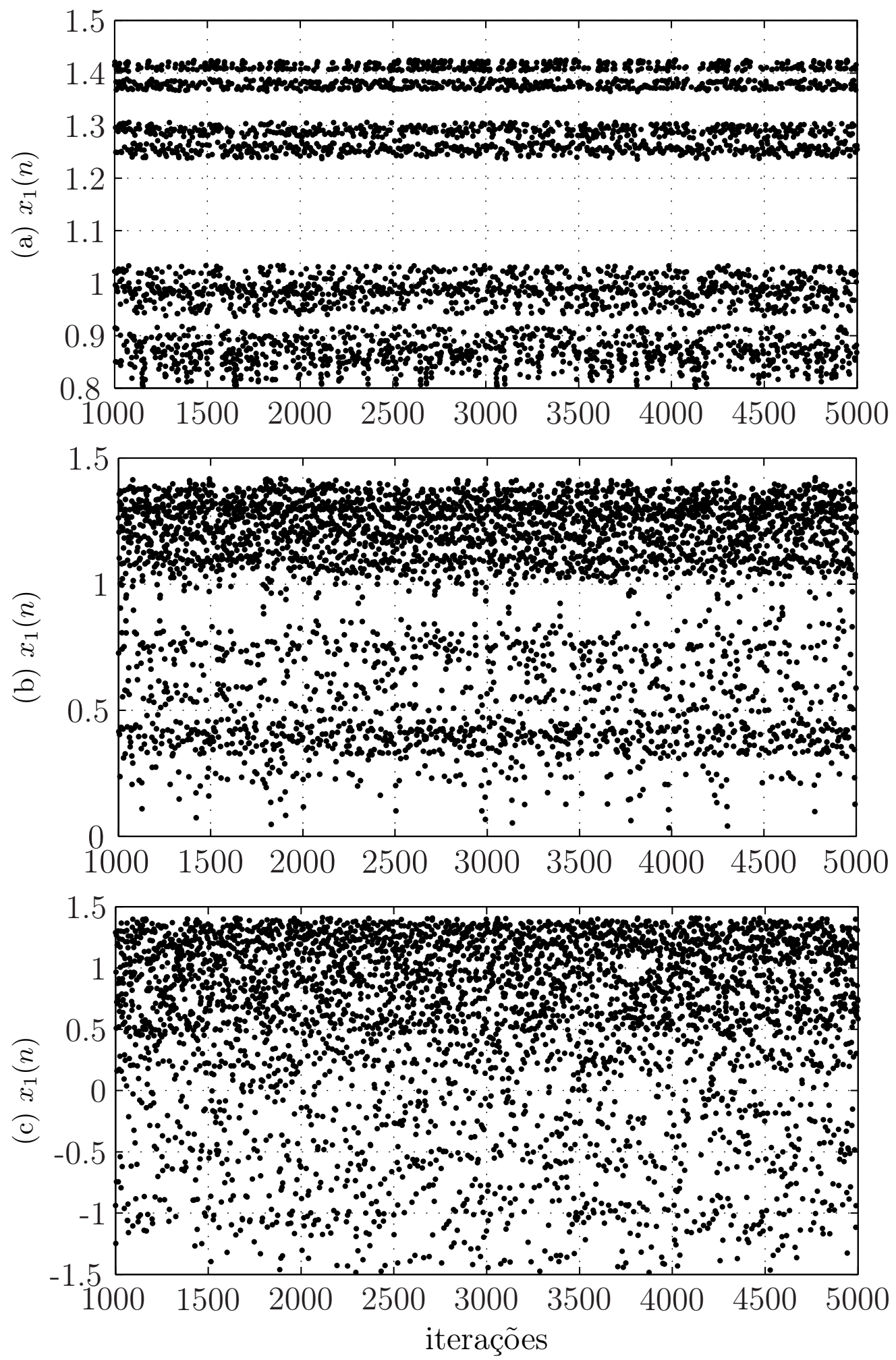

Figura 5.5: Sinal $x_{1}(n)$ considerando o mapa de Hénon e a codificação (5.6) $\operatorname{com} \gamma_{2}=0,3$ e (a) $\gamma_{1}=0,05$, (b) $\gamma_{1}=0,6$ e (b) $\gamma_{1}=0,92$. 


\subsection{Resultados de simulação}

Nesta seção, são apresentados resultados de simulação para verificar o comportamento do algoritmo $\mathrm{cNLMS}_{+}$no sistema com o mapa de Hénon. A fim de comparar o desempenho do sistema que utiliza a codificação com a soma com o desempenho do sistema que utiliza a codificação com a multiplicação, foram utilizados cenários semelhantes aos apresentados anteriormente. Para o mapa de Hénon, foram considerados os parâmetros $\alpha=1,4$ e $\beta=0,3$ [Hénon, 1976] e os vetores de estados foram inicializados com $\mathbf{x}(0)=\mathbf{0}$ e $\widehat{\mathbf{x}}(0)=[0,1-0,1]^{\mathrm{T}}$, respectivamente. A codificação de $s(n)$ foi feita utilizando a função (5.9), $\operatorname{com} \gamma_{1}(n)=0,9$ e $\gamma_{2}(n)=0,3$ para todo $n$. Os canais de comunicação utilizados estão listados na Tabela 3.1, na página 30.

Inicialmente é considerada a transmissão de uma sequência binária equiprovável $m(n) \in$ $\{-1,1\}$ através do Canal 1 (IIR), com $\Delta=0$, na ausência de ruído. A mensagem estimada utilizando o equalizador CNLMS $_{+}$e o erro após o decisor (ambos para uma única realização) são mostrados nas Figuras 5.6-(b) e (c). A média dos dois coeficientes e o EMSE ao longo das iterações, estimados por uma média de 1000 realizações, são mostrados respectivamente nas Figuras 5.6-(d) e (e). Como pode ser notado, o algoritmo cNLMS $_{+}$converge para a solução ótima $\mathbf{w}_{\mathrm{o}}$, indicada pelas linhas tracejadas na Figuras 5.6 (c) e o equalizador é capaz de recuperar adequadamente a sequência transmitida, o que pode ser confirmado por meio dos erros após o decisor mostrados na Figura 5.6-(c). O EMSE diminui a cada iteração à medida que os coeficientes do equalizador ficam mais próximos dos coeficientes da solução ótima de Wiener, da mesma forma como ocorreu quando se utilizou a codificação com a multiplicação. Novamente, na ausência do equalizador, a comunicação não é possível, como mostrado na Figura $5.6+(\mathrm{a})$.

Em seguida, é considerado o caso da variação abrupta do canal, na ausência de ruído, em que $s(n)$ é inicialmente transmitido através do Canal 2 e, em $n=30 \times 10^{3}$, é feita uma alteração abrupta para o Canal 3. Para ambos os canais, é utilizado um equalizador com $M=12$ coeficientes e um atraso de $\Delta=7$ amostras.

Os resultados para essa situação são mostrados na Figura 5.7. Novamente, o cNLMS + converge para a solução de ótima de Wiener, cujos coeficientes são mostrados pelas linhas tracejadas na Figura 5.7 (d). Pode-se notar que o cNLMS + é capaz de acompanhar a variação abrupta no canal, atingindo o estado estacionário novamente. Como no caso da codificação com multiplicação, o equalizador tem um papel importante antes da variação abrupta do canal, já que o desempenho do sistema sem o equalizador é muito prejudicado como pode ser observado na Figura 5.7-(a). Além disso, no caso da codificação com a soma, pode-se notar que o desempenho apresentado com $M=12$ coeficientes é mais adequado do que o apresentado 

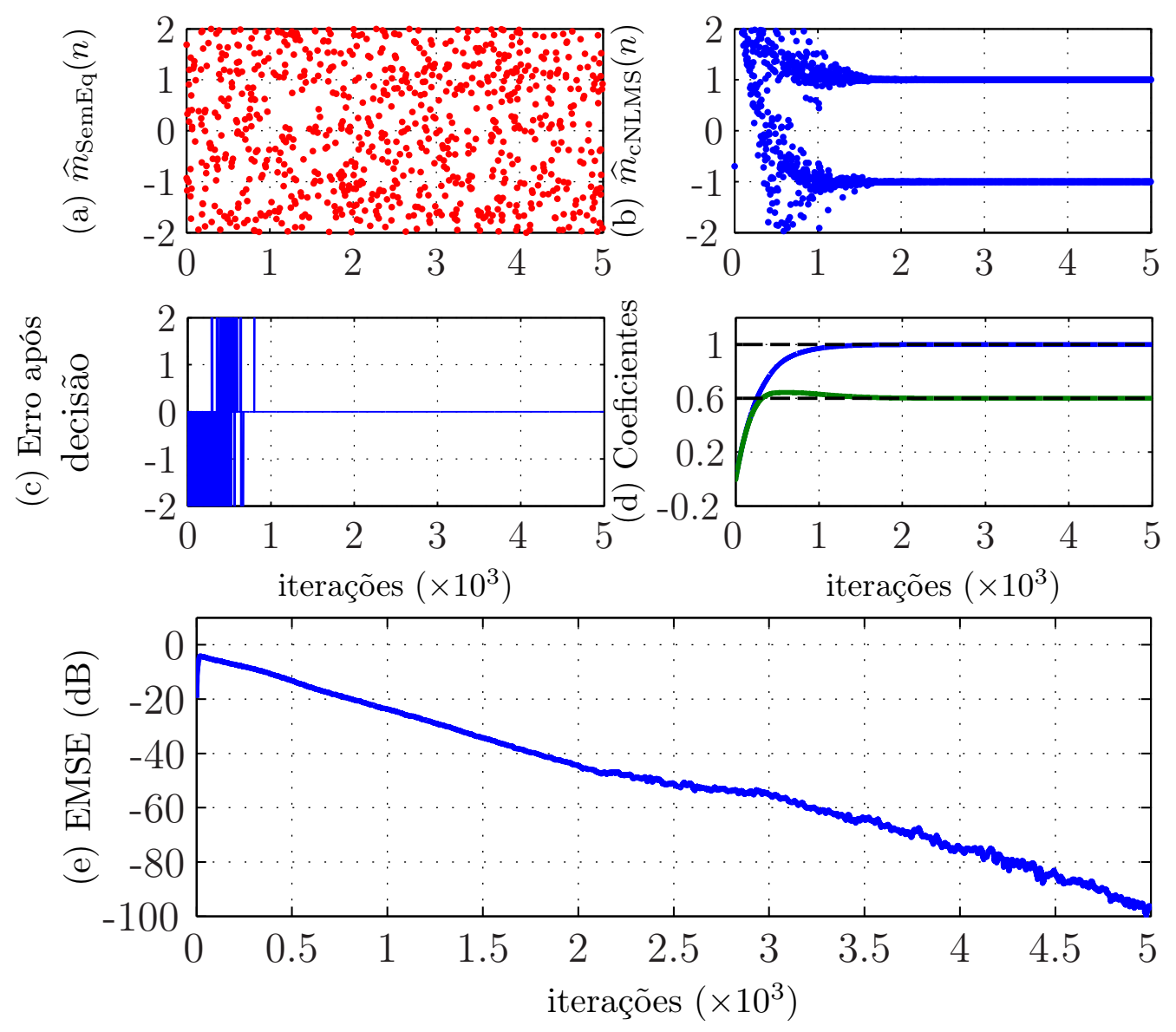

Figura 5.6: Sequência recuperada com o sistema utilizando o mapa de Hénon e codificação com soma $\left(\gamma_{1}(n)=0,9\right.$ e $\left.\gamma_{2}(n)=0,3\right)$ (a) sem equalizador e (b) com uma realização do $\mathrm{cNLMS}_{+}\left(\widetilde{\mu}=0,01 ; \delta=10^{-5} ; M=2 ; \Delta=0\right)$; (c) Erro após decisão; (d) Média dos coeficientes do cNLMS $_{+}$e solução de Wiener (linhas tracejadas); (e) EMSE estimado; média de 1000 realizações; Canal 1.

com a codificação com a multiplicação, o que pode ser observado comparando os erros após a decisão mostrados na Figura 5.7-(c) com os erros após a decisão obtidos quando se utiliza a codificação com a multiplicação, mostrados na Figura 4.7.(c), na página 49. Com $M=25$ coeficientes, o algoritmo cNLMS + não converge para os coeficientes ótimos e não é possível recuperar a mensagem.

Uma desvantagem da utilização da codificação com a soma é a redução da velocidade de convergência do algoritmo como pode ser observado comparando a média dos coeficientes do equalizador, mostrada na Figura 5.7-(d) com o resultado análogo obtido com a codificação utilizando a multiplicação, mostrado na Figura 4.7ł(d), na página 49. Para contornar esse problema, pode-se utilizar os parâmetros $\gamma_{1}(n)$ e $\gamma_{2}(n)$ variantes no tempo e fazer inicialmente a transmissão direta do sinal de mensagem, sem utilizar a codificação no sinal caótico e, após 

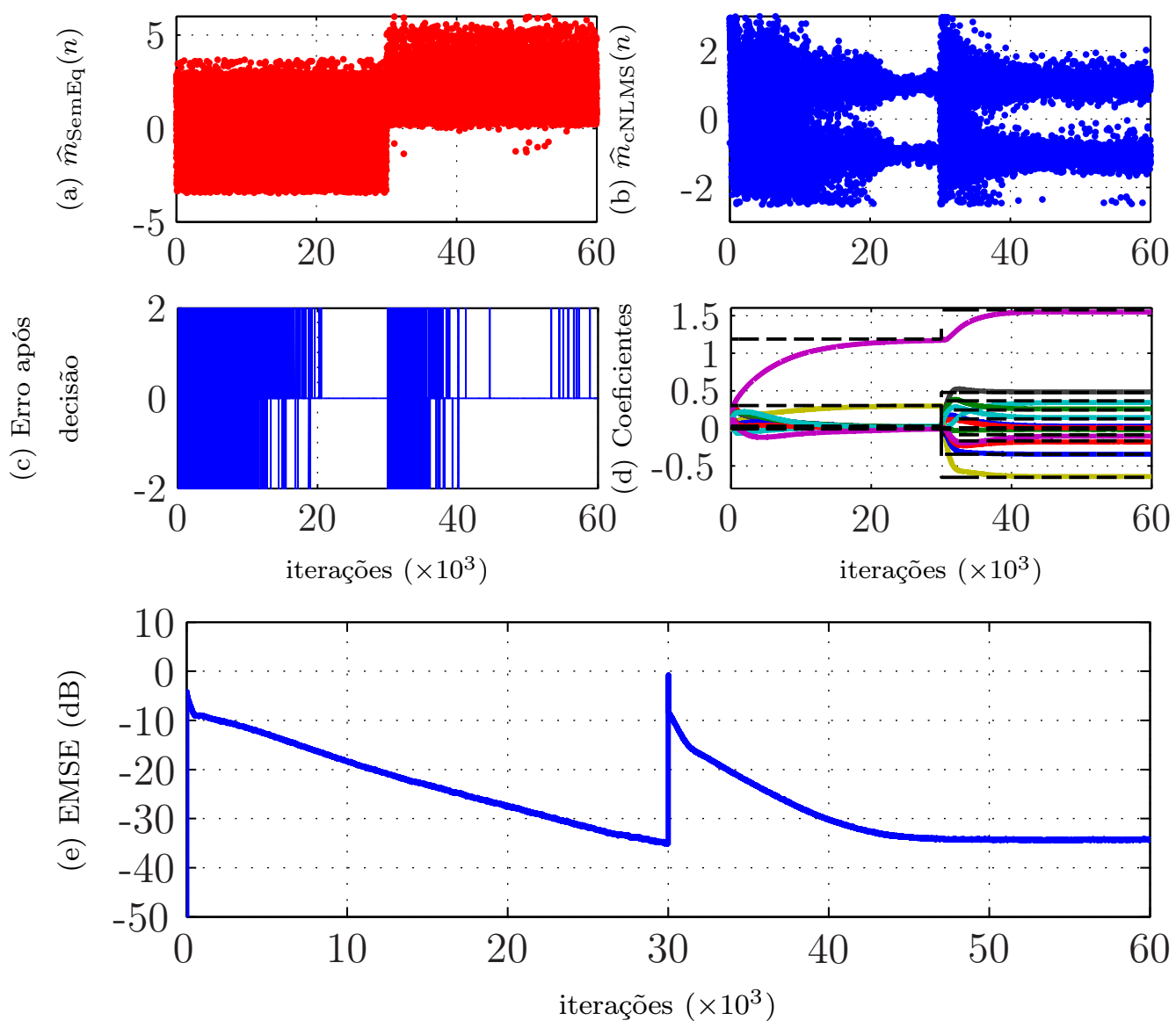

Figura 5.7: Sequência recuperada com o sistema utilizando o mapa de Hénon e codificação com soma $\left(\gamma_{1}(n)=0,9\right.$ e $\left.\gamma_{2}(n)=0,3\right)$ (a) sem equalizador e (b) com o cNLMS $+\left(\widetilde{\mu}=0,02 ; \delta=10^{-2}\right.$; $M=12 ; \Delta=7$ ); (c) Erro após decisão; (d) Média dos coeficientes do cNLMS + e solução de Wiener (linhas tracejadas); (e) EMSE estimado; média de 1000 realizações; variação abrupta do Canal 2 para o Canal 3 em $n=30 \times 10^{3}$.

a convergência dos coeficientes do equalizador, fazer o chaveamento para o regime caótico, com a mensagem codificada no estado $x_{1}(n)$ do GSC. Na Figura 5.8, são mostrados os resultados obtidos no cenário de variação abrupta do canal, quando é utilizado esse esquema de chaveamento com os parâmetros $\gamma_{1}(n)$ e $\gamma_{2}(n)$ variantes no tempo. Nesse caso, foram escolhidos inicialmente $\gamma_{1}(n)=0$ e $\gamma_{2}(n)=0,46$, de forma que o sinal obtido tivesse a mesma potência do sinal obtido com os parâmetros utilizados no regime caótico. Após a convergência dos coeficientes, em $n=15 \times 10^{3}$, foi feito o chaveamento para os parâmetros $\gamma_{1}(n)=0,9$ e $\gamma_{2}(n)=0,3$, obtendo-se o regime caótico. Em $n=30 \times 10^{3}$, após a variação abrupta do canal, foi feito novamente o chaveamento para a transmissão direta da mensagem com $\gamma_{1}(n)=0$ e $\gamma_{2}(n)=0,46$ e, após a convergência para os novos coeficientes, foi feito novamente o chaveamento para o regime caótico com os parâmetros $\gamma_{1}(n)=0,9$ e $\gamma_{2}(n)=0,3$. Para manter a 

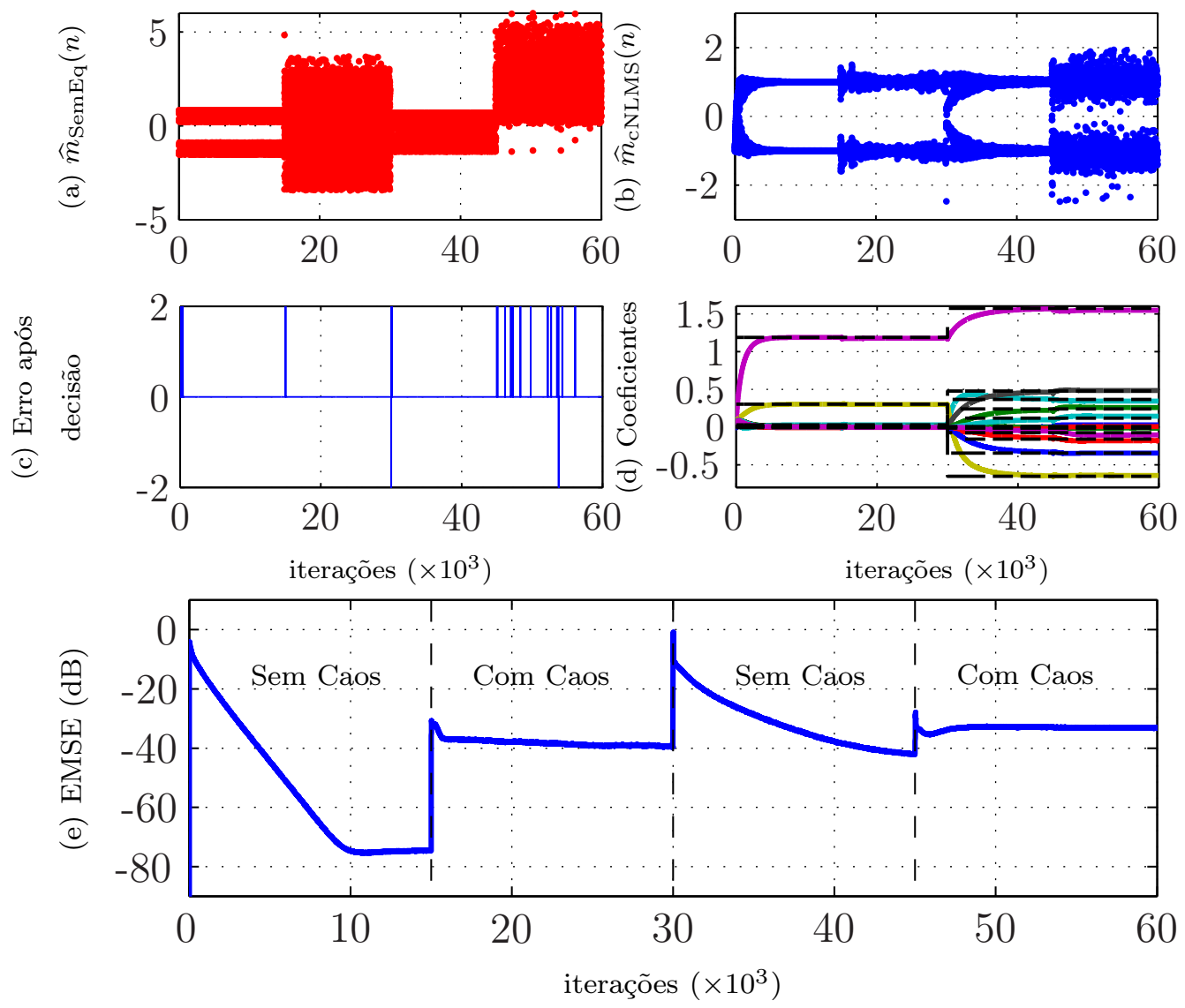

Figura 5.8: Sequência recuperada com o sistema utilizando o mapa de Hénon e codificação com soma considerando o chaveamento entre a transmissão da mensagem sem codificação e a transmissão da mensagem codificada $\left(\gamma_{1}(n)=0\right.$ e $\gamma_{2}(n)=0,46$ para $0<n \leq 15 \times 10^{3}$ e para $30 \times 10^{3}<n \leq 45 \times 10^{3}$ e $\gamma_{1}(n)=0,9$ e $\gamma_{2}(n)=0,3$ para $15 \times 10^{3}<n \leq 30 \times 10^{3}$ e para $45 \times 10^{3}<n \leq 60 \times 10^{3}$ ). Perturbação no vetor de estados do transmissor quando o valor de $\gamma_{1}$ ou $\gamma_{2}$ é alterado. (a) sem equalizador e (b) com o $\operatorname{cNLMS}_{+}\left(\widetilde{\mu}=0,02 ; \delta=10^{-2}\right.$; $M=12 ; \Delta=7$ ); (c) Erro após decisão; (d) Média dos coeficientes do cNLMS + e solução de Wiener (linhas tracejadas); (e) EMSE estimado; média de 1000 realizações; variação abrupta do Canal 2 para o Canal 3 em $n=30 \times 10^{3}$.

DSCI do sistema, no instante de transição dos parâmetros $\gamma_{1}(n)$ e $\gamma_{2}(n)$, foi feita uma perturbação no vetor de estados do transmissor, fazendo $\mathbf{x}(n) \leftarrow \mathbf{x}(n)+\boldsymbol{\epsilon}$, sendo $\boldsymbol{\epsilon}$ um vetor de variáveis aleatórias independentes e identicamente distribuídas uniformemente no intervalo

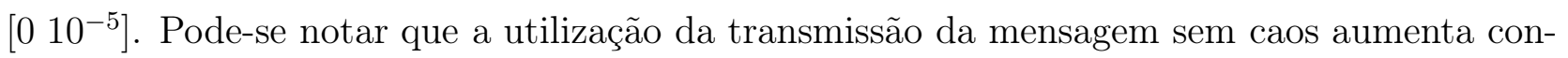
sideravelmente a velocidade de convergência do equalizador no caso do Canal 2 mas não altera significativamente a velocidade de convergência no caso do Canal 3. Para ambos os canais, há uma melhora considerável no desempenho do sistema durante a convergência dos coeficientes do equalizador quando se utiliza a transmissão da mensagem sem caos, como pode ser notado 
por meio dos erros após a decisão mostrados na Figura 5.8 (c). No entanto, vale notar que as características oferecidas pelo sistema de comunicação baseado em caos são perdidas ao se utilizar a transmissão da mensagem sem caos. Após o chaveamento para regime caótico, o desempenho apresentado pelo sistema é semelhante àquele apresentado quando não foi utilizado o chaveamento dos parâmetros $\gamma_{1}(n)$ e $\gamma_{2}(n)$, como pode ser observado comparando os erros após a decisão mostrados nas Figuras 5.8 - (c) e 5.7 - (c).

Para verificar o comportamento do equalizador na presença de um canal variante no tempo, foi considerada a transmissão de $s(n)$ através do Canal 4 na ausência de ruído. Os resultados para esse cenário são mostrados na Figura 5.9. Como no caso da codificação com a multiplicação, o equalizador é capaz de adaptar os coeficientes conforme o canal varia, obtendo uma boa estimativa da solução de Wiener instantânea, mostrada pelas linhas tracejadas na Figura 5.9 -(d).
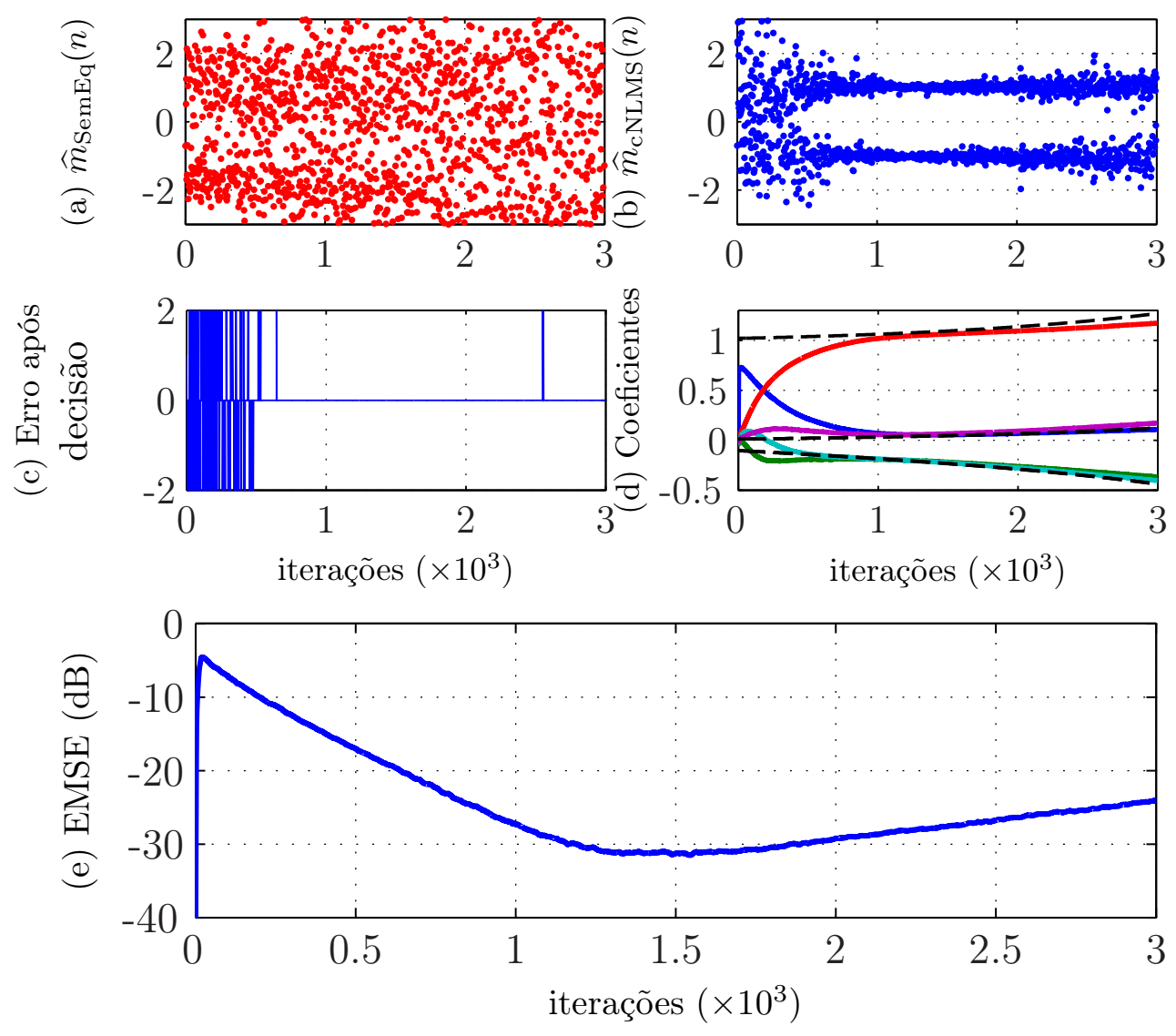

Figura 5.9: Sequência recuperada com o sistema utilizando o mapa de Hénon e codificação com soma $\left(\gamma_{1}(n)=0,9\right.$ e $\left.\gamma_{2}(n)=0,3\right)$ (a) sem equalizador e (b) com o cNLMS $+\left(\widetilde{\mu}=0,1, \delta=10^{-5}\right.$, $M=5 ; \Delta=3$ ); (c) Erro após decisão; (d) Média dos coeficientes do cNLMS + e solução de Wiener (linhas tracejadas); (e) EMSE estimado; média de 1000 realizações; Canal 4, variante no tempo. 
Para mostrar a sensibilidade quanto ao ruído da sincronização caótica utilizando a codificação com soma foram obtidas curvas de BER do sistema considerando o Canal 5, com $M=21$ coeficientes, atraso $\Delta=11$ e foi adicionado ruído branco gaussiano ao sinal na saída do canal, de modo a obter uma relação sinal-ruído (SNR ) de 60 dB. As curvas de BER para esse caso são mostradas na Figura 5.10. Assim como feito anteriormente, para o caso sem equalizador, foi feita a comparação da sequência recuperada com $m(n-\Delta)$, considerando $\Delta=1$, devido apenas ao atraso causado pelo canal. Para facilitar a comparação, na Figura 5.10, também foi incluída a curva de BER mostrada na Figura 4.11 com os resultados obtidos utilizando a codificação com a multiplicação. Pode-se notar que o cNLMS + é praticamente capaz de eliminar os efeitos do canal, obtendo equalização quasi-perfeita $\left(\mathrm{BER}<10^{-5}\right.$ ) para $0 \leq h_{0} \leq 0,4$ enquanto a solução de Wiener é capaz de obter equalização quasi-perfeita para $0 \leq h_{0} \leq 0,45$. Ambas as soluções tem desempenho melhor do que o caso sem equalizador, para $0<h_{0}<0,5$. Comparando o desempenho do sistema com o resultado obtido com a codificação usando a multiplicação, é possível notar que a codificação com a soma apresenta uma maior robustez à presença de ruído, já que apresenta níveis menores de BER. Vale notar que, mesmo quando o canal é ideal $\left(h_{0}=0\right)$, a presença do equalizador é importante para permitir a recuperação da mensagem. Conforme $h_{0}$ aumenta, o canal de comunicação se torna mais difícil de equalizar, sendo que, para $h_{0}=0,45$, o resultado obtido com a codificação com a soma é próximo ao resultado obtido com a codificação com a multiplicação e, para $h_{0}=0,5$, o canal apresenta um nulo espectral e ambas as soluções apresentam a BER em torno de $10^{-1}$.

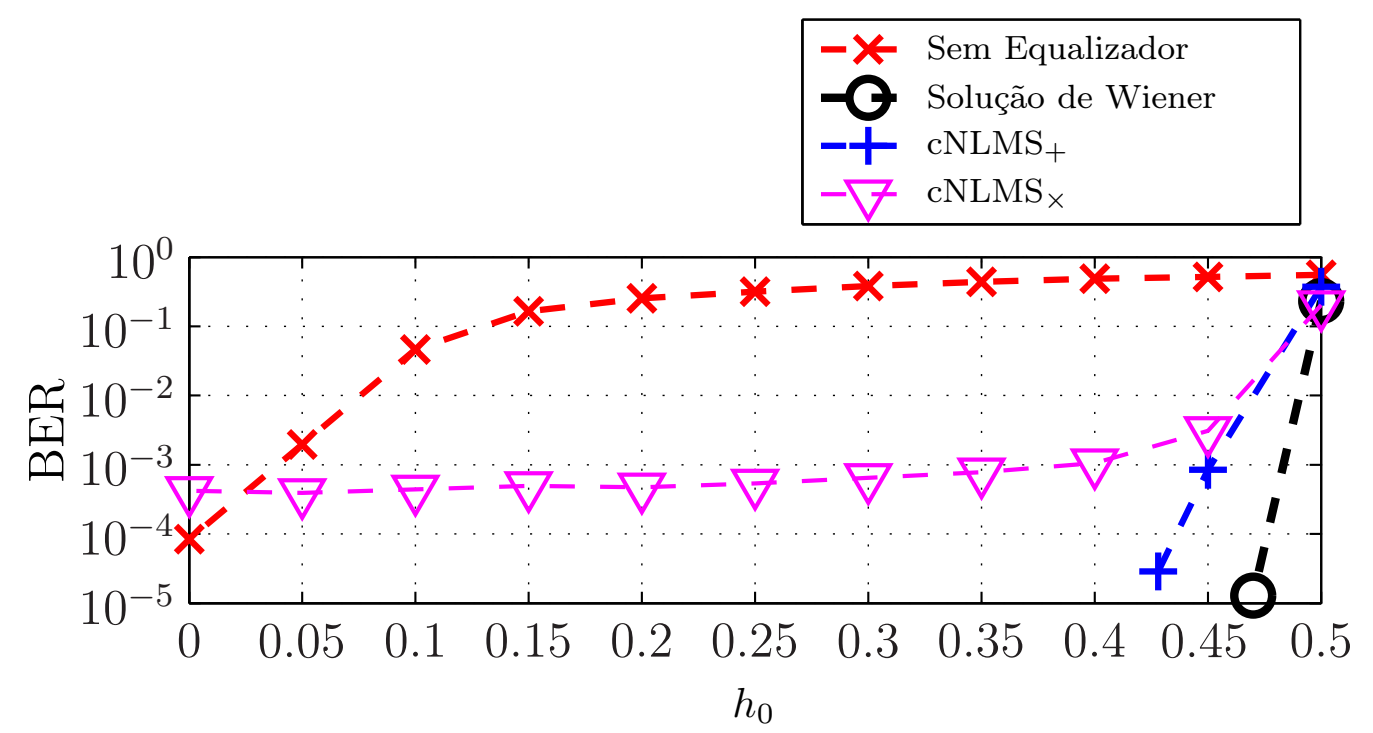

Figura 5.10: Taxa de erro de bit para o Canal 5 em função de $h_{0}$ com SNR $=60$ dB; Sistema utilizando o mapa de Hénon e codificação com soma $\left(\gamma_{1}(n)=0,9\right.$ e $\left.\gamma_{2}(n)=0,3\right)$; cNLMS $_{+}$ $\operatorname{com} \tilde{\mu}=0,005$ para $h_{0}=0$ e $h_{0}=0,05$ e $\widetilde{\mu}=0,01$ para $h_{0} \geq 0,1 ; \delta=10^{-5} ; M=21 ; \Delta=11$. 
Por fim, considerando novamente o Canal $5 \operatorname{com} h_{0}(n)=0,25$, foram obtidas curvas de BER em função da SNR, conforme mostrado na Figura 5.11. Como valor de referência para equalização em um cenário dispersivo e com ruído, também foram incluídas curvas de BER para o canal AWGN não dispersivo, obtidas com o sistema mostrado na Figura 4.1, utilizando a codificação com soma mas sem o equalizador. Para fins de comparação, também é apresentada na Figura 5.11, a curva obtida com a codificação com a multiplicação, mostrada na Figura 4.12 e a curva obtida com o equalizador ótimo no caso do sistema convencional, mostrada na Figura 3.7. Pode-se notar que a BER obtida utilizando a codificação com a soma e o algoritmo $\mathrm{cNMLS}_{+}$é inferior à obtida quando se utiliza a codificação com a multiplicação para relações sinal-ruído de $30 \mathrm{~dB}$ a $60 \mathrm{~dB}$. Para SNRs menores, de $0 \mathrm{~dB}$ a $30 \mathrm{~dB}$, a BER obtida com a codificação com a soma e o algoritmo cNMLS + é semelhante à obtida com a codificação com a multiplicação. Vale notar que a solução ótima de Wiener apresenta BER menor do que a obtida com o algoritmo cNMLS + e próxima à obtida para o canal AWGN não dispersivo para SNRs de $20 \mathrm{~dB}$ a $60 \mathrm{~dB}$. Isso ocorre devido à escolha do passo de adaptação do algoritmo cNMLS $_{+}$, sendo possível obter resultados mais próximos aos da solução de Wiener diminuindose o passo de adaptação, porém diminuindo a velocidade de convergência do algoritmo. Como no caso da codificação com a multiplicação, a ausência do equalizador em um canal dispersivo leva a taxas de erro proibitivas.

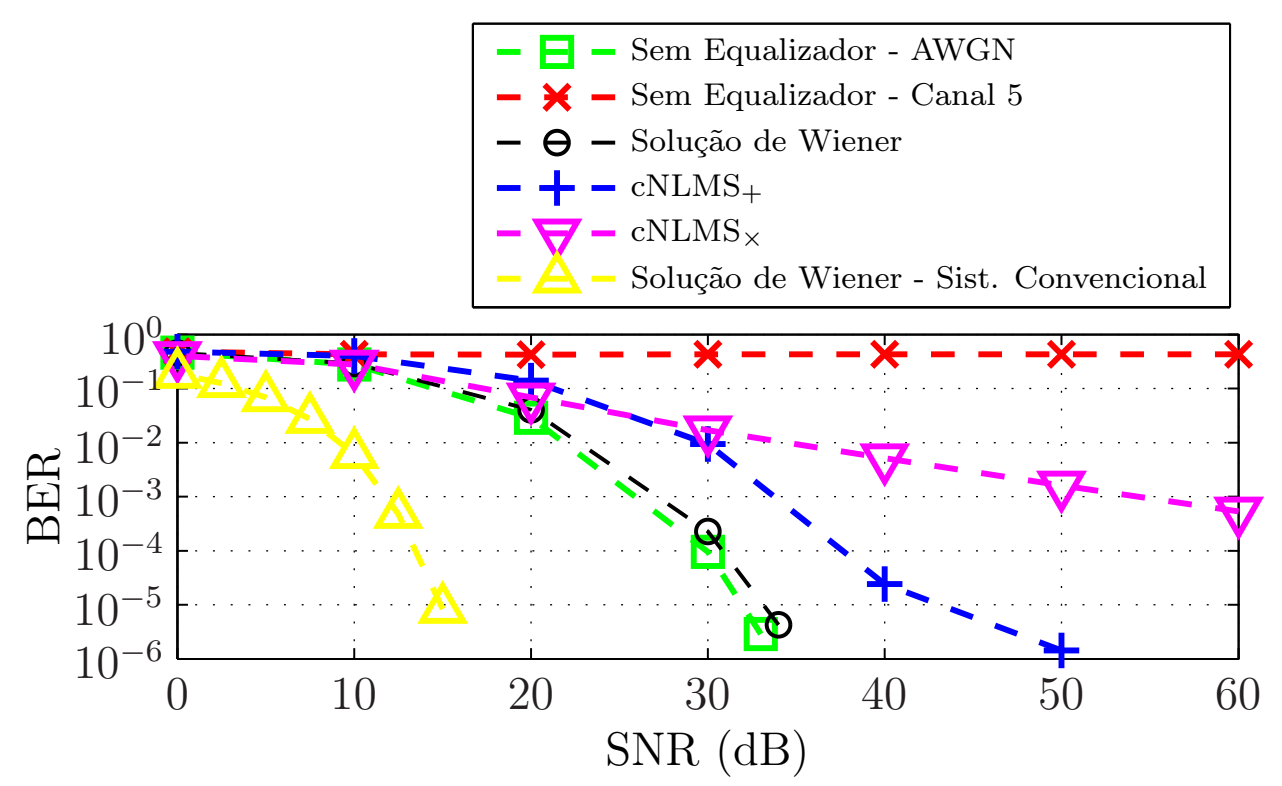

Figura 5.11: Taxa de erro de bit para o canal AWGN não dispersivo e para o Canal 5 com $h_{0}=0,25$, em função da relação sinal-ruído (SNR); Sistema utilizando o mapa de Hénon e codificação com soma $\left(\gamma_{1}(n)=0,9\right.$ e $\left.\gamma_{2}(n)=0,3\right)$; $\operatorname{cNLMS}_{+} \operatorname{com} \tilde{\mu}=0,02 ; \delta=10^{-5}$; $M=21 ; \Delta=11$. 


\subsection{Conclusões}

Conforme mostrado nas simulações com a codificação utilizando a soma, o sistema de comunicação baseado em caos apresenta maior robustez à presença de ruído em relação ao sistema com a codificação utilizando a multiplicação. No entanto, utilizar uma codificação diferente da multiplicação com o mapa de Hénon, faz com que a dinâmica do mapa seja alterada, obtendo-se um sistema com características diferentes em termos da amplitude dos sinais gerados e da bacia de atração, fazendo com que o sistema possa gerar sinais sem DSCI ou até mesmo divergir.

Além disso, para diversos valores dos parâmetros $\gamma_{1}(n)$ e $\gamma_{2}(n)$ da função de codificação, o equalizador não apresenta um bom desempenho, provavelmente devido à convergência para mínimos locais. Entender melhor os motivos pelos quais ocorrem essas dificuldades é uma questão em aberto, que envolve um estudo da dinâmica do equalizador juntamente com a dinâmica do mapa e função de codificação.

Por fim, é importante notar que, apesar do desempenho do sistema utilizando a codificação baseada na soma ter melhorado em relação ao desempenho obtido com a codificação com a multiplicação, ambos os sistemas apresentam desempenho inferior àquele apresentado por sistemas de comunicação convencionais, em termos de BER, No entanto, cabe ressaltar que apesar desse desempenho inferior em termos de BER, o sistema de comunicação baseado em caos apresenta algumas vantagens em relação ao convencional como a dificuldade de deteç̧ão não autorizada, o espalhamento espectral ou a possibilidade da geração dos sinais utilizando propriedades intrínsecas dos lasers. Por isso, soluções alternativas para melhorar o desempenho desse sistema em termos de BER são sempre bem-vindas, como a codificação com soma, proposta neste capítulo. 


\section{Capítulo 6}

\section{Conclusões e trabalhos futuros}

Devido às características interessantes dos sinais caóticos do ponto de vista de telecomunicações, diferentes sistemas de comunicação baseados em caos têm sido propostos na literatura. Dentre as propriedades apresentadas por esses sistemas, pode-se citar a dificuldade de detecção não autorizada, a mitigação do desvanecimento devido ao multipercurso e a robustez a interferências de banda estreita [Lau e Tse, 2003]. Além disso, um outro fator que causa interesse nesse tipo de sistema é que os sinais podem ser gerados usando circuitos muito simples, sendo uma potencial solucãa de custo efetivo para comunicacõos de banda larga [Kolumbán et al., 1997].

Entretanto, estudos sobre sistemas caóticos sugerem que o sincronismo não é suficientemente robusto para aplicações práticas em comunicações quando ruído e [SI são introduzidas pelo canal [Kolumbán et al., 1996; Williams, 2001]. Apesar do problema, a maioria dos trabalhos na área descrevem o desempenho dos sistemas de comunicação baseados em caos em condições ideais de canal, raramente considerando as limitações encontradas na prática como distorção, limitação em banda, ruído aditivo e atrasos inerentes a canais especialmente os sem fio.

Nesta tese, foi considerado o sistema de comunicação baseado em caos que utiliza a versão de tempo discreto da modulação caótica de Wu e Chua [Eisencraft et al., 2009] e foram propostos algoritmos de equalização baseados no NLMS para possibilitar seu funcionamento na presença de canais não ideais e ruído aditivo. Para a geração dos sinais caóticos, foram considerados os mapas de Hénon [Hénon, 1976] e Ikeda [Ikeda, 1979].

Um dos fatores importantes no projeto de sistemas de comunicação que utilizam modulação caótica é a função utilizada para a codificação da mensagem. Neste trabalho, inicialmente, foi considerada uma função baseada na multiplicação da mensagem por um dos estados do GSC. Em seguida, a fim de melhorar o desempenho do sistema, foi considerada uma função baseada 
na soma da mensagem com um dos estados do GSC.

A tese foi estruturada em seis capítulos. Os Capítulos 2 e 3 contêm uma introdução aos fundamentos de sinais caóticos e à equalização adaptativa, respectivamente. No Capítulo 4 foi proposto um sistema de comunicação utilizando a codificação com a multiplicação e no Capítulo 5 foi descrito um sistema de comunicação utilizando a codificação com a soma. Na Tabela 6.1, são listados os principais tópicos abordados nos Capítulos 4 e 5 e as conclusões são apresentadas a seguir.

Tabela 6.1: Tópicos abordados na tese.

\begin{tabular}{|c|l|}
\hline Capítulo & Tópicos principais \\
\hline \multirow{5}{*}{4} & - Algoritmo cNLMS $\times$ \\
\cline { 2 - 3 } & $\begin{array}{l}\text { - Sistema e equalizador para o caso do mapa de Hénon e codificação } \\
\text { com multiplicação }\end{array}$ \\
\cline { 2 - 3 } & $\begin{array}{l}\text { - Sistema e equalizador para o caso do mapa de Ikeda e codificação } \\
\text { com multiplicação }\end{array}$ \\
\cline { 2 - 3 } & - Questões sobre a geração de sinais caóticos com o mapa de Ikeda \\
\hline \multirow{5}{*}{5} & - Função de codificação baseada na soma \\
\cline { 2 - 3 } & - Algoritmo cNLMS + \\
\cline { 2 - 2 } & $\begin{array}{l}\text { - Sistema e equalizador para o caso do mapa de Hénon e codificação } \\
\text { com soma }\end{array}$ \\
\hline
\end{tabular}

\section{Sistema com o mapa de Hénon}

Utilizando o mapa de Hénon no GSC, foram considerados dois sistemas de comunicação: um deles fazendo a codificação pela multiplicação do sinal de mensagem por um estado do GSC e o outro fazendo a codificação pela soma ponderada do sinal de mensagem com um estado do GSC,

A função de codificação que utiliza a multiplicação apresenta uma propriedade interessante no caso do mapa de Hénon pois garante que os sinais gerados sejam caóticos. Utilizando essa função para codificar a mensagem, foi proposto um algoritmo de equalização e foi possível verificar o bom funcionamento do mesmo em diversos cenários. No entanto, foi possível observar que, em cenários onde a ISI não é eliminada completamente, como o caso do Canal 4 e em cenários em que há a presença de ruído, o desempenho do sistema obtido é prejudicado, apesar do funcionamento adequado do equalizador.

Para melhorar o desempenho do sistema em cenários em que não é possível eliminar completamente a ISI e em cenários em que há a presença de ruído, foi proposta a função de 
codificação que utiliza a soma. Com essa função, a questão da geração de sinais caóticos pelo transmissor não é evidente e depende da escolha adequada dos parâmetros utilizados na codificação. Foi verificado também que a escolha dos parâmetros influencia no funcionamento de equalizador já que, dependendo dos valores escolhidos, o equalizador não é capaz de convergir para solução ótima, o que prejudica muito o desempenho do sistema. Por meio de simulações, foi feita uma possível escolha para esses parâmetros, de forma a gerar sinais que apresentam DSCI e permitir o funcionamento do equalizador. Foi possível verificar, por meio de simulações, que a função de codificação que utiliza a soma permite uma melhora no desempenho nos cenários em que a função que utiliza a multiplicação obteve desempenho ruim.

No entanto, vale notar que ao comparar o desempenho dos sistemas baseados em caos mostrados nos Capítulos 4 e 5 com o desempenho de um sistema de comunicação convencional, mostrado no Capítulo 3 é possível verificar que os sistemas baseados em caos apresentam um desempenho inferior ao dos convencionais em termos de BER, Entretanto, os sistemas baseados em caos podem apresentar outras vantagens em compensação à diferença de desempenho. Além disso, pode haver outras funções de codificação e outros mapas que podem melhorar o desempenho dos sistemas baseados em caos.

\section{Sistema com o mapa de Ikeda}

Considerando o mapa de Ikeda, foi proposto um sistema utilizando modulação caótica baseado no sincronismo de Wu e Chua e a codificação utilizando a multiplicação. Foi possível verificar que é possível obter sincronismo entre os sistemas mestre e escravo e foi proposto um algoritmo de equalização para o sistema, baseado no algoritmo NLMS. Por meio de simulações, foi mostrado que o algoritmo é capaz de eliminar a ISI, convergindo na média para os coeficientes ótimos.

No entanto, verificou-se que, utilizando a função de codificação com a multiplicação, os sinais gerados pelo transmissor deixam de apresentar DSCI. Apesar de ser possível corrigir o problema utilizando uma outra função de codificação, como mostrado no Apêndice $\mathrm{A}$, verificouse que o sistema baseado no mapa de Ikeda pode apresentar um problema de sincronismo quando o transmissor gera sinais caóticos e o efeito de um canal não ideal for capaz de levar o vetor de estados do receptor para fora da bacia de atração do regime caótico.

$\mathrm{Na}$ literatura, a maioria dos trabalhos que propõem o uso de sinais caóticos em sistemas de comunicação não apresentam um estudo para verificar se os sinais são ou não caóticos. Por isso, o contraexemplo do mapa de Ikeda apresentado nesta tese é uma contribuição relevante no sentido de se fazer um estudo envolvendo os mapas usados no GSC para verificar se a característica de DSCI dos sinais gerados se mantém. 


\section{Trabalhos futuros}

Diante das contribuições e conclusões expostas, existem algumas possibilidades de trabalhos futuros. Dentre elas, destacam-se:

\section{TF1 Utilização de mensagens considerando outras modulações.}

Além do caso da mensagem binária e polar, é interessante verificar o comportamento do sistema considerando outras modulações com maior número de símbolos, como 4-PAM, em que $m(n) \in\{-3 ;-1 ; 1 ; 3\}$ e até mesmo constelações complexas como 4-QAM, em que $m(n) \in\{-1-j 1 ;-1+j 1 ; 1+j 1 ; 1-j 1\}$.

TF2 Utilização de outros mapas e outras funções de codificação no GSC.

Existem diversos outros mapas que podem ser interessantes para a utilização em sistemas de comunicação baseados em caos. Em particular, os mapas unidimensionais têm a vantagem de não dependerem de sincronismo caótico, já que existe apenas um estado no sistema dinâmico, que deve ser utilizado para codificar a mensagem. Também é interessante considerar outras funções de codificação, já que o desempenho do sistema depende da função escolhida.

\section{TF3 Análise dos algoritmos.}

A fim de entender melhor o comportamento dos algoritmos de equalização no caso de sistemas baseados em caos, é interessante fazer uma análise teórica, a fim de obter expressões para o EMSE, por exemplo. Esses resultados podem facilitar a escolha dos parâmetros do algoritmo e podem explicar alguns casos em que os algoritmos não funcionam adequadamente. Entretanto, devido à natureza não linear dos sistemas envolvidos, pode ser que não seja possível utilizar as formas tradicionais de análise.

\section{TF4 Caso autodidata.}

É interessante considerar o sistema de comunicação baseado em caos no caso autodidata. De forma semelhante à realizada neste trabalho, a partir de algoritmos de equalização para o caso autodidata para sistemas convencionais, podem ser derivadas as versões para o caso dos sistemas baseados em caos.

\section{TF5 Estudos quanto à dificuldade de detecção não autorizada.}

Uma das características mais interessantes dos sistemas baseados em caos é a dificuldade de detecção não autorizada. Entretanto, poucos trabalhos tratam desse assunto formalmente. Na maioria das vezes, só é feita uma inspeção visual quanto a possibilidade de 
enxergar a mensagem no sinal transmitido. É interessante fazer um estudo mais aprofundado, do ponto de vista de criptografia, da possibilidade de decodificar a mensagem a partir do sinal transmitido. 


\section{Referências Bibliográficas}

G. A. Abib. Sobre o desempenho em canal com ruído de um sistema de comunicação baseado em caos. Dissertação de mestrado, Universidade Federal do ABC, 2013.

G. A. Abib e M. Eisencraft. Sobre o desempenho em canal com ruído de um sistema de comunicação baseado em caos. In Anais do Simpósio Brasileiro de Telecomunicações (SBrT'13), Rio de Janeiro, RJ, 2013.

C. Abraham, G. Biau e B. Cadre. On lyapunov exponent and sensitivity. Journal of Mathematical Analysis and Applications, 290(2):395-404, Fev. 2004.

R. P. Agarwal. Difference equations and inequalities, volume 155. Marcel Dekker Inc., New York, 1992.

K. T. Alligood, T. Sauer e J. A. Yorke. Chaos: An Introduction to Dynamical Systems. Textbooks in Mathematical Sciences. Springer, 1997.

A. Argyris, D. Syvridis, L. Larger, V. Annovazzi-Lodi, P. Colet, I. Fischer, J. Garcia-Ojalvo, C. R. Mirasso, L. Pesquera e K. A. Shore. Chaos-based communications at high bit rates using commercial fibre-optic links. Nature, 438(7066):343-346, Nov. 2005.

R. R. F. Attux e J. M. T. Romano. Chaotic phenomena in adaptive blind equalisers. IEE Proceedings on Vision, Image and Signal Processing, 150(6):360 - 364, 2003.

S. Boccaletti, J. Kurths, G. Osipov, D.L. Valladares e C.S. Zhou. The synchronization of chaotic systems. Physics Reports, 366(1-2):1 - 101, 2002.

S. Bouchired, D. Roviras e F. Castani. Equalisation of satellite mobile channels with neural network techniques. Space Comm., 15:209-220, 1998/1999.

R. Candido, M. Eisencraft e M. T. M. Silva. Channel equalization for synchonization of Ikeda maps. In Proc. of $21^{\text {st }}$ European Signal Processing Conference (EUSIPCO'2013), Marrakesh, Marocco, 2013. 
S. Chen, B. Mulgrew e S. McLaughlin. Adaptive Bayesian equalizer with decision feedback. IEEE Transactions on Signal Processing, 41(9):2918-2927, Set. 1993.

K. M. Cuomo e A. V. Oppenheim. Circuit implementation of synchronized chaos with applications to communications. Phys. Rev. Lett., 71(1):65-68, Jul 1993.

R. Devaney. An Introduction to Chaotic Dynamical Systems, 2nd Edition. Westview Press, Boulder, Colo., second edition, Jan. 2003.

Z. Ding e Y. Li. Blind Equalization and Identification. Marcel Dekke, 2001.

M. Eisencraft, R. D. Fanganiello e L. A. Baccalá. Synchronization of discrete-time chaotic systems in bandlimited channels. Mathematical Problems in Engineering, 2009:1-12, 2009.

M. Eisencraft, R. D. Fanganiello e L. H. A. Monteiro. Chaotic synchronization in discrete-time systems connected by bandlimited channels. IEEE Communications Letters, 15(6):671-673, 2011.

M. Eisencraft, R. D. Fanganiello, J. M. V. Grzybowski, D. C. Soriano, R. R. F. Attux, A. M. Batista, E. E. N. Macau, L. H. A. Monteiro, J. M. T. Romano, R. Suyama e T. Yoneyama. Chaos-based communication systems in non-ideal channels. Communications in Nonlinear Science and Numerical Simulation, 17(12):4707-4718, 2012.

M. Eisencraft, R. R. F. Attux e R. Suyama, editores. Chaotic Signals in Digital Communications. CRC Press, Inc., 2013.

T. Endo e L. O. Chua. Chaos from phase-locked loops. IEEE Transactions on Circuits and Systems, 35(8):987-1003, 1988.

B. Farhang-Boroujeny. Adaptive Filters - Theory and Applications. John Wiley \& Sons, West Sussex, 1998.

M. Feki, B. Robert, G. Gelle e M. Colas. Secure digital communication using discrete-time chaos synchronization. Chaos, Solitons \& Fractals, 18(4):881-890, Nov. 2003.

G. D. Forney Jr. Maximum-likelihood sequence estimation of digital sequences in the presence of intersymbol interference. IEEE Transactions on Information Theory, IT-18:363-378, Mai. 1972 .

G. J. Gibson, S. Siu e C. F. N. Cowan. The application of nonlinear structures to the reconstruction of binary signals. IEEE Transactions on Signal Processing, 39(8):1877-1884, Ago. 1991. 
D. N. Godard. Self-recovering equalization and carrier tracking in two dimensional data communication system. IEEE Transactions on Communications, 28:1867-1875, Nov. 1980.

J. Grzybowski, M. Eisencraft e E. Macau. Chaos-based communication systems: Current trends and challenges. In S. Banerjee, M. Mitra e L. Rondoni, editores, Applications of Chaos and Nonlinear Dynamics in Engineering - Vol. 1, volume 71 of Understanding Complex Systems, 203-230. Springer Berlin / Heidelberg, 2011.

A. Gutierrez e W. E. Ryan. Performance of volterra and MLSD receivers for nonlinear bandlimited satellite systems. IEEE Transactions on Communications, 48:1171-1177, Jul. 2000.

B. A. Harb e A. M. Harb. Chaos and bifurcation in a third-order phase locked loop. Chaos, Solitons \& Fractals, 19(3):667 - 672, 2004.

S. Hayes, C. Grebogi e E. Ott. Communicating with chaos. Phys. Rev. Lett., 70:3031-3034, Mai. 1993.

S. Haykin. Communication systems. Wiley, New York, 4th edition, 2000.

S. Haykin. Adaptive Filter Theory. Prentice Hall, Upper Saddle River, 4th edition, 2002.

M. Hénon. A two-dimensional mapping with a strange attractor. Communications in Mathematical Physics, 50:69-77, 1976.

K. Ikeda. Multiple-valued stationary state and its instability of the transmitted light by a ring cavity system. Optics Communications, 30(2):257 - 261, 1979.

C. R. Johnson Jr. et al. Blind equalization using the constant modulus criterion: a review. Proceedings of the IEEE, 86:1927-1950, Out. 1998.

G. Kaddoum, M. Vu e F. Gagnon. Chaotic symbolic dynamics modulation in MIMO systems. In 2012 IEEE International Symposium on Circuits and Systems (ISCAS), 157-160, Mai. 2012.

G. Kaddoum, G. Gagnon e F. Gagnon. Spread spectrum communication system with sequence synchronization unit using chaotic symbolic dynamics modulation. Int. J. Bifurcation Chaos, 23(02):1350019, Fev. 2013.

M. P. Kennedy e G. Kolumbán. Digital communications using chaos. Signal Processing, 80 (7):1307-1320, 2000. 
M. P. Kennedy, G. Setti e R. Rovatti, editores. Chaotic Electronics in Telecommunications. CRC Press, Inc., Boca Raton, FL, USA, 2000.

G. Kolumbán, M. P. Kennedy e L. O. Chua. The role of synchronization in digital communications using chaos. i f fundamentals of digital communications. IEEE Transactions on Circuits and Systems I: Fundamental Theory and Applications, 44:927-936, Out. 1997.

G. Kolumbán, J. Dedieu, J. Schweizer, J. Ennitis e B. Vizvári. Performance evaluation and comparison of chaos communications systems. In Proceedings of 4 th International Workshop in Nonlinear Dynamics Electronic Systems, volume 1, Jun. 1996.

J. F. Kurose e K.W. Ross. Computer Networking: A Top-down Approach. Always learning. Pearson, 2013.

B. P. Lathi e Z. Ding. Modern Digital and Analog Communication Systems. Oxford University Press, New York, 4th edition edition, Jul. 2009.

F. C. M. Lau e C. K. Tse. Chaos-based digital communication systems. Springer, Berlin, 2003.

T. Li e J. A. Yorke. Period three implies chaos. The American Mathematical Monthly, 82(10): 985, Dez. 1975.

W. Liu, J. C. Príncipe e S. Haykin. Kernel Adaptive Filtering: A Comprehensive Introduction. Wiley, 2010.

E. N. Lorenz. Deterministic nonperiodic flow. J. Atmos. Sci., 20(2):130-141, Mar. 1963.

G. Maral e M. Bousquet. Satellite Communications Systems: Systems, Techniques and Technology. Wiley, Chichester; New York, third edition, July 1998.

L. H. A. Monteiro, A. C. Lisboa e M. Eisencraft. Route to chaos in a third-order phase-locked loop network. Signal Processing, 89(8):1678-1682, Abr. 2009.

B. Mulgrew. Applying radial basis function. IEEE Signal Processing Magazine, 13:50-65, Mar. 1996.

V. H. Nascimento e M. T. M. Silva. Adaptive filters. In R. Chellappa and S. Theodoridis, editores, Academic Press Library in Signal Processing: Signal Processing Theory and Machine Learning. Academic Press, 2014.

D. C. Park e T.-K. J. Jeong. Complex-bilinear recurrent neural network for equalization of a digital satellite channel. IEEE Transactions on Neural Networks, 13(3):711-725, Mai. 2002. 
L. M. Pecora e T. L. Carroll. Synchronization in chaotic systems. Phys. Rev. Lett., 64(8): 821-824, Fev. 1990.

L. M. Pecora, T. L. Carroll, G. A. Johnson, D. J. Mar e J. F. Heagy. Fundamentals of synchronization in chaotic systems, concepts e applications. Chaos: An Interdisciplinary Journal of Nonlinear Science, 7(4):520-543, 1997.

G. Picchi e G Prati. Blind equalization and carrier recovery using a "stop-and-go" decisiondirected algorithm. IEEE Transactions on Communications, COM-35:877-887, Set. 1987.

S. U. H. Qureshi. Adaptive equalization. Proceedings of the IEEE, 73(9):1349-1387, Set. 1985.

H. Ren, M. S. Baptista e C. Grebogi. Wireless communication with chaos. Phys. Rev. Lett., 110:184101, Abr. 2013.

A. A. Rontogiannis e K. Berberidis. Efficient decision feedback equalization for sparce wireless channel. IEEE Transactions on Wireless Communications, 2:570-581, Mai. 2003.

W. J. Rugh. Linear System Theory. Prentice-Hall Information \& System Sciences Series. Prentice Hall, 1996.

N. F. Rulkov e L. S. Tsimring. Synchronization methods for communication with chaos over band-limited channels. International Journal of Circuit Theory and Applications, 27(6): 555-567, 1999.

I. Santamaria, C. Pantaleon, L. Vielva e J. Ibanez. Blind equalization of constant modulus signals using support vector machines. IEEE Transactions on Signal Processing, 52(6): 1773-1782, Jun. 2004.

A. H. Sayed. Adaptive Filters. John Wiley \& Sons, NJ, 2008.

W. A. Sethares. Adaptive algorithms with nonlinear data and error functions. IEEE Transactions on Signal Processing, 40(9):2199-2206, Set. 1992.

F. O. Souza, R. M. Palhares, E. M. A. M. Mendes e L. A. B. Torres. Synchronizing continuous time chaotic systems over nondeterministic networks with packet dropouts. International Journal of Bifurcation and Chaos, 22(12):1250300, 2012.

P. Stavroulakis, editor. Chaos Applications in Telecommunications. CRC Press, Inc., Boca Raton, FL, USA, 2005. 
S. H. Strogatz. Nonlinear Dynamics and Chaos: with Applications to Physics, Biology, Chemistry and Engineering. Perseus Books Group, 2001.

C. Z. W. H. Sweatman, B. Mulgrew e G. J. Gibson. Two algorithms for neural-network design and training with application to channel equalization. IEEE Transactions on Neural Networks, 9(3):533-543, Mai. 1998.

D. Syvridis. Optical chaos encoded communications: solutions for today and tomorrow. In Proc. of IEEE Lasers and Electro-Optics Society Annual Meeting (LEOS), 759-760, 2009.

M. S. Tavazoei e M. Haeri. Chaos in the apfm nonlinear adaptive filter. Signal Processing, 89 (5):697 - 702, 2009.

S. Theodoridis, C.F.N. Cowan, C.P. Callender e C.M.S. See. Schemes for equalisation of communication channels with nonlinear impairments. IEE Proc. Communications, 142(3): 165-171, Jun. 1995.

J. R. Treichler e B. Agee. A new approach to multipath correction of constant modulus signals. IEEE Transactions on Acoustics, Speech and Signal Processing, ASSP-28:334-358, Abr. 1983.

J. R. Treichler, I. Fijalkow e C. R. Johnson Jr. Fractionally spaced equalizers. IEEE Signal Processing Magazine, 13:65-81, Mai. 1996.

S. Tsekeridou, V. Solachidis, N. Nikolaidis, A. Nikolaidis, A. Tefas e I. Pitas. Statistical analysis of a watermarking system based on Bernoulli chaotic sequences. Signal Processing, 81(6):1273-1293, 2001.

J. Tsimbinos e L.B. White. Error propagation and recovery in decision-feedback equalizers for nonlinear channels. IEEE Transactions on Communications, 49:239-242, Fev. 2001.

A. Uchida. Optical Communication with Chaotic Lasers: Applications of Nonlinear Dynamics and Synchronization. Wiley-VCH, Singapore, 2012.

C. Williams. Chaotic communications over radio channels. Circuits and Systems I: Fundamental Theory and Applications, IEEE Transactions on, 48(12):1394 -1404, Dez. 2001.

C. W. Wu e L. O. Chua. A simple way to synchronize chaotic systems with applications to secure communication systems. International Journal of Bifurcation and Chaos, 3(6): 1619-1627, Dez. 1993. 


\section{Apêndice A}

\section{Transmissor com mapa de Ikeda e DSCI}

Como comentado na Seção 4.4.1, no sistema de comunicação utilizando o mapa de Ikeda, a codificação com a multiplicação faz com que o GSC convirja para o ponto fixo e deixe de gerar sinais que apresentam DSCI. Para contornar o problema, em vez da multiplicação, pode ser considerada a função de codificação

$$
s(n)=x_{2}(n)+\frac{\gamma}{2}[1+m(n)] .
$$

Na Figura A.1 é mostrado o atrator caótico no espaço de fases juntamente com sua bacia de atração, indicada em amarelo, considerando (A.1) como função de codificação. Os pontos vermelhos indicam pontos do atrator caótico que levam a órbita a deixar a bacia de atração e convergir para o ponto fixo caso um bit "1" seja codificado. Nas Figuras A.1 (a), (b) e (c) é considerado A.1) com $\gamma=1, \gamma=10^{-2}$ e $\gamma=10^{-3}$, respectivamente. É possível notar que $\gamma=1$ não é uma boa escolha, já que há muitos pontos do atrator que levam a órbita ao ponto fixo quando um bit "1" é codificado. Fazendo $\gamma=10^{-2}$, ainda restam alguns pontos do atrator que podem levar a órbita ao ponto fixo. Por fim, considerando $\gamma=10^{-3}$, a órbita permanece na área amarela, convergindo para o atrator caótico.

Como uma forma de testar a DSCI dos sinais transmitidos, foi calculado o máximo expoente de Lyapunov das órbitas geradas por (2.14)-(2.15) com $s(n)$ dado por (A.1) no lugar de $x_{2}(n)$. Para isso, foi usado o método baseado no Jacobiano, descrito na Seção 2.2 e $m(n)$ foi considerado como um parâmetro variante no tempo. A substituição de $x_{2}(n)$ por $s(n)$ pode ser vista como uma perturbação na órbita original, o que faz com ela convirja para um dos atratores do mapa de Ikeda: o ponto fixo com $\kappa_{1} \approx-0,11$ ou o atrator estranho com $\kappa_{1}=$ 0,51. Considerando (A.1), na Figura A.2 é mostrado o máximo expoente de Lyapunov obtido numericamente em função de $\gamma$ para condições iniciais aleatórias, símbolos equiprováveis, considerando um transitório de $10^{6}$ amostras e usando $10^{6}$ amostras para o cálculo. A curva 

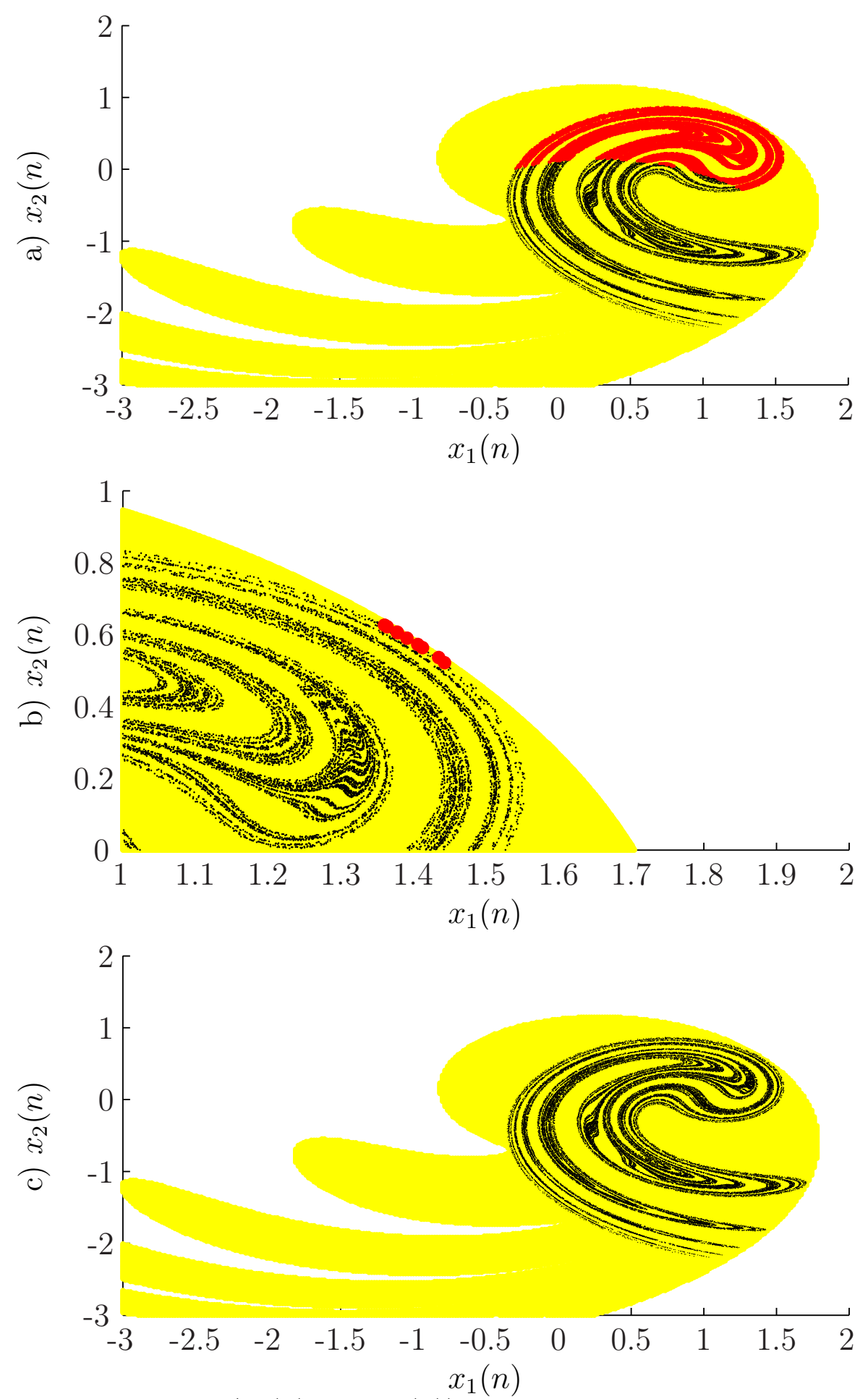

Figura A.1: Espaço de fases $\left(x_{1}(n)\right.$ por $\left.x_{2}(n)\right)$, indicando os pontos que levariam a órbita a convergir para o ponto fixo se um bit " 1 " fosse codificado usando (A.1) com (a) $\gamma=1$, (b) $\gamma=10^{-2}$ e (c) $\gamma=10^{-3}$; Mapa de Ikeda com os parâmetros dados por (2.16). 
resultante claramente coincide com o resultado mostrado na Figura A.1. Para $\gamma$ menor que aproximadamente $0,8 \times 10^{-2}$, o sinal transmitido apresenta DSCI.

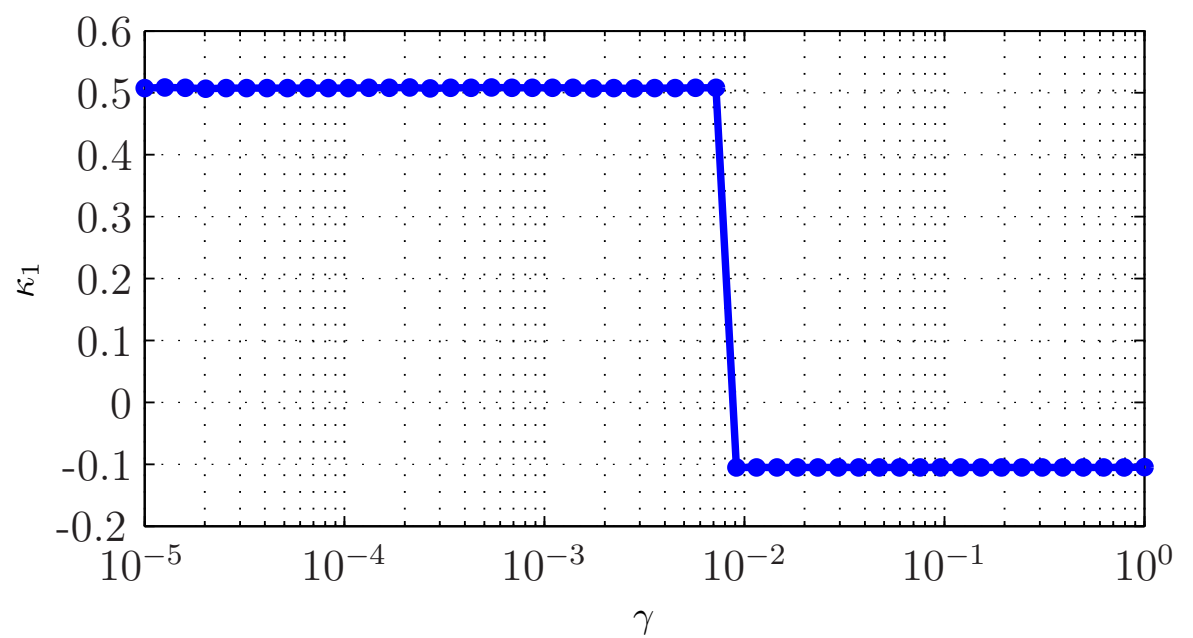

Figura A.2: Máximo expoente de Lyapunov $\kappa_{1}$ em função de $\gamma$ da Eq. (A.1), considerando uma mensagem binária e equiprovável.

Com a solução proposta, é possível fazer com que os sinais gerados pelo transmissor apresentem DSCI. No entanto, como comentado na Seção 4.4.2, ao garantir que os estados do transmissor fiquem com sua órbita dentro da bacia de atração do atrator caótico, o sistema com o mapa de Ikeda apresenta um problema de sincronismo que inviabiliza sua utilização na presença de canais não ideais. 